\title{
Measuring Intangible Capital with Market Prices *
}

\author{
Michael Ewens ${ }^{1}$, Ryan H. Peters ${ }^{2}$, And Sean Wang ${ }^{3}$ \\ ${ }^{1}$ California Institute of Technology $\& 3$ NBER \\ ${ }^{2}$ Tulane University \\ ${ }^{3}$ Southern Methodist University
}

October 2020

\begin{abstract}
Current standards prohibit the capitalization of internally created intangibles, resulting in a downward bias of reported assets. We estimate a capitalization model using market prices of intangibles to estimate the parameters of the capital accumulation process. Two settings provide intangible asset values: publicly traded equity prices and exit prices. We use these parameters to estimate intangible capital stocks and subject them to an extensive set of validation tests that compare them with stocks estimated using existing parameters. Intangible stocks developed from exit price parameters outperform both stocks developed by publicly traded parameters and those stocks developed with existing estimates.
\end{abstract}

\footnotetext{
*Authors' email addresses: mewens@caltech.edu, ryan.peters@tulane.edu and seanwang@smu.edu. The paper previously circulated under the title "Acquisition Prices and the Measurement of Intangible Capital." Special thanks to Dimitris Papanikolaou and Luke Taylor. We thank Gordon Phillips for providing data for the SDC-Compustat merge and Shiyu Zhang for research assistance. Jan Bena (discussant), Anthony Cookson (discussant), Andrea Eisfeldt (discussant), Nagpurnanand Prabhala (discussant), William Mann (discussant), Hila Fogel-Yaari, Bronwyn Hall, Arthur Korteweg, Pierre Liang, Song Ma, Tom Ruchti and seminar participants at Columbia University, Cornell University (accounting and finance), University of Arizona (accounting and finance), University of Rochester, Michigan State University, University of Michigan, UT-Dallas, Southern Methodist University, Singapore Management University, National University of Singapore, HKUST, University of Hong Kong, CityU Hong Kong, University of Utah, Tulane University, Caltech, NBER SI Research on Income and Wealth, American Finance Association, Paris Financial Management conference, Washington University Conference on Corporate Finance, Midwest Finance Association, European Finance Association, the Cass Mergers and Acquisitions Conference, and the Finance, Organizations and Market Conference (2018) provided helpful feedback. Code and data to incorporate the intangible capital measures can be found at: http://bit.ly/intan_cap. First version: September 2018.
} 
Corporate investment has transformed over the last few decades, with U.S. firms spending less on tangible assets and more on intangibles related to knowledge and organizational capacity (Figure 1). This reduction in tangible capital investment, along with the weaker connection between investment and firm valuation, is described as a "broader investment puzzle" by Gutiérrez and Philippon (2017) and Crouzet and Eberly (2019). A shared conclusion of both papers is that standard measures of investment on firms' balance sheets fail to capture the growing importance of intangible assets, resulting in a downward bias in the recorded book values of invested capital. ${ }^{1}$ This bias has grown over time, as evidenced by the dramatic upward trend in market-to-book ratios.

Reliable measures of intangible capital are important for capital markets and financial managers. For instance, numerous studies have provided evidence of mispriced equity for firms with higher levels of intangible capital, which could lead to suboptimal resource allocation. ${ }^{2}$ In debt markets, research shows that banks are less willing to lend to firms with higher information asymmetry and more uncertainty about their liquidation values, two primary characteristics of intangible intensive firms. ${ }^{3}$ In corporate finance, financial managers making capital budgeting decisions must estimate book values of intangible capital to calculate returns to intangible capital (Hall, Mairesse, and Mohnen, 2010). To adjust for the downward bias in firms' invested capital, researchers in economics and finance estimate the off-balance sheet intangible capital with accumulated flows of $\mathrm{R}^{4} \mathrm{D}^{4}$, SG\&A ${ }^{5}$, or both. ${ }^{6}$ Such adjustments require assumptions about the capital accumulation process, such as intangible depreciation rates and the fraction of SG\&A to be capitalized. Unfortunately, as Corrado, Hulten, and Sichel (2009) highlight, "relatively little is known about depreciation rates

\footnotetext{
${ }^{1}$ Accounting rules for intangibles originated in 1974 when intangible investments were only a small proportion of the economy, and they have not changed, despite a fundamental change towards intangibles as economic value drivers. Specifically, a firm's internal Research and Development (R\&D) costs and Selling, General, and Administrative (SG\&A) activities are immediately recorded as expenses and thus do not appear on its balance sheet. This lack of capitalization reduces the informativeness of accounting book values in explaining market values (e.g., Lev and Zarowin, 1999).

${ }^{2} \mathrm{~A}$ partial list of these studies includes Daniel and Titman (2006); Eberhart, Maxwell, and Siddique (2004); Aksoy, Cooil, Groening, Keiningham, and Yalçın (2008); Edmans (2011); Eisfeldt and Papanikolaou (2013).

${ }^{3}$ Williamson (1988); Shleifer and Vishny (1992); Loumioti (2012); Mann (2018)

${ }^{4}$ Bernstein and Nadiri (1988); Chan, Lakonishok, and Sougiannis (2001); Hirshleifer, Hsu, and Li (2013)

${ }^{5}$ Eisfeldt and Papanikolaou (2013, 2014); Belo, Lin, and Vitorino (2014)

${ }^{6}$ Falato, Kadyrzhanova, and Sim (2013); Peters and Taylor (2017)
} 
for intangibles" (pp 674). With no consensus, the most commonly used rates for knowledge capital originate from Li and Hall (2016) who use BEA data, ${ }^{7}$ while Hulten and Hao (2008) provide the main parameter for organizational capital (hereafter, we refer to the combination of these parameters as "BEA-HH"). These measures of depreciation rates, however, are limited by gaps in industry coverage. ${ }^{8}$

In this paper, we propose a capitalization model that incorporates market prices of intangible assets to estimate a new set of intangible capitalization parameters from a firm's prior flows of intangible investments. While researchers have generally agreed that using market prices to develop such parameters is advantageous, ${ }^{9}$ they have also recognized that most firms conduct R\&D and other intangible investment activities for use within the firm, i.e. it is not a simple task to directly observe market prices for a firm's intangible asset (e.g., Griliches, 1996; Li and Hall, 2020). We infer the market values for intangible assets from two different approaches - publicly-traded prices and exit prices - and use them to estimate the model's capitalization parameters. We then take both sets of parameters and calculate the values of off-balance sheet intangible capital for a full panel of Compustat firms from 1978-2017. Because the two approaches require different assumptions in order to obtain the intangible valuations, we develop a series of validation diagnostics which we use to systematically compare the implied intangible capital stocks in out-of-sample settings. Using these tests, we compare the performance of these two measures of intangible stocks against each other, as well as with stocks developed by existing BEA-HH parameters. Overall, we conclude that out of the three measures, exit-price based intangible stocks are of the highest quality, i.e. they best reflect economic outcomes.

Our first approach uses publicly-traded equity prices to infer the value of a firm's intangible assets (hereafter "Trading"). Using the universe of CRSP-Compustat public firms, we take the

\footnotetext{
${ }^{7}$ This paper first circulated in 2010 .

${ }^{8}$ Less than $15 \%$ of 4 -digit SIC codes have depreciation rates for knowledge capital. Organizational capital parameters have only been estimated in the pharmaceutical industry.

${ }^{9}$ For example, prices allow us to incorporate non-production benefits such as real option value while not having to take a stance on production functions or the lag structure of intangible investment benefits.
} 
market enterprise value and subtract an estimate of the market value of tangible assets, leaving us with the market value of intangible assets. While this approach can apply to all firms with publicly traded prices, it demands we estimate the markup of each firm's tangible assets (reported at book value) to market value. We follow prior literature from Erickson and Whited (2006, 2012) and Peters and Taylor (2017) and use gross PPE to proxy for the market value of intangible assets in the estimation. Our second approach, relies on valuations which come from a set of exit pricing events which include acquisitions, bankruptcies, and liquidations (hereafter, "Exits"). While the "Trading" approach required an assumed markup for book values, no such assumptions are required for acquisitions. This is because target firms in acquisitions are required to have all assets marked to market by valuation experts during the purchase price allocation, such that the price paid for the target's net assets equals the marked-to-market value of tangible assets less liabilities plus total intangible assets, in the form of either identifiable intangible assets (IIA) or goodwill (GW). We take the sum of IIA and GW (after adjusting for overpayment and synergies) as the market's pricing of intangible capital in an acquisition. ${ }^{10}$ Our acquisition sample spans the years 1996-2017 and comprises a substantial fraction of U.S. publicly traded acquirer-target pairs found in SDC's M\&A database. For bankruptcy events, we estimate intangible asset valuations by collecting recovered asset values from Moody's Default and Recovery database and multiply by the average ratio of intangibles scaled by total assets, which we calculate from acquisitions in the same 4-digit SIC code.

We use both samples of intangible asset values to estimate parameters of the capitalization model. While the magnitudes of the two parameter estimates differ, we find two commonalities. First, the parameter that captures the fraction of SG\&A expenditures that is investment varies across industry. This variation is in sharp contrast to the assumed single value for the parameter used in the literature. Second, while the R\&D depreciation parameter estimate is close to the

\footnotetext{
${ }^{10}$ One can view the sum of IIA and GW as the residual after the auditor assigns market values of net tangible assets, which is likely an easier task. Thus, unbiased estimates of total intangible assets follow from unbiased market values of net tangible assets.
} 
current benchmark BEA-HH across all industries, we find higher depreciation rates in the two industries with the most R\&D spending: healthcare and information technology.

Parameter estimates in hand, we use a series of validations to compare our price-based intangible asset estimates to the BEA-HH benchmark. The primary validation test asks whether augmenting book values of invested capital with our intangible asset estimates improves their ability to explain market enterprise values (excluding the firm-years used in the estimation). We compare the explanatory power from using both sets of our intangible prices to augment book values to book values augmented with estimates using BEA-HH parameters. The "Exits" parameters produce intangible stocks that improve the $R^{2}$ in the cross-section in all years from 1986 to 2017, and this additional power is statistically significant in all but six years. Conversely, the "Trading" parameters explains less of the $R^{2}$ than the intangible stocks estimated with BEA-HH parameters. We follow this test with additional diagnostic tests to determine whether the outperformance of the "Exits" based intangible stocks is pervasive across other out-of-sample tests.

The next two tests verify whether our estimates of organizational capital better capture differences in human capital and brand value versus BEA-HH estimates of organizational capital. We follow Eisfeldt and Papanikolaou (2013) in examining whether firms with high organizational capital are more likely to disclose risks regarding the potential loss of key talent in their 10-K filings. To do so, we analyze text from management discussions about risk in over one hundred thousand 10-K filings from 2002-2017 and identify whether the firm mentions "personnel" or "key talent." The "Exits"-based measure of organizational capital stock outperforms both BEA-HH and the "Trading" stocks: firms in the top quintile of organizational capital stock are significantly more likely to mention these human capital risks than those in the bottom quintile. A similar exercise using firms' brand (Interbrand) and employee satisfaction ranking (Edmans, 2011) also show that the exit-based organizational capital estimates are superior. The final validation asks if and how our the new estimates of intangible capital can explain previously established measures of patent values and trademark production. We find that the "Exits" stocks explain relatively more of the 
cross-sectional variation in patent valuations from Kogan, Papanikolaou, Seru, and Stoffman (2017) and the number of new trademarks filed by a firm in a given year (Heath and Mace, 2020).

From assumptions about physical markup, sample selection and price adjustments, each of our proposed methods have strengths and weaknesses. The collection of validation tests lead us to select the intangible asset estimates derived from the set of exit prices as the preferred method. Although the results suggest that incorporating these new intangible stocks will improve the empirical performance in a wide variety of finance and accounting research settings, the flexible estimation framework allows future researchers to improve upon the model's data input.

We take a first step in this direction by incorporating our measure of intangible assets into book equity and calculating market-to-book ratios, the return on equity and estimating returns on a value premium factor. First, the incorporation of intangibles impacts the time series of average market-to-book. Since 1997, the unadjusted market-to-book ratio drifts upward 0.041 per year. After adjusting book equity for intangibles, this upward trend falls by $70 \%$, demonstrating that unadjusted book equity measures are systematically understated. Next, we explore the impact of augmenting book values with off balance-sheet intangible capital on the return on equity. Here, we adjust both the earnings measure (e.g. R\&D and SG\&A are is no longer immediately expensed but are depreciated over time) and book equity. Adjusted ROEs fall $40 \%$ compared to the standard measure and the final average mirrors the cost of equity capital estimates from the literature (e.g. Graham and Harvey, 2018; Damodaran, 2020). Third, we show that adjustments to book equity resulting from the inclusion of off-balance sheet intangible capital shifts $18 \%$ of firm-month observations away from their original HML portfolio assignment with unadjusted book equity values (Fama and French, 1992, 1993). The resulting returns from intangibles-adjusted HML factor have higher returns and lower standard deviations than the standard measures, implying that the inclusion of intangible capital increases the precision of HML portfolio sorts.

We contribute to three broad literatures. First, we provide parameter estimates to corporate finance researchers that rely on estimates of intangible capital as an input to examine real outcomes 
in firms (Eisfeldt and Papanikolaou, 2013; Gourio and Rudanko, 2014; Sun and Zhang, 2018). Second, we contribute to a long-standing literature on growth economics that attempts to measure the value of knowledge in the economy. Specifically, our work both re-estimates the knowledge capital accumulation process using market prices and extends these estimates to organizational capital for the first time (Corrado, Hulten, and Sichel, 2009; Corrado and Hulten, 2010; Acemoglu, Akcigit, Alp, Bloom, and Kerr, 2013; Hall, Mairesse, and Mohnen, 2010). Finally, we contribute to an active debate surrounding off-balance sheet intangible capital. Lev (2018) suggests that standard-setters' resistance to recognizing intangibles on firm balance sheets has substantial costs to both firms and the broader economy. In addition to confirming the value-relevance of currently included intangible assets such as goodwill, we provide evidence that estimating the value of internally generated intangible capital is feasible and provides meaningful information to financial statement users.

\section{A Framework for Estimating Intangible Capital}

Generally Accepted Accounting Principles (GAAP) rules rarely allow firms to capitalize intangible capital on the balance sheet. Researchers have responded to this lack of disclosure by constructing estimates for the stock of intangible capital using the perpetual inventory method, which aggregates net investment flows over the life of the firm. ${ }^{11}$ This is done by adding the beginning value of the intangible capital stock to any periodic intangible investment flows and subtracting any depreciation as shown below in (1), for capital stock $K$ at the end of year $t$ :

$$
K_{t}=K_{t-1}+Z_{t}-D_{t}
$$

\footnotetext{
${ }^{11}$ e.g., Cockburn and Griliches (1988); Eisfeldt and Papanikolaou (2013, 2014); Hall, Mairesse, and Mohnen (2010); Hulten and Hao (2008)
} 
where $Z_{t}$ represents periodic investment, and $D_{t}$ represents depreciation during period t of existing stock $K_{t-1}$. Assuming that $K$ depreciates geometrically at the rate of $\delta$, we have:

$$
K_{t}=K_{t-1}(1-\delta)+Z_{t}
$$

Through iterative substitution, the intangible capital stock becomes the total sum of all undepreciated intangible investments throughout the firm's existence.

$$
K_{t}=\sum_{i=0}^{\infty}(1-\delta)^{i} Z_{t-i}
$$

Thus, to measure a firm's stock of intangible capital via (3), we need the depreciation rate, $\delta$, and a mapping from accounting statements to periodic measures of investment, $Z{ }^{12}$

The literature focuses on two distinct categories of intangibles: knowledge and organizational capital. Given that knowledge capital relates to information learned about processes, plans or designs that can lead to economic benefits in future periods, prior literature has used a firm's Research and Development (R\&D) expenses as a proxy for its periodic investment in knowledge capital. ${ }^{13}$

The definition of organizational capital is more vague. Evenson and Westphal (1995) define organizational capital as knowledge used to combine human skills and physical capital into systems for producing and delivering want-satisfying products. Eisfeldt and Papanikolaou (2013, 2014) define organization capital as intangible capital that relies on essential human inputs, i.e. the firm's key employees. Lev and Radhakrishnan (2005) define organizational capital more broadly,

\footnotetext{
${ }^{12}$ Due to data limitations on intangible expenditures, e.g. unobservable accounting expenditures prior to the firm being publicly-traded, (3) is often modified as follows:

$$
K_{t}=(1-\delta)^{k} K_{t-k}+\sum_{i=0}^{k}(1-\delta)^{k-i} Z_{t-i}
$$

where $K_{t-k}$ is an initial intangible capital stock.

${ }^{13}$ Consistent with this notion, ASC 730 defines research activities as development of "the translation of research findings or other knowledge into a plan or design for a new product or process."
} 
as an agglomeration of technologies such as business practices, processes and designs that gives a firm a competitive advantage and enables it to extract additional economic rent from its operating activities.

Because of GAAP's broad definition of Selling, General, and Administrative Expenses (SG\&A), which aggregate a variety of operating expenses unrelated to the cost of goods sold, researchers must decide which SG\&A flows should be capitalized into organizational capital and which SG\&A flows should be expensed. For example, employee training and advertising expenses should be capitalized and depreciated because their economic benefits extend past the contemporaneous period where the expenditure was made, while others such as rent expenses, legal fees and overtime wages clearly should not be capitalized since they represent payments for services rendered for a specific period of time. As a result, researchers often assume that a proportion of SG\&A should be capitalized into organizational capital. As such, we define the fraction of total SG\&A expense which represents an organizational capital investment as $\gamma_{S}$.

Thus, attempts to capitalize intangible investments requires values for the parameters governing the capital accumulation process. To the best of our knowledge, there is no comprehensive estimate of the depreciation rate of organizational capital. The only estimate of $\gamma_{S}$ comes from Hulten and Hao (2008), who estimate it based on descriptions of income statement items from six pharmaceutical firms in 2006, applying the investment share of expensed items from Corrado, Hulten, and Sichel (2006). Conversely, there have been a number of attempts to estimate the depreciation rate for R\&D investments $\left(\delta_{G}\right)$. The main challenges in estimating $\delta_{G}$, as stated by Griliches (1996) and $\mathrm{Li}$ and Hall (2020), stem from the fact that the majority of firms conduct R\&D activities for use within the firm, and thus market prices do not exist for most R\&D assets. Most models that estimate R\&D depreciation therefore require explicit assumptions about the channel through which knowledge capital affects firm behavior or outcomes.

Pakes and Schankerman (1984), for example, develop a model by which they infer $\delta_{G}$ by examining the decline in patent renewals over time. This assumes that valuable R\&D must result in 
patents and that the value of $R \& D$ is directly inferable from the patent renewal decision. Lev and Sougiannis (1996) assume that amortization of knowledge capital enters the production function directly and estimates an amortization model by regressing firms' current period operating income on lagged values of R\&D expenditures. Li and Hall (2020) also use a production function approach. Their model assumes a concave profit function for R\&D investment and that the firm invests optimally in $R \& D$ capital to maximize the net present value of its investment. Unlike tangible assets, the model assumes that R\&D capital depreciates solely because its contribution to the firm's profit declines over time. Their estimated parameters are based on NSF-BEA data and cover only $10.5 \%$ of 4-digit SIC codes and $28 \%$ of firm-year in Compustat, thus requiring other assumptions for firms in SIC codes outside of these estimations.

Our goal in this paper is to develop a panel set of firm-year intangible capital stocks that most accurately represents the undisclosed economic assets that are expected to yield future benefits to the firm. In order to do this, we need estimates of the key parameters, i.e. $\delta_{G}, \gamma_{S}$, that have minimal bias and noise. Prior approaches to estimate these accumulations of intangible capital have estimation issues due either to assumptions embedded in the structural model or assumptions about the channel through which these investments produce value. ${ }^{14}$ Many of these issues are detailed in Griliches (1996). To avoid many of these pitfalls in previous approaches, we rely on market prices, as detailed below.

\subsection{Empirical Strategy}

Using firm prices provides several benefits to our estimation process. Since firm prices represent the present discounted value of all future benefits to the firm, we can account for non-production benefits such as real option value. Our estimates do not rely on either a well-specified production

\footnotetext{
${ }^{14}$ For example, investigating the descriptions of income statements directly forces the researcher to make judgment call about what items represent an investment into long-lived capital. Estimating the value of intangible assets via patent renewals or a production function assumes that a single channel is the only mechanism through which intangible assets can produce value, while in reality intangible investments may benefit the firm's cost of equity or provide strategic real option value. The production function approach also necessitates taking a strong stance on the lag structure of benefits produced by intangible investments.
} 
process or any knowledge of the lag structure of benefits generated by intangible assets. Finally, by simultaneously estimating the stock of knowledge and organizational capital, we can account for any potential complementarity between these assets.

We estimate an equation of the form

$$
P_{i t}^{I}=f\left(I_{i t}, K_{i t}^{i n t}\left(\theta_{i t}\right) ; \xi_{i t}\right)
$$

where $P_{i t}^{I}$ is the market price of intangibles in the firm, $I_{i t}$ is the balance sheet value of externally acquired intangibles ${ }^{15}, K_{i t}^{\text {int }}$ is the book value of internally generated intangible capital stock as a function of a set of estimated parameters $\left(\theta_{i t}\right)$ and $f\left(\cdot ; \xi_{i t}\right)$ is the mapping from book values to market prices of intangibles.

A firm's externally purchased intangibles, $I_{i t}$, are disclosed on the asset side of its balance sheet (Compustat item intan). Building on the large empirical literature discussed in Section 1 above, we measure the value of internally generated intangible capital as the sum of knowledge and organizational capital,

$$
K_{i t}^{i n t}=G_{i t}+S_{i t}
$$

where $G_{i t}$ is the value of knowledge capital, and $S_{i t}$ is the value of organizational capital for firm $i$ in year $t$. We calculate these capital stocks by accumulating a fraction $\gamma_{S}, \gamma_{G}$ of past spending in R\&D and SG\&A ${ }^{16}$ using the perpetual inventory method:

$$
\begin{aligned}
G_{i t} & =\left(1-\delta_{G}\right) G_{i, t-1}+\gamma_{G} R \& D_{i t} \\
S_{i t} & =\left(1-\delta_{S}\right) S_{i, t-1}+\gamma_{S} S G \& A_{i t} .
\end{aligned}
$$

\footnotetext{
${ }^{15}$ Under GAAP regulations, firms are required to report intangibles acquired in mergers or acquisitions as either identifiable intangible assets or goodwill

${ }^{16} \mathrm{SG} \& \mathrm{~A}$ is measured net of R\&D expense $(x r d)$ and Research and Development in Process $(r d i p)$.
} 
Therefore, the fully specified capitalization model is:

$$
K_{i t}^{i n t}=\left(1-\delta_{G}\right) G_{i, t-1}+\gamma_{G} R \& D_{i t}+\left(1-\delta_{S}\right) S_{i, t-1}+\gamma_{S} S G \& A_{i t}
$$

We assume that the function $f$ in Equation (4) is linear and that the market-to-book enters as a multiplicative factor $\xi_{i t} \in(0, \infty)$ :

$$
P_{i t}^{I}=\xi_{i t}\left(I_{i t}+K_{i t}^{i n t}\right)
$$

Our ultimate goal is to estimate the structural parameters of the perpetual inventory Equation (7), $\theta=\left(\delta_{G}, \delta_{S}, \gamma_{G}, \gamma_{S}\right)$ and $\xi_{i t}$, by comparing the stock of intangible capital to the market price of intangible capital $P_{i t}^{I}$. Rearranging (8) shows that $\xi_{i t}$ is the intangible market-to-book ratio $\left(\xi=\frac{P}{I+K^{i n t}}\right)$.

\subsection{Estimation details}

Our objective of estimating the book value of intangibles $I_{i t}+K_{i t}^{\text {int }}$ requires an assumption about $\xi_{i t}$. One option is to let $f\left(\cdot ; \xi_{i t}\right)$ be the identity function, equivalent to setting $\xi_{i t}=1$. Theories of firm dynamic investment such as Hayashi (1982) predict that $\xi_{i t}$ is on average, one.

To implement this in our framework we let $\xi_{i t}$ be a function of time through a modified year fixed effect which is assumed to be one on average over time: ${ }^{17}$

$$
\begin{aligned}
\xi_{i t} & =\rho_{t} \\
\text { st. } \sum_{t} \frac{\rho_{t}}{T} & =1 .
\end{aligned}
$$

The estimation of (8) proceeds in several steps. First, to avoid weighting firms by size, and without an obvious scaling variable, we first take the natural logarithm of each side of Equation

\footnotetext{
${ }^{17}$ It is important in this case to average the year fixed effect over time, rather than across observations, because any imbalance in our sample panel may lead us to over- or under-weight certain time periods. This is especially a concern in our firm exit sample discussed in Section 2.2 below. Firm acquisitions and failures tend to cluster in economic booms and busts, respectively. In this setting, averaging the fixed effects across observations would cause the estimation to overweight these time periods in estimation of the fixed effects.
} 
(8):

$$
\log \left(P_{i t}^{I}\right)=\log \left(\rho_{t}\right)+\log \left(I_{i t}+K_{i t}^{i n t}\right)
$$

Next, due to the nature of R\&D and SG\&A spending, in particular that they are very stable within firms over time, the parameters $\gamma$ and $\delta$ in each capital accumulation process are not separately identifiable. To see this, using SG\&A spending as an example, consider the perpetual inventory equation for a firm $i$ :

$$
S_{i t}=\sum_{k} \gamma S G \& A_{i, t-k}\left(1-\delta_{S}\right)^{k}
$$

If $S G \& A_{i t}$ is constant for firm $i, S G \& A_{i t}=S G \& A$, we have

$$
S_{t}=\sum_{k} \gamma_{S} S G \& A\left(1-\delta_{S}\right)^{k}=\gamma S G \& A \frac{1}{1-\left(1-\delta_{S}\right)}=\gamma S G \& A\left(\frac{1}{\delta_{S}}\right)=\frac{\gamma_{S}}{\delta_{S}} S G \& A
$$

In this case we can only identify the ratio $\frac{\gamma_{S}}{\delta_{S}}$. A similar result holds if SG\&A has a constant growth rate.

We address this issue by reducing the parameter space through calibration of a subset of parameters. In particular, for organizational capital, we estimate the parameter $\gamma_{S}$, taking the depreciation of organizational capital $\delta_{S}$ as the standard $20 \%$ from the literature. We explore the implications of this assumption in Section 5. Briefly, any change in the calibration of $\delta_{S}$ has an offsetting effect on the estimate of $\gamma_{S}$ and has relatively small implications for the stock of organizational capital in any given firm-year. Given that our goal is to build accurate and unbiased stocks of both organizational and knowledge capital, we are comforted by the aforementioned fact. For knowledge capital, we assume that $\gamma_{G}=1$, as is standard in the literature, and estimate $\delta_{G} \cdot{ }^{18}$

\footnotetext{
${ }^{18}$ One should think about this calibration in the following way. R\&D projects can be successful, generating knowledge capital, or failed, generating nothing. The parameter $\gamma_{G}$ represents the fraction of projects that are successful. Since we do not observe project success, we assume all projects are successful $\left(\gamma_{G}=1\right)$ and the fraction of failures is subsumed by the estimate of $\delta_{G}$. When R\&D spending is constant, and only the quantity $\gamma_{G} / \delta_{G}$ is identified, this will manifest by increasing the estimate of $\delta_{G}$ relative to its true value by a factor of $\left(1 / \gamma_{G}\right)$. While this assumption does not perfectly hold in reality, as with organizational capital above the implications for the stock of knowledge capital in any given firm-year are quite small.
} 
Finally, since we hypothesize that the capital accumulation parameters likely vary significantly by industry, as demonstrated by, for example, Li and Hall (2020), we allow the parameters to vary by industry. Substituting for the $G$ and $S$ in Equation (11), we estimate the structural parameters by minimizing the sum of squared errors of the non-linear equation:

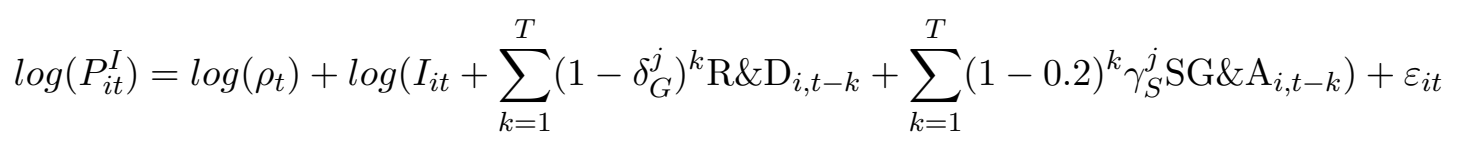

Since the model is in logs, model fit is assessed by comparing the exponent of the root mean standard error generated by the model to the exponentiated root mean squared error of a model that contains only a constant in the estimation. Because the model does not contain a constant, a negative pseudo $R^{2}$ is possible. Last, we calculate standard errors by bootstrap, re-drawing price observations, and thus the full time-series of company investments, with replacement. ${ }^{19}$

\subsection{Previous parameter estimates and assumptions}

As discussed in Section 1 above, prior research has used numerous methods to measure $\delta_{G}$, the R\&D depreciation rate from Equation (5), and these methods have produced a variety of values due to differing assumptions and models. For instance, Pakes and Schankerman (1984) estimate $\delta_{G}=0.25$ from a sample of patent renewals from the 1930s while Lev and Sougiannis (1996) finds $\delta_{G}$ to vary between 0.11 and 0.20 across industries. Bernstein and Mamuneas (2006) estimate a $\delta_{G}$ of $18 \%$. Li and Hall (2020) use BEA data and find $\delta_{G}$ between 0.12 and 0.38. As a result, researchers have used a range of assumptions for $\delta_{G}$. For example, Corrado, Hulten, and Sichel (2009) assume $\delta_{G}$ is 0.2. Falato, Kadyrzhanova, and $\operatorname{Sim}(2013)$ assume $\delta_{G}$ equals 0.15. Peters and Taylor (2017) use the $\delta_{G}$ estimates from Li and Hall (2020) and use 15\% when estimates are unavailable, an approach that has become common in recent years. To our knowledge, there have been no estimates of $\gamma_{G}$ in the literature, with researchers generally assuming that $\gamma_{G}=1$, a convention we maintain.

\footnotetext{
${ }^{19}$ We run bootstraps with 1,000 replications, re-drawing across all events before weighting to match the unconditional relative frequency of event types.
} 
Prior estimations of the parameters for organizational capital have been more sparse. The sole estimate of $\gamma_{S}$ comes from Hulten and Hao (2008), who estimate $\gamma_{S}$ from the income statements of 6 pharmaceutical firms, and there are no direct estimates of $\delta_{S} \cdot{ }^{20}$ Accordingly, a variety of assumptions have been used for $\gamma_{S}$ and $\delta_{S}$. For example, Eisfeldt and Papanikolaou (2013) rank firms by organizational capital stock within industry assuming a $\delta_{S}$ of 0.15 , based on the common assumption for $\delta_{G}$. Eisfeldt and Papanikolaou (2014), Li, Qiu, and Shen (2018), and Peters and Taylor (2017) measure organizational capital by assuming $\gamma_{S}$ is 0.3 and $\delta_{S}$ is 0.2 , while Falato, Kadyrzhanova, and Sim (2013) assume both $\delta_{S}$ and $\gamma_{S}$ on SG\&A to be 0.20.

In summary, the lack of a consensus for $\gamma_{S}$ and $\delta_{G}$ has led to a wide range of parameters being used to capitalize internally generated intangibles. Commonly used proxies assume that knowledge capital depreciates according to the parameters estimated by Li and Hall (2020), when available, and $15 \%$ otherwise while using the estimate that $30 \%$ of SG\&A represents an investment into organizational capital with a depreciation of $20 \%$ per year. This parameterization - henceforth "BEA-HH" - is the benchmark comparison in the validation tests below.

\section{Intangible Asset Prices}

Our goal is to estimate the capital accumulation parameters in Equation (12) that allow us to build capital stocks $G_{i t}$ and $S_{i t}$ produced by a firm's past flows in R\&D and SG\&A. Data for the independent variables in (12) are the firm's reported value of externally acquired intangibles, R\&D and SG\&A (less R\&D and In-Process Research and Development). All variables are available from Compustat. We use ten years of prior flows relative to the date that the price is observed, back-filling where needed. ${ }^{21}$ The dependent variable, $P_{i t}^{I}$, in (12) requires significantly more consideration.

In using $P_{i t}^{I}$ to estimate $\delta_{G}$ and $\gamma_{S}$, the sample of market prices should have minimal measure-

\footnotetext{
${ }^{20}$ The depreciation rates of some sub-components, e.g. brand capital, exist. For example, Lambin (1976) reports that the depreciation rate estimates for advertising effects are on average around $50 \%$ per year across a series of products.

${ }^{21}$ Details of the back-filling procedure follow Peters and Taylor (2017) and rely on estimated real R\&D and SG\&A growth rates by firm age relative to the IPO year. See their Appendix B2 for details.
} 
ment error and be representative of the universe of firms for which we will estimate $G_{i t}$ and $S_{i t}$. We rely on two sources of market prices: (1) a panel of Compustat firms, and (2) a sample of firms whose intangible assets are valued by the market in exits. Given that each has a distinct set of advantages and disadvantages, we rely on the validation tests described in Section 3 below to compare relative performance.

\subsection{Intangible Valuations from Publicly Traded Equity Prices}

The first set of intangible valuations - hereafter, "Trading" prices - use market prices of publiclytraded common equity. Publicly-traded equity reflects the market's valuation of a firm's net assets values, which are composed of both physical and intangible assets less preferred stock and liabilities. Given values for physical assets, preferred stock and liabilities, we can infer the firm's intangible asset value. A primary advantage of this approach is that the sample of firms used to estimate the accumulation parameters is representative of the population where researchers will most likely use them: public firms. We arrive at the market value of intangibles by solving for $P_{i t}^{I}$ in the decomposition of total assets. Here, $P_{i t}^{\text {Total }}$ reflects the sum of physical and intangible assets, and is financed by common equity, preferred equity, and debt:

$$
P_{i t}^{\text {Total }}=P_{i t}^{\text {Tangible }}+P_{i t}^{I}=P_{i t}^{\text {Equity }}+P_{i t}^{\text {Liabilities }}+P_{i t}^{\text {Preferred }}
$$

For publicly-traded firms, we observe market values of equity, but only book values of liabilities, preferred stock and total assets. We follow prior literature and assume that market values of preferred stock and debt are well-approximated by their book values. We also require an assumption about the market value of physical assets, since accounting rules mandate that the balance sheet report them at their original purchase prices and the assets cannot be marked to market. We follow Erickson and Whited (2006, 2012) and Peters and Taylor (2017) and use the sum of gross PPE, current assets and "other" (physical) assets. ${ }^{22}$ Ultimately, any measurement error in the markups

\footnotetext{
${ }^{22}$ As an alternative, we estimate the assumption of gross markup to reflect Erickson and Whited (2006) who
} 
will be reflected in the dependent variable $P_{i t}^{I}$ and lower the precision of our parameter estimates $\delta_{G}$ and $\gamma_{S}$, and ultimately the precision of $G_{i t}$ and $S_{i t}$.

\subsection{Intangible Valuations from Firms Exiting Equity Markets}

We source the second set of intangible valuations from firms that exit publicly traded markets (hereafter, "Exits"). This sample consists of a set of events that allow us to derive intangible valuations-the mark-to-market valuation of intangibles from public firm acquisitions of other public firms and recovery asset values for firms that delist from publicly traded markets due to bankruptcy. A primary advantage of the Exits sample is that it does not rely on an estimate of the market value of physical assets in order to arrive at a value for $P_{i t}^{I}$ (recall that we use gross PPE). The exit price transaction provides a direct revelation of intangible market prices. With acquisitions, accounting regulations (ASC 350) require that intangibles being purchased by the acquirer are directly recorded at market value on the acquirer's balance sheet as either Identifiable Intangible Assets (IIA) or goodwill (GW). Subsequently, $P_{i t}^{I}$ is calculated directly as the sum of IIA and GW. Furthermore, these intangible asset valuations measured during an acquisition event undergo an extensive due diligence process by expert appraisers that result in precise valuations. Most important, because we use the value of total intangibles, we need only trust the valuation of physical assets and liabilities. The valuation of these assets and liabilities has a long history with standardized practice. ${ }^{23}$ Section A3 provides several real-world examples found in our data. For bankruptcy events, we estimate $P_{i t}^{I}$ by collecting recovered asset values from Moody's Default and Recovery database and multiply by the average ratio of intangibles scaled by total assets, which we calculate from acquisitions in the same 4-digit SIC code. ${ }^{24}$

use the compounded rate of inflation to estimate the markup of net PPE. Untabulated results from validation tests indicate that using gross PPE as a markup tool outperform this alternative markup assumption.

${ }^{23}$ Figure IA1 in the Appendix provides a basic examples of the purchase method that provides this information.

${ }^{24}$ This file covers fully resolved large public U.S. corporate defaults between 1987 and 2019, and includes the final recovery of total debt, based on 10-K, 10-Q, press releases, and other legal filings. The data field named "FAMILY_RECOVERY" provides the dollar-weighted proportion of debt recovered after discounting for lost interest. We find exact matches with our sample of CRSP delistings for 95 of 478 events. We use industry (Fama-French five industries) average recovery rates from the same database for the remaining firms (49\% across all firms). This 
While the Exits sample does not require a markup assumption, we make two assumptions about goodwill values and bankruptcy recovery rates not found in building the Trading sample. First, prior studies (e.g., Roll, 1986) have shown goodwill to be related to over-payment and acquisitionspecific synergy values. Because our goal is to precisely measure the target firm's stand-alone values of organizational and knowledge capital, we remove these acquisition-specific factors from goodwill, leaving the remaining value to proxy for unidentifiable intangible assets. Specifically, we use the probability scaling method from Bhagat, Dong, Hirshleifer, and Noah (2005) and apply this to announcement day returns to estimate the synergy and over-payment component of the acquisition. The method - fully detailed in Appendix Section A2.2 - uses changes in target and acquirer market valuations in response to the acquisition announcement to estimate synergies. This estimate of acquisition-specific value is subtracted from the goodwill value reported in the purchase price allocation. ${ }^{25}$ Second, the Moody's Default and Recovery Database (DRD) only covers a partial sample of our delistings in CRSP, and thus we must estimate the percent of assets recovered for the remaining firms. We estimate these recovery rates using the modified FamaFrench 5 industry average recovery rates from the Moody's DRD. This recovery rate multiplied by the outstanding debt forms the "deal value" for these firms. Ultimately, both of our samples rely on different assumptions to arrive at a value of intangible capital. We thus rely on the validation tests detailed below to assess which set of parameters imply intangible stocks with the best out-of-sample performance.

\subsection{Data Sources}

The panel of firm-years used in the Trading sample includes all firms in the CRSP-Compustat merge outside of financial services, resources, real estate, or utilities. ${ }^{26}$ To avoid overlapping time recovery rate multiplied by outstanding debt forms our "deal value" for this sample of firms.

${ }^{25}$ In cases where the adjustment exceeds goodwill (less than $15 \%$ of deals), the remainder is removed from the IIA valuation. Additionally, we add one to both sides to avoid dropping observations with an implied price of intangibles of zero. Additional details on construction of acquisition prices is provided in the Appendix.

${ }^{26}$ We also exclude firms with gross PPE less than $\$ 5 \mathrm{~m}$, any firm with missing gross PPE, negative or missing sales or missing assets. 
series from a full Compustat estimation (excluding our acquirer-target deal-years), we randomly sample each firm once over its lifetime (after three years of trading) for 1986-2017 ${ }^{27}$ leaving us with 10,348 firm years for which we calculate $P_{i t}^{I}$ as previously discussed in Section 2.1. We then estimate Equation 12 with independent variables being comprised of the firm's reported value of externally acquired intangibles, R\&D and SG\&A from Compustat. We use ten years of prior flows relative to the date that the price is observed, back-filling where needed. ${ }^{28}$

Data on acquisitions, liquidations and bankruptcies comes first from Thomson's SDC Merger \& Acquisition database. We consider all U.S. public acquirer and public targets for deals that closed between 1996 and 2017 with a reported deal size. ${ }^{29}$ We drop deals where the acquirer or target has a financial services, resources, real estate or utility SIC code. ${ }^{30}$ We also exclude all deals that use the pooling method pre-2001. ${ }^{31}$ We also require data on the acquirer's purchase price allocation of the target's assets in order to collect prices paid for goodwill and identifiable intangible assets (IIA). When available, these purchase price allocations were found in the acquirer's subsequent $10-\mathrm{K}, 10-\mathrm{Q}, 8-\mathrm{K}$ or S-4 filing. We found information on the purchase price allocation for $81 \%$ $(1,719)$ of all candidate acquisitions. ${ }^{32}$ In the final step, we merge the target and acquirer firms to Compustat and CRSP, leaving us with a total of 1,521 acquisition events. We add to this sample, a set of 479 bankruptcy events from CRSP firm delistings between 1996 and 2017. We are able to find direct matches on asset recoveries from Moody's Default and Recovery Database for 95 of these events and use the estimation process described in Section 2.2 to estimate asset recovery for the remainder. In total, our panel of exit prices for which we estimate $\delta_{G}$ and $\gamma_{S}$ consists of 2,000 firm observations. We follow the same estimation procedures as with the Trading sample, using externally acquired intangibles and 10 prior years of R\&D and SG\&A data from Compustat.

\footnotetext{
${ }^{27}$ For robustness, we later repeat this exercise with several random samples, and find similar results.

${ }^{28}$ Details of the back-filling procedure follow Peters and Taylor (2017) and rely on estimated real R\&D and SG\&A growth rates by firm age relative to the IPO year. See their Appendix B2 for details.

${ }^{29}$ Our sample begins in 1996 because we require financial statements from the SEC's EDGAR website.

${ }^{30}$ The excluded SICs are 6000 to 6399,6700 to 6799,4900 to 4999,1000 to 1499.

${ }^{31}$ The results presented below for all deals from 1996-2017 are robust to exclusion of all pre-2002 deals.

${ }^{32}$ Some filings lacked the footnote for the acquisition (e.g., the acquisition was immaterial) or we could not identify any filing for the acquiring firm (e.g., the firm has a unique registration type with the SEC).
} 


\subsection{Parameter estimates}

We estimate the full-sample parameters for $\delta_{G}$ and $\gamma_{S}$ as well as industry-specific parameters using a modified Fama-French 5 industry classification ${ }^{33}$ over the full sample. In each estimation, we assume that $\delta_{S}$ and $\gamma_{G}$ are equal to 0.2 and 1.0, respectively. Table 1 reports the parameter estimates from Equation 12 using the Trading and Exits prices. For comparison, columns (1) and (2) report BEA-HH parameters. Recall that $\delta_{G}$ represents the depreciation rate of R\&D capital, and $\gamma_{S}$ represents the proportion of SG\&A that is to be classified as a long-lived asset. Thus, Equation 12 tells us that higher (lower) values of $\delta_{G}\left(\gamma_{S}\right)$ will lead to higher levels of $G_{i t}\left(S_{i t}\right)$. For example, examining the "All" row in Table 1, we can compare the values of Trading to BEA-HH and conclude that the capitalized intangible stocks using Trading parameters will be larger than capitalized intangible stocks using BEA-HH parameters. This is because $\gamma_{S}$ is larger (0.45 vs. 0.3$)$, which results in a higher level of organizational capital, and $\delta_{G}$ is smaller (0.33 vs 0.28), which results in a higher level of knowledge capital. Conversely, the Exits sample has smaller capitalized stocks relative to the BEA-HH stocks because its parameter estimates of $\gamma_{S}$ is $10 \%$ smaller $(0.27$ vs 0.3 ) and $\delta_{G}$ is $18 \%$ larger (0.33 vs 0.28 ). Finally, note that the pseudo- $\mathrm{R}^{2}$ values for Exits are $37 \%$ larger than Trading, indicating that $P_{i t}^{I}$ variation is better explained with the stock from the Exits parameters. We use an array of out-of-sample tests, introduced in Section 3 below, to systematically compare the capital stocks implied by these estimated parameters.

\section{Validation Tests}

As discussed in Section 2, estimating accumulation parameters using Exits and Trading prices require making assumptions about $P_{i t}^{I}$. These assumptions may result in different parameter estimates for $\delta_{G}$ and $\gamma_{S}$, and thus variation in the size of the capitalized intangible stocks, $G_{i t}$ and $S_{i t}$. To assess the performance of these accumulation parameters, we run an array of validation tests

\footnotetext{
${ }^{33}$ We make two changes to the FF5 industries, reclassifying SIC codes 8000-8099 (Health Services) as Consumer and Radio/TV broadcasters are Consumer (from High-tech).
} 
on our resulting capital stocks. In designing such tests, we have two goals. First, the intangible capital stocks should proxy for the expected future benefits the intangibles will provide to its owner. Second, applying the stocks to create new total invested capital should strengthen those stocks' relationship with other cross-sectional measures of intangibles. To avoid circularity that would result in better validation test performance of our stocks over those using the BEA-HH parameters, we exclude from the analysis the firm-years used in the estimation (i.e. targets in acquisitions, delisted firms and the randomly selected years from the Trading sample).

Using estimates from Table 1, we construct the knowledge and organizational capital stocks $G_{i t}$ and $S_{i t}$, as well as total invested capital (including intangible capital) $K_{i t}^{T O T}$ using 10-years of trailing R\&D and SG\&A data, $\gamma_{G}=1$ and $\delta_{S}=0.2$ from 1976-2018 for the CRSP-Compustat universe of firms. Our accumulation process for knowledge and organizational capital follow (5) and (6). Total invested capital is the sum of knowledge and organizational capital stocks, the book value of externally acquired intangibles and the book value of physical capital.

The diagnostic tests include direct tests of organizational capital, total intangible capital, as well as total invested capital that reflects the addition of off-balance sheet intangibles. The tests are one of two types. The first type sorts firm-years by the magnitude of the intangible component into separate groups (from high to low) and examines whether these resorted groups, e.g. high versus low organizational capital stock firms, results in larger differences of expected outputs for each type of intangible investment. The second diagnostic type examines fit, where we ask whether applying the intangible capital stocks improves the explanatory power in regression analyses where dependent variables are related to intangible values or economic realizations of intangible investments, such as patents and trademarks.

In sections 3.1 to 3.3 , we briefly describe the motivation of each test and report the results for intangible stocks estimated using Trading and Exits-based accumulation parameters, as well as results from stocks based on BEA-HH parameters. In section 3.4, we summarize the results of these tests. 


\subsection{Explaining Market Valuations}

The first diagnostic examines changes in the informativeness of book values of invested capital in explaining market enterprise values when total invested capital is adjusted for off-balance sheet intangibles. Connections between a firm's book invested capital and market enterprise value play important roles in the investment-q and asset pricing literatures. Book values, when properly measured, reflect the firm's capital investments that are available to produce future cash flows. Market values reflect investor expectations of these discounted future cash flows. To the extent that intangible capital stocks have been properly measured and are now reflected in total book invested capital, we expect a stronger association between market enterprise value and book invested capital. We use a simple regression of firm enterprise value on measures of total invested capital to evaluate the new intangible asset estimates:

$$
\log \left(E_{i t}\right)=\alpha+\beta \log \left(K_{i t}^{\text {tot }}\right)+\varepsilon_{i t}
$$

where $E_{i t}$ firm $i$ 's year $t$ enterprise value (i.e. the sum of end of fiscal year market capitalization, total debt and preferred stock) and $K_{i t}^{\text {tot }}$ is the book value of the capital stock (Compustat at)

adjusted for capitalized intangibles. That is, $K_{i t}^{\text {tot }}$ is equal to $K_{i t}^{\text {phy }}+K_{i t}^{i n t}$ where $K_{i t}^{i n t}$ is the sum of externally acquired and internally generated intangibles from our accumulation parameters, prior R\&D and SG\&A. We estimate (14) in the cross section by year. We expect the most precise measures of intangible capital to result in total invested capital measures that have the strongest associations with market enterprise values. To avoid any circularity in this test that would benefit the market price-based approaches relative to $\mathrm{BEA}-\mathrm{HH}$, all samples in this section exclude the firm-years used in the estimation (i.e., targets in acquisition in the 10 years prior to the deal, the acquirer in the year of the deal and all the firm-years in the Compustat estimation).

Since the explanatory power of the BEA-HH regression is already quite high, our diagnostic compares the additional explanatory power of each alternative over the standard BEA-HH measure 
of $K_{i t}^{\text {int }}$. Let $R S S^{B E A-H H}$ be the residual sum of squares from the BEA-HH approach. The diagnostic reports the annual ratio $\frac{R S S^{B E A-H H}-R S S^{A l t}}{R S S^{B E A-H H}}$ where $R S S^{A l t}$ is the residual sum of squares from the Trading and Exits-based capital stocks. A value greater than zero indicates improved fit, relative to BEA-HH. Figure 2 presents the results of the test statistic by year for each of the two samples and Figure 3 reports the t-statistic by year. Intangible stocks estimated from Exit prices perform better than BEA-HH in all years, with the results being statistically significant at the $5 \%$ confidence level for all but 6 years of the 39 year sample period. Conversely, stocks estimated from Trading prices perform worse than BEA-HH in all years, and perform significantly worse in all but 8 years of the time-series.

\subsection{Validation Tests of Organizational Capital}

Lev and Radhakrishnan (2005) describe organizational capital as "an agglomeration of technologies - business practices, processes and designs, and incentive and compensation systems - that together enable some firms to consistently and efficiently extract from a given level of physical and human resources a higher value of product". We employ three diagnostics for our measures of organizational capital: human capital risk, brand quality and employee satisfaction.

\subsubsection{Human Capital Risk}

Eisfeldt and Papanikolaou (2013) propose a model whereby organizational capital is a firm-specific investment which has outputs measured by a firm's key talent. Their model shows that the outside option of the firm's key talent determines the share of the firm's cash flows that accrue to shareholders, and thus shareholders bear more risk for firms with higher levels of organizational capital. They estimate the stock of organizational capital by capitalizing a firm's SG\&A expenses, and validate their measure by examining the MD\&A of firms with higher (lower) levels of organizational capital, and showing that firms with higher (lower) levels are more (less) likely to disclose the potential for key personnel loss as a significant risk factor to the firm. To do so, they seek out references for 
personnel risk in 10-K filings and argue that any firm sorting by a measure of organizational capital should correlate with such mentions. We follow a similar approach, using over 120,000 10-K filings from 2002-2016. ${ }^{34}$ We calculate the fraction of words in the MD\&A statement that reference risk of personnel loss (keywords: "personnel" or "talented employee" or "key talent").

Because a more exact measure of organizational capital will more precisely sort firms into highest (lowest) quintiles of human capital risk, we expect that a more exact measure of organizational capital will have more (less) frequent mentions of personnel loss as a risk factor in the firm's MD\&A. Thus, our diagnostic test compares the relative performance of the two sets of organizational capital estimates $\hat{S}$ based on Trading and Exits accumulation parameters by partitioning firms into quintiles based on their organizational capital stock scaled by assets in each year using each measure and then calculating the frequencies of mentions between the high and low partitions for each year. Figure 4 reports the t-statistic by year from the difference in means for the top versus bottom quintile of firms for the fraction of words that reference personnel loss.

Using Exits-based parameters, the fraction with some reference of personnel risk in the top quintile versus the bottom is $66 \%$ and $52 \%$, respectively. This compares to $58 \%$ and $52 \%$ for the quintiles sorted using the $\mathrm{HH}(\gamma=0.3)$ method from the literature and $61 \%$ and $52 \%$ for those implied by Trading prices. In all years of the sample period, the difference between top and bottom quintile is significant using Exits stocks. Stocks created with Trading parameters produce significant t-statistics in all but two years, however, they are uniformly smaller than those from the acquisition method. Both methods out-perform the current literature estimates ("HH") where differences are statistically significant in only six of fifteen years. We conclude that the Exits parameters create organizational capital stocks that provide more predictive power of the firm's assessment of its own human capital risk. ${ }^{35}$

\footnotetext{
${ }^{34}$ See https://github.com/apodobytko/10K-MDA-Section for the code to run this search.

${ }^{35}$ Reassuringly, sorting firms by our organizational capital stocks (by year) results in similar patterns of firm productivity, size and executive characteristics as found in Eisfeldt and Papanikolaou (2013) (see Appendix Table IA1).
} 


\subsubsection{Brand Quality}

Another well-documented subset of firms' organizational capital is brand quality (Vomberg, Homburg, and Bornemann (2015), Mizik and Jacobson (2008)). Thus, our second validation test asks whether our organizational capital stocks (and total intangible capital) exhibit stronger associations with brand quality. We collect the top 100 global brands according to Interbrand, a brand consultancy, from 2000 to $2018 .{ }^{36}$ We extract the ranking and merge each company (or brand) to U.S. public firms in Compustat. ${ }^{37}$ This diagnostic is a simple fit test where we regress the log of a firm's brand rank on the log of organizational capital (and the log of total intangible capital). Thus, more precise measures of intangible capital will have stronger associations with brand quality, thus leading to higher $R^{2}$ in the regression analyses. ${ }^{38}$ Table 2 reports the pooled regression results. Columns (1)-(3) use the log of organizational capital as the independent variable, while columns (4)-(6) use the log of total intangible capital as the independent variable. Results indicate that the coefficients on organizational (total intangible) capital load negatively for both of our price-based stocks as well as stocks based on HH parameters. These findings are consistent with the notion that firms with higher organizational capital stocks have higher brand equity. Relative to HH, both sets of price-based stocks improve the explanatory power $\left(R^{2}\right.$ in columns $(2),(3)$ and (5), (6)) with the Exits-based stocks exhibiting both the largest loading and $R^{2}$ in both sets of regressions.

\subsubsection{Employee Satisfaction}

The third validation test evaluates the quality of organizational capital stocks by testing their association with employee satisfaction. We use employee satisfaction data ("Best Companies to Work For") from Edmans (2011) and additional rankings from the online firm Glassdoor. The latter reports the "Best Places to Work" 39 using reviews posted by current employees. The Glassdoor

\footnotetext{
${ }^{36}$ See https://www.interbrand.com/best-brands/best-global-brands/previous-years/2000/ for the raw data.

${ }^{37}$ If two brands from the same firm are on the list, we take the average rank within-firm.

${ }^{38}$ The limited sample size restricts this diagnostic to a pooled OLS regression.

${ }^{39}$ For example, see their 2019 ranking here https ://www.glassdoor.com/Award/Best-Places-to-Work-LST_KQ0, 19.htm.
} 
rankings extend the Edmans (2011) sample for 2012 to 2018. We merge the annual rankings to Compustat and correlate these firms' estimated organizational capital stock ranks with their em-

ployee satisfaction ranks. We expect that firms sorted by organizational capital $\hat{S}$ should similarly sort by employee satisfaction, i.e. organizational capital measures are of higher quality when their stocks result in higher $R^{2}$ in the regression between the $\hat{S}$ sort and employee satisfaction. Because our resulting dataset has only 910 firm-year observations following our Compustat merge, we run a pooled panel regression. Results are tabulated in Table 3. Panel A documents the regression of log employee satisfaction rank on log organizational capital rank. Exits-based stocks exhibit the highest $R^{2}$ of the three measures and a weakly positive loading. Panel B reports the pairwise correlates of intangible capital estimate rankings with employee satisfaction rank. As expected, each set of stocks exhibit a statistically significant positive correlation with employee satisfaction, with Exit-based estimates exhibiting the stronger association. Overall, all three diagnostic tests of organization capital stocks show that Exit-based capital stocks are better proxies than the Trading-based stocks and HH measures for these out-of-sample measures of organizational capital components.

\subsection{Validation Tests of Total Intangible Capital}

The final three validation tests evaluate outputs associated with investments in both knowledge and organizational capital.

\subsubsection{Patent Valuations}

Prior literature (Hall, Jaffe, and Trajtenberg, 2005; Subramaniam and Youndt, 2005; Dakhli and De Clercq, 2004) finds that innovation related to both knowledge and human capital. We use patent valuations from Kogan, Papanikolaou, Seru, and Stoffman (2017) as a measure of innovation quality and examine the association of our total intangible capital measures and innovation. We let the patent valuation for firm $i$ in year $t$ be Patent $i t$ (set to zero if missing). The regression takes the 
following form:

$$
\log \left(\text { Patent }_{i t}\right)=\beta_{0}+\beta_{1} X_{i t-1}+\beta_{2} \log \left(\hat{G}_{i t-1}+\hat{S}_{i t-1}+I_{i t-1}\right)+\nu_{i t}
$$

where $X_{i t-1}$ is a control for the number of patents held by the firm. This diagnostic will incorporate alternative measures of $\hat{G}_{i t-1}$ and $\hat{S}_{i t-1}$. Better performance is captured with a higher $R^{2}$ from (15). ${ }^{40}$ We report the ratio of two values of $R^{2}$, where the benchmark (denominator) is the $R^{2}$ using estimated intangible capital from the BEA-HH method and the numerator is the $R^{2}$ using estimated intangible capital from Exits or Trading prices. Results indicate that estimated stocks from the Trading-based parameters produce less explanatory power than those current used in the literature in all years. It is important to simultaneously highlight that this difference is negative, but very small. In contrast, stocks based on Exits parameters improve explanatory power - again, weakly - in all but five of the sample years.

\subsubsection{Trademarks}

Similar to the patent validation tests in Section 3.3.1, the second validation test examines ratios of two $R^{2}$ values from regressions of newly filed trademarks on total intangible capital. The numerator (denominator) is the $R^{2}$ from stocks accumulated by two price based measures (BEA-HH parameters). The intuition is that firms with higher levels of intangible capital will have, on average, more powerful brands. In order to protect their brand equity, they will file for trademark protection. Using data provided by Heath and Mace (2020), we regress the count of new trademarks on total intangible capital by year. ${ }^{41}$ The regressions take the following form:

$$
\log \left(\operatorname{Trademark}_{i t}+1\right)=\alpha_{0}+\alpha_{1} \log \left(\hat{S}_{i t-1}+\hat{G}_{i t-1}+I_{i t-1}+1\right)+\alpha_{2} \log \left(T S_{i t-1}+1\right)+\nu_{i t}
$$

\footnotetext{
${ }^{40}$ Untabulated, we find that $\beta_{2}$ is positive and significant with all capital stocks.

${ }^{41}$ The data are available in the Internet Appendix of Heath and Mace (2020).
} 
where Trademark $i t$ is one plus the number of new trademarks in year $t$ and $T S_{i t-1}$ is the $\log$ of the previous year's active trademarks. Once again, a total intangible capital measure out-performs when it has a relatively higher $R^{2}$ from (16) (relative to the BEA-HH benchmark). Figure 6 displays the annual $R^{2}$ ratios of the two price based measures. Results and comparisons appear to similar to the patent $R^{2}$ results. Trading-based stocks underperform BEA-HH in all but one year, while Exits-based stocks outperform BEA-HH in all but two years. Overall, intangible stocks based on Exit prices are best at explaining variation in trademark filings.

\subsection{Summary of Validation Tests}

Each validation shows that Exits-based stocks produce the sharpest cross-sectional sorts and explain more variation in innovative output proxies. We therefore consider it the ideal choice among all the options, including the BEA-HH parameters most commonly used in the literature. As discussed in Section 2.3, each method has its own strengths and weaknesses. The potential concerns for each set of prices (i.e. physical markup, noisy goodwill, bankruptcy recovery rates) are not to be downplayed, but rather weighed against the improved performance in this range of out-of-sample tests. We hope that future researchers can apply the general model in Section 1 with improved data.

\section{Descriptive analysis using Exits-based stocks}

We now explore some descriptive analysis using estimated intangible capital from the Exits-based stocks.

\subsection{Comparison to existing methods}

Figure 7 presents the difference between our estimates ("Exits") and the current methods ("Current"), scaled by the latter. All parameters are time-invariant, so time-series variation stems from changes in the relative use of R\&D and SG\&A. The differences in our estimated intangible capital 
stocks relative to those from the literature vary across industries. The "All" line in the figure shows that the new estimate is approximately $10 \%$ smaller across all firm-years. Our intangible capital stocks are smaller than commonly assumed in both the consumer and manufacturing industries.

In contrast, our intangible stocks are larger in all years for high-tech firms and half the years for healthcare. In both cases, higher estimates of $\delta_{G}$, which imply smaller knowledge capital stocks, are outweighed by larger implied organizational capital investments. Given the larger estimated depreciation of R\&D for healthcare (34\% vs. $17 \%$ ), the relatively smaller stocks in healthcare in the 2000s reflect firms' shift from organizational capital to knowledge capital investments. Overall, we find economically meaningful differences in implied stocks compared to existing methods. Next, we validate whether the differences improve the informativeness of capital stock book values.

\subsection{Intangible capital stocks by industry and time}

The growing importance of disclosing capitalized intangibles to firms' balance sheets is based on the idea that such intangibles are becoming an increasingly important component of how today's firms create economic value. Figure $8 \mathrm{a}$ presents time series trends of intangible capital for the four industries. Each series plots intangible intensity, calculated as the average ratio of intangible capital $K^{i n t}\left(S_{i t}+G_{i t}+I_{i t}\right)$ to total assets, e.g., intangible and physical assets (Compustat ppegt). As expected, intangible intensities are lowest in consumer and manufacturing industries. Firms in these industries have experienced an increase in the role of intangibles in their total assets since only the late 1990s. In contrast, healthcare and high-tech firms have higher intangible intensities that have each grown continually since the 1970s. The patterns in Figure 8a conform to basic predictions about differences across industries and time and provide further validation that our estimates measure real economic assets.

Figure 8b explores the relative importance of knowledge versus organizational capital by plotting the ratio of the former to total intangibles $K^{i n t}$. Healthcare has the highest intensity of knowledge capital (and thus the lowest organizational capital intensity). Both healthcare and high-tech firms 
experienced increases in knowledge capital stocks from 1977 - 1996. Since 1996, growth has either stalled (Healthcare) or the levels have fallen back to 1970's levels. ${ }^{42}$

\subsection{Market-to-book ratios}

Next, we re-examine the time series behavior of market-to-book ratios with these new capital stocks and compare them with the time series behavior of unadjusted market-to-book ratios. We calculate the average market-to-book equity ratios from the period 1997-2017 for both sets of capital stocks, and run the following regression:

$$
\frac{M}{B}=\beta_{0}+\beta_{1} \text { Year }_{t}+\epsilon_{t}
$$

Figure 9 reports two time-series plots with best-fit lines for the unadjusted M/B and the M/B adjusted using the Exits-based stocks. Each series excludes the sample of acquirers and targets (in the year of the acquisition for the former and the ten years up to and prior to the acquisition for the latter). Unadjusted (i.e. internal intangibles excluded from assets), the slope coefficient of 0.041 shows that, on average, the M/B ratio is drifting upwards by 0.041 per year. After our adjustments for intangible capital, we find the slope coefficient to be 0.012 , a decrease in the upward trend of $70 \%$. We view this basic result as a validation that our measure significantly attenuates the increasing downward bias that results from the combination of accounting rules that mandate the expensing of intangibles and increasing intangible investments over time.

\subsection{Return on equity}

Return on equity (ROE) is traditionally calculated as the firm's net income scaled by its beginning of year book value of common equity. However, because traditional accounting expenses intangible investments, both the numerator and denominator of the ratio are biased. Specifically, the de-

\footnotetext{
${ }^{42}$ One possible (yet to be explored) explanation are changes in R\&D tax credits (Bloom, Schankerman, and Van Reenen (2013)). Many of these originated in 1981 (a period of increase in Figure 8b).
} 
nominator lacks the off-balance sheet intangibles, while the numerator nets out the current year's intangible investment while ignoring the depreciation of off-balance sheet capital. The downward bias in the denominator results in an upward bias in unadjusted ROE's when intangibles are excluded. Assuming competitive markets, long-term averages of ROE should approach the market's cost of equity capital. While it is beyond the scope of our study to debate the market's cost of equity capital, we rely on some agreement from the literature. Graham and Harvey (2018) survey CFOs from 2000-2017 and find an equity risk premium of 4.42\%, while Damodaran (2020) finds an implied equity risk premium using a free cash flow to equity model of 4.33\% from 1978-2017. Adding these values to the 10-year t-bond rate of $6.16 \%$ from 1978-2017 results in expected market-wide returns on equity of $10.58 \%$ and $10.49 \%$, respectively.

Figure 10 displays the impact of incorporating intangibles into the ROE calculation across our panel of firms from 1978-2017. Specifically, we plot the unadjusted average annual ROE across the full sample (dashed), along with the average annual ROE (solid) after making adjustments to both the numerator and denominator for the capitalization of intangibles. ${ }^{43}$ These adjustments for intangible capital lower the average annual ROE from $16.82 \%$ to $10.20 \%$ (untabulated), a decrease of 40\%, and closely in-line with expectations based on Graham and Harvey (2018) and Damodaran (2020) . Finally, the degree of ROE bias - the unadjusted ROE less the exits-adjusted ROE (scatter and dotted linear fit) - has steadily risen over time. This rise is consistent increasing intangible intensity over time, and further highlights the importance of capitalizing intangibles.

\subsection{Asset pricing factors}

The multi-factor Fama-French (FF) model (e.g., Fama and French $(1992,1993))$ is widely used in calculating expected returns. One key component in the FF model is HML (high-minus-low),

\footnotetext{
${ }^{43}$ Our adjustment $\mathrm{Adj}_{{ }_{t}}$ to net income is as follows:

$$
N I_{i t}^{a d j}=N I_{i t}+\left(\mathrm{RD}_{i t}+\gamma_{s} \mathrm{SGA}_{i t}-G_{i t} \delta_{G}-S_{i t} \delta_{S}\right)(1-0.35)
$$

The adjustment adds back the capitalized portion of the knowledge and organizational capital investment and subtracts the current year's depreciation of the capitalized asset. Because all the investment flows are pre-tax, we multiply by $1-0.35$, where 0.35 is an estimated tax rate for our sample.
} 
the realized returns to a portfolio that is long (short) high (low) book equity-to-market equity firms. Given that current accounting standards prohibit the capitalization of internally generated intangible investments, book equity values will be depressed by the amount of the intangible capital. As a result, we expect some proportion of firms in a traditional FF HML portfolio sort to be misclassified, relative to an HML sort that uses our exit-price parameters that adjust for intangible capital. Table 4 documents the consequences of these misclassifications on the observed return. Columns 1 and 2 show that monthly return spreads are $77 \%$ larger, 36.6 vs 20.6 basis points $(p=0.04)$, upon the adjustment for intangible capital to the numerator.

Upon further exploration, we find that $82 \%$ of firms in the high or low $\mathrm{B} / \mathrm{M}$ portfolios are correctly sorted, i.e. they do not move across portfolios after intangible capitalization, and that the return spreads are quite similar (36.6 vs $34.5 \mathrm{bp}$ ) between the adjusted portfolio and the FF portfolio using only properly sorted firms. Thus, the large difference in observed return spreads must be driven by the missorted firms. Column 5 shows that $20 \%$ (15\%) of firm-month observations in the traditional FF sort have substantially high (low) intangible capital such that they transition out of the short (long) sides of the portfolio. Column 6 shows the returns in each B/M portfolio for these misclassifications and finds that the well-documented HML relationship not only disappears, but also exhibits negative return spreads $(-25 \mathrm{bp})$. While the conclusive mechanism of why HML is predictive of future returns is beyond the scope of our paper, Korteweg (2010) has shown that higher intangible firms have greater distress risk, while Edmans (2011) has documented that stock market underreacts to the value of intangible capital. Our empirical results are consistent with both such possibilities and highlight the importance of capitalizing intangibles when HML is used in asset pricing tests.

\section{Assumption validation and robustness}

We perform several robustness analyses, beyond those discussed throughout the results above. 


\subsection{Parameter Calibration}

Given the inherent difficulties in separately identifying both the fraction of SG\&A that is investment $\left(\gamma_{S}\right)$ and the rate of depreciation $\left(\delta_{S}\right)$ discussed in Secion 1.2, Figure 11a presents the main estimation in the Exits sample under alternative assumptions about the rate of organization capital depreciation rates. We consider a range of $[.1, .3]$ for the $\delta_{S}$ and re-estimate equation 12 , reporting both the new parameter estimates for $\gamma_{S}$ and $\delta_{G}$ along with the $R^{2}$. We find that Figure 11a shows little variation in the estimate of $\delta_{G}$. As we increase the $\delta_{S}$ from 0.1 to 0.3 , the estimated $\gamma_{S}$ increases from .2 to .4 . The $R^{2}$ from the model estimation (right axis) remains nearly static across these dynamics, varying by only $2 \%$. We conclude two things from this exercise: (1) that our assumed $\delta_{S}=.2$ is not driving any of our results, and (2) that the pair of $\left(\gamma_{S}, \delta_{S}\right)$ is the key assumption for measuring organization capital.

\subsection{Estimation within time-period subsamples}

We next analyze whether the baseline parameter estimates vary significantly over time. We estimate $\gamma_{S}^{t}$ and $\delta_{G}^{t}$ for each year using a ten year rolling window. This allows us to investigate the validity of our assumption that $\gamma_{S}$ and $\delta_{G}$ are constant over time, in addition to whether business cycles or merger waves confound our estimates. The estimation is the same as in Section 1.1 with one exception: rather than estimate year fixed effects within each time-period, the year fixed effects are instead taken from the full sample estimation, reported in Figure IA4, and imposed within the non-linear least squares estimation. ${ }^{44}$

Figure $11 \mathrm{~b}$ reports time varying coefficients of $\gamma_{S}^{t}$ (blue solid line) and $\delta_{G}^{t}$ (red dashed line). Also reported are full-sample estimates of $\gamma_{S}$ (horizontal blue line) and $\delta_{G}$ (horizontal red line) from Table 1. Parameter estimates are static across subsamples with any time-series variation in $\gamma_{S}$ and $\delta_{G}$ being insignificantly different from their full-sample counterparts. In addition to having only small fluctuations over time, $\gamma_{S}$ and $\delta_{G}$ estimates strongly co-move together $\left(\rho_{\gamma_{S}, \delta_{G}}=0.81, p<0.001\right)$.

\footnotetext{
${ }^{44}$ This leaves in place the identifying assumption from the main estimation that the time-series average marketto-book of intangibles is unity over the entire sample, 1995-2017, rather than within each 10-year window.
} 
Because higher levels of $\gamma_{S}\left(\delta_{G}\right)$ increase (decrease) the accumulation of intangible capital, $\gamma_{S}$ and $\delta_{G}$ variation will offset each other and total intangible stocks will be even less sensitive to any timeseries variation. These results complement a similar exercise in Li and Hall (2016), who present some evidence for declining R\&D depreciation rates between 1987 and 2007. The results here do not exhibit such trends, consistent with our baseline assumptions about static depreciation and capitalization parameters over time.

\subsection{Exits sample alternatives: non-adjusted goodwill or excluding bankruptcies}

Two of the major assumptions in the Exits approach is our adjustment to reported goodwill and the use of delisted firms. Recall that the former adjustment attempts to remove acquisition or pair-specific value embedded in goodwill using market reactions to the merger announcement.

Panel A of Table 5a reports the main estimation including only the 1521 non-bankruptcy acquisitions. As expected, excluding failed firms from the analysis raises the average fraction $(\gamma)$ of SG\&A that represents an investment in long-lived organizational capital from 0.27 to 0.43 , an increase of $59 \%$. The point estimates for $\delta_{G}$ are lower than those in Table 1, with the full sample implying an average depreciation rate of knowledge capital of $27 \%$ per year. ${ }^{45}$ Reassuringly, when we repeat each validation test from Section 3 (unreported), the stocks implied by these alternative parameters under-perform those when delistings are included.

Finally, Table 5b repeats the Exits parameter estimation without the adjustment to goodwill discussed in Section 2.2. As expected, the adjustments to goodwill have a large impact on estimates. $\mathrm{R} \& \mathrm{D}$ depreciation rates are $50 \%$ higher and the percentage of SG\&A that is investment is $37 \%$ lower with the adjusted goodwill. These changes demonstrate that our adjustments are controlling for a large part of the synergies and over-payment found in raw goodwill. In unreported results, the stocks implied by these parameters under-perform the main Exits-based stocks in all validations.

\footnotetext{
${ }^{45}$ The negative depreciation for "Other" is mainly driven by one acquisition where the target had less than $\$ 30 \mathrm{~m}$ in annual R\&D and had acquired intangibles of over $\$ 2 \mathrm{~b}$ (after adjustments).
} 


\section{Conclusion}

Despite the growing importance of intangible capital in today's economy, existing research still lacks a consensus regarding the parameters that govern the capitalization of intangible assets. We develop and test a model that uses market prices to validate parameter estimates of the depreciation of knowledge capital based on prior R\&D spending and the fraction of SG\&A capital that represents investment into long-lived organizational capital. ${ }^{46}$ We estimate the parameters in our model based on market prices from two sources (1) publicly traded equity prices ("Trading") and (2) exit prices ("Exits"). Because each sample has a different set of strengths and weaknesses, we develop a set of validation tests to determine the best set of parameters for future research that is based on assessing the ability of the intangible capital stock developed by the parameters in explaining expected outputs from intangible capital investment (e.g. market value, patents, human capital). We subject both capital stocks to a series of validation tests where their performance is benchmarked against existing estimates. Overall, we find that capital stocks developed using Exits price parameters perform best in these validation tests, showing performance improvements in the stocks' ability to explain market enterprise values, expected returns, human capital, job satisfaction, brand rankings, patent values and trademarks.

\footnotetext{
${ }^{46}$ Implied stocks and estimation parameters are available for public download and usage at http://bit.1y/intan_ cap.
} 


\section{References}

Acemoglu, Daron, Ufuk Akcigit, Harun Alp, Nicholas Bloom, and William R Kerr, 2013, Innovation, reallocation and growth, Discussion paper, National Bureau of Economic Research.

Aksoy, Lerzan, Bruce Cooil, Christopher Groening, Timothy L Keiningham, and Atakan Yalçın, 2008, The long-term stock market valuation of customer satisfaction, Journal of Marketing 72, 105-122.

Ayers, Benjamin C, Craig E Lefanowicz, and John R Robinson, 2000, The financial statement effects of eliminating the pooling-of-interests method of acquisition accounting, Accounting Horizons 14, 1-19.

Belo, Frederico, Xiaoji Lin, and Maria Ana Vitorino, 2014, Brand capital and firm value, Review of Economic Dynamics 17, 150-169.

Bena, Jan, and Kai Li, 2014, Corporate innovations and mergers and acquisitions, The Journal of Finance 69, 1923-1960.

Bernstein, Jeffrey I, and Theofanis P Mamuneas, 2006, R\&D depreciation, stocks, user costs and productivity growth for U.S. R\&D intensive industries, Structural Change and Economic Dynamics 17, 70-98.

Bernstein, Jeffrey I, and M Ishaq Nadiri, 1988, Interindustry r\&d spillovers, rates of return, and production in high-tech industries, The American Economic Review 78, 429-434.

Bhagat, Sanjai, Ming Dong, David Hirshleifer, and Robert Noah, 2005, Do tender offers create value? New methods and evidence, Journal of Financial Economics 76, 3-60.

Bloom, Nicholas, Mark Schankerman, and John Van Reenen, 2013, Identifying technology spillovers and product market rivalry, Econometrica 81, 1347-1393.

Chan, Louis KC, Josef Lakonishok, and Theodore Sougiannis, 2001, The stock market valuation of research and development expenditures, The Journal of Finance 56, 2431-2456.

Cockburn, Iain, and Zvi Griliches, 1988, The estimation and measurement of spillover effects of R\&D investment-industry effects and appropriability measures in the stock market's valuation of R\&D and patents, The American Economic Review 78, 419-423.

Corrado, Carol A, and Charles R Hulten, 2010, How do you measure a "technological revolution"?, American Economic Review 100, 99-104.

— , and Daniel E Sichel, 2006, Intangible capital and economic growth, .

— 2009, Intangible capital and US economic growth, Review of income and wealth 55, 661-685.

Crouzet, Nicolas, and Janice C Eberly, 2019, Understanding weak capital investment: the role of market concentration and intangibles, Working Paper 25869 National Bureau of Economic Research. 
Dakhli, Mourad, and Dirk De Clercq, 2004, Human capital, social capital, and innovation: a multi-country study, Entrepreneurship $\& 3$ regional development 16, 107-128.

Damodaran, Aswath, 2020, Equity risk premiums: Determinants, estimation and implications-the 2020 edition, Estimation and Implications-The.

Daniel, Kent, and Sheridan Titman, 2006, Market reactions to tangible and intangible information, The Journal of Finance 61, 1605-1643.

Eberhart, Allan C, William F Maxwell, and Akhtar R Siddique, 2004, An examination of long-term abnormal stock returns and operating performance following R\&D increases, The Journal of Finance 59, 623-650.

Edmans, Alex, 2011, Does the stock market fully value intangibles? employee satisfaction and equity prices, Journal of Financial economics 101, 621-640.

Eisfeldt, Andrea L, and Dimitris Papanikolaou, 2013, Organization capital and the cross-section of expected returns, The Journal of Finance 68, 1365-1406.

— 2014, The value and ownership of intangible capital, American Economic Review 104, 189-94.

Erickson, Timothy, and Toni M Whited, 2006, On the accuracy of different measures of q, Financial management $35,5-33$.

— 2012, Treating measurement error in tobin's q, The Review of Financial Studies 25, 1286-1329.

Evenson, Robert E, and Larry E Westphal, 1995, Technological change and technology strategy, Handbook of development economics 3, 2209-2299.

Falato, Antonio, Dalida Kadyrzhanova, and Jae Sim, 2013, Rising intangible capital, shrinking debt capacity, and the US corporate savings glut, Working paper.

Fama, Eugene F, and Kenneth R French, 1992, The cross-section of expected stock returns, the Journal of Finance 47, 427-465.

- 1993, Common risk factors in the returns on stocks and bonds, Journal of financial economics 33, $3-56$.

Gourio, Francois, and Leena Rudanko, 2014, Customer capital, Review of Economic Studies 81, 1102-1136.

Graham, John R, and Campbell R Harvey, 2018, The equity risk premium in 2018, Working paper.

Griliches, Zvi, 1996, RESD and Productivity: The Econometric Evidence (Chicago University Press).

Gutiérrez, Germán, and Thomas Philippon, 2017, Investmentless growth: An empirical investigation, Brookings Papers on Economic Activity p. 89. 
Hall, Bronwyn H, Adam Jaffe, and Manuel Trajtenberg, 2005, Market value and patent citations, RAND Journal of economics pp. 16-38.

Hall, Bronwyn H, Jacques Mairesse, and Pierre Mohnen, 2010, Measuring the returns to r\&d, in Handbook of the Economics of Innovationvol. 2 . pp. 1033-1082 (Elsevier).

Hayashi, Fumio, 1982, Tobin's marginal q and average q: A neoclassical interpretation, Econometrica 50, 213-224.

Heath, Davidson, and Christopher Mace, 2020, The strategic effects of trademark protection, The Review of Financial Studies 33, 1848-1877.

Hirshleifer, David, Po-Hsuan Hsu, and Dongmei Li, 2013, Innovative efficiency and stock returns, Journal of Financial Economics 107, 632-654.

Hulten, Charles R, and Xiaohui Hao, 2008, What is a company really worth? Intangible capital and the "Market to book value" puzzle, Discussion paper, National Bureau of Economic Research.

Kogan, Leonid, Dimitris Papanikolaou, Amit Seru, and Noah Stoffman, 2017, Technological innovation, resource allocation, and growth, The Quarterly Journal of Economics 132, 665-712.

Korteweg, Arthur, 2010, The net benefits to leverage, The Journal of Finance 65, 2137-2170.

Lambin, Jean-Jacques, 1976, Advertising, competition and market conduct in oligopoly over time; an econometric investigation in western European countries (Amsterdam (Netherlands) North Holland Pub.).

Lev, Baruch, 2018, Ending the accounting-for-intangibles status quo, European Accounting Review forthcoming.

— , and Suresh Radhakrishnan, 2005, Measuring capital in the new economy, in The valuation of organization capital . pp. 73-110 (University of Chicago Press).

Lev, Baruch, and Theodore Sougiannis, 1996, The capitalization, amortization, and value-relevance of R\&D, Journal of Accounting and Economics 21, 107-138.

Lev, Baruch, and Paul Zarowin, 1999, The boundaries of financial reporting and how to extend them, Journal of Accounting research 37, 353-385.

Li, Kai, Buhui Qiu, and Rui Shen, 2018, Organization capital and mergers and acquisitions, Journal of Financial and Quantitative Analysis pp. 1-39.

Li, Wendy CY, and Bronwyn H Hall, 2016, Depreciation of business r\&d capital, Review of Income and Wealth.

, 2020, Depreciation of business r\&d capital, Review of Income and Wealth 66, 161-180. 
Loumioti, Maria, 2012, The use of intangible assets as loan collateral, Available at SSRN 1748675.

Mann, William, 2018, Creditor rights and innovation: Evidence from patent collateral, Journal of Financial Economics 130, 25-47.

Mizik, Natalie, and Robert Jacobson, 2008, The financial value impact of perceptual brand attributes, Journal of Marketing Research 45, 15-32.

Newey, W.K., and D. McFadden, 1994, Large sample estimation and hypothesis testing., in Handbook of Econometricsvol. 4 . pp. 2111-2245 (Elsevier).

Pakes, Ariel, and Mark Schankerman, 1984, The rate of obsolescence of patents, research gestation lags, and the private rate of return to research resources, in RED, patents, and productivity . pp. 73-88 (University of Chicago Press).

Peters, Ryan H, and Lucian A Taylor, 2017, Intangible capital and the investment-q relation, Journal of Financial Economics 123, 251-272.

Robinson, John R, and Philip B Shane, 1990, Acquisition accounting method and bid premia for target firms, Accounting Review pp. 25-48.

Roll, Richard, 1986, The hubris hypothesis of corporate takeovers, Journal of business pp. 197-216.

Shleifer, Andrei, and Robert W Vishny, 1992, Liquidation values and debt capacity: A market equilibrium approach, The Journal of Finance 47, 1343-1366.

Subramaniam, Mohan, and Mark A Youndt, 2005, The influence of intellectual capital on the types of innovative capabilities, Academy of Management journal 48, 450-463.

Sun, Qi, and Mindy X Zhang, 2018, Financing intangible capital, Journal of Financial Economics forthcoming.

Vomberg, Arnd, Christian Homburg, and Torsten Bornemann, 2015, Talented people and strong brands: The contribution of human capital and brand equity to firm value, Strategic Management Journal 36, $2122-2131$.

Williamson, Oliver E, 1988, Corporate finance and corporate governance, The journal of finance 43, 567-591. 


\section{$7 \quad$ Figures and tables}

Figure 1: Capital expenditures and R\&D: 1977-2018

The figure reports average Research and Development Expense (R\&D) and Capital Expenditures (CAPEX) as a fraction of lagged total assets (without internally generated intangibles) for Compustat firms from 1977-2018.

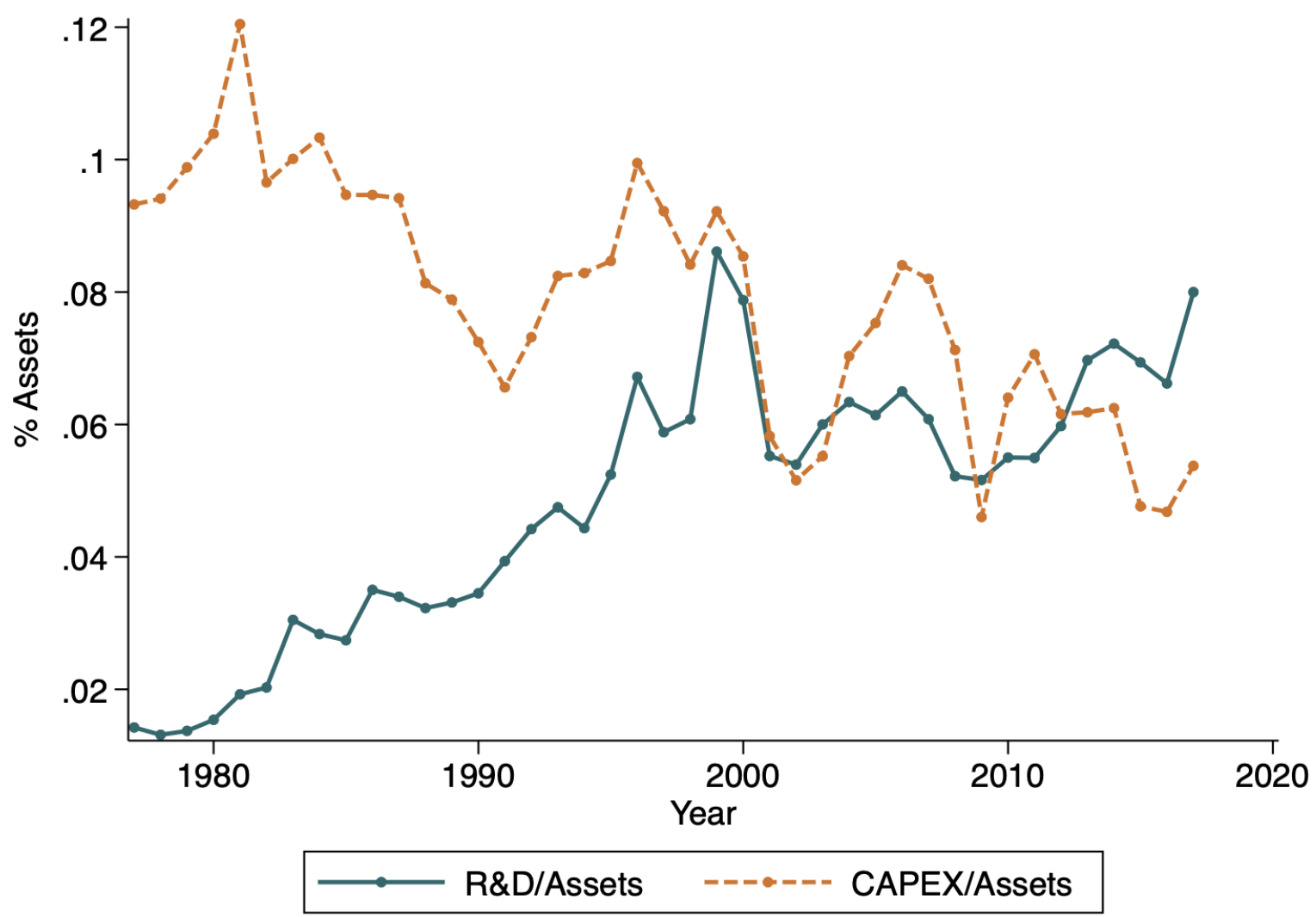


Figure 2: Explanatory power of assets for market enterprise Value

The figure reports the explanatory power of the estimated capital stock relative to a BEA-HH capital stock measurement in annual regressions of the firm's log market enterprise value (market capitalization plus debt and preferred stock) on the log of book value of capital stock:

$$
\log \left(E_{i t}\right)=\alpha+\beta \log \left(K_{i t}^{t o t}\right)+\varepsilon_{i t}
$$

where $E_{i t}$ firm $i$ 's year $t$ enterprise value and $K_{i t}^{\text {tot }}$ is the standard book value of capital stock (Compustat at). To avoid mechanical outperformance over BEA-HH, this analysis excludes any firm-years used in the parameter estimation of Equation 12 (i.e. acquisition targets and delisted firms in the Exits sample and the randomly selected firm-years from the Trading sample).

Relative explanatory power is plotted by year, and calculated as excess residual variance explained:

$$
\frac{R S S^{B E A-H H}-R S S^{A l t}}{R S S^{B E A-H H}}
$$

where $R S S$ represents the residual sum of squares from the regression models.

The baseline (i.e. "RSS $B E A-H H ")$ is the benchmark "BEA-HH" model that uses the parameters reported in columns (1) and (2) of Table 1. "RSS Alt" reflects the use of an alternate model based on market prices. A ratio greater than zero indicates that the market-price estimated capital stocks have stronger explanatory power. The "Exits" model estimates intangible stocks using the exit prices parameter estimates (Section 2.2). The "Trading" model estimates the intangible stocks using the trading prices parameter estimates (Section 2.1).

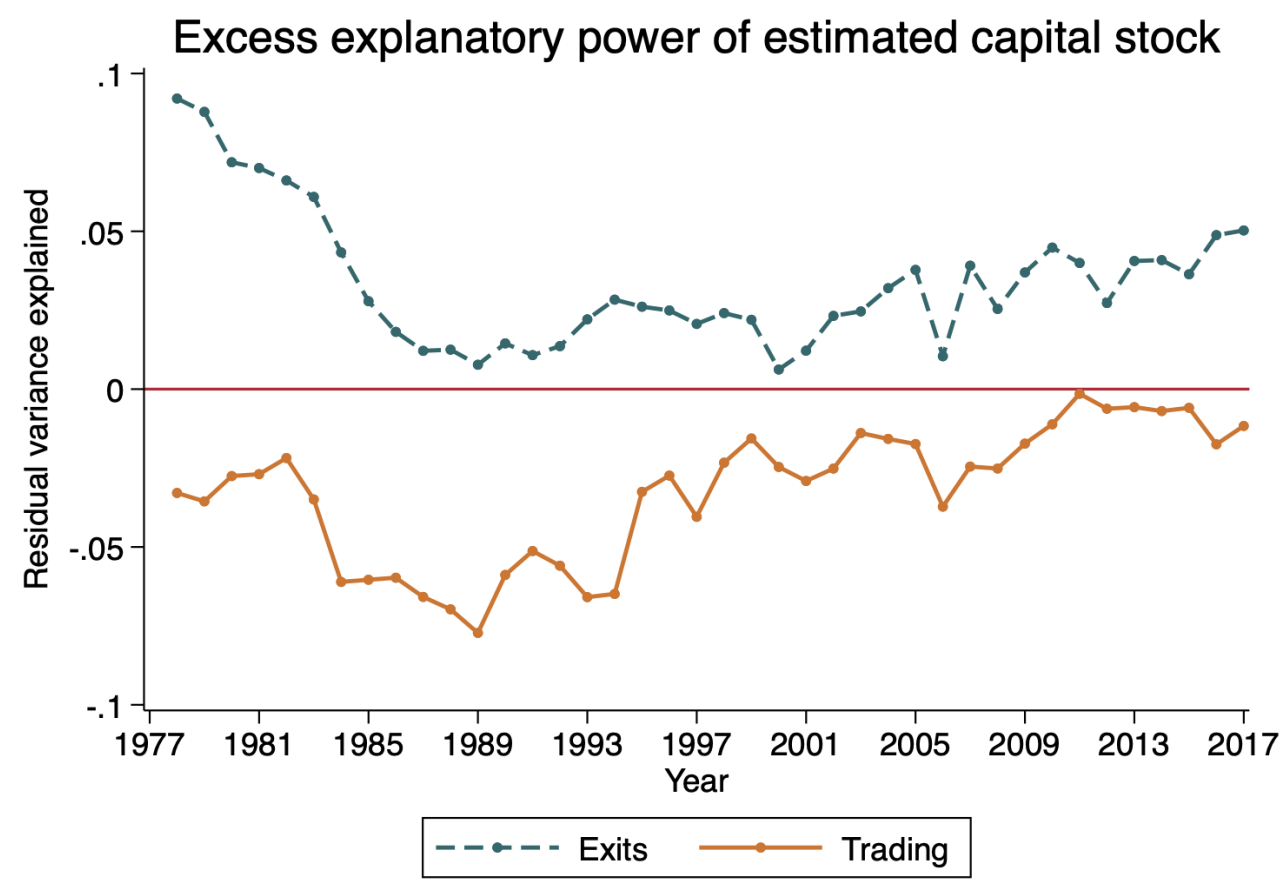


Figure 3: Explanatory power vs BEA-HH: Tests for differences in explanatory power

Using the same regressions described in Figure 2, this figure reports the t-statistics from the test of the hypothesis that the $R^{2}$ using each intangible capital alternative is the same as the $R^{2}$ from BEA-HH. The test statistic uses the influence function method (Newey and McFadden (1994)) to compare the two separate model statistics. The horizontal lines represent t-statistics of 1.96 and -1.96. To avoid mechanical outperformance over BEA-HH, this analysis excludes any firm-years used in the parameter estimation of Equation 12 (i.e. acquisition targets and delisted firms in the Exits sample and the randomly selected firm-years from the Trading sample).

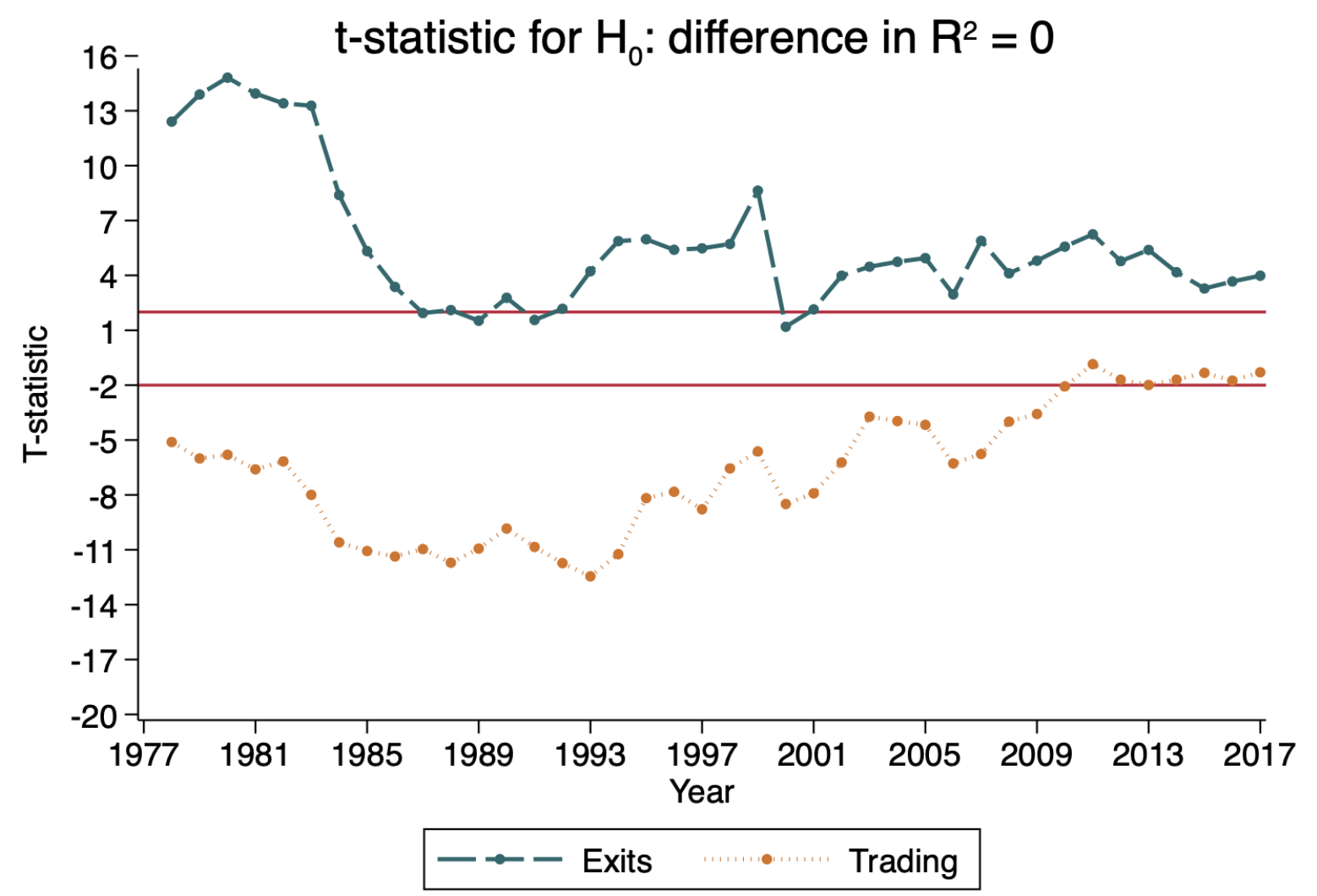


Figure 4: Human capital risk

In each fiscal year, we sort firms into quintiles based on their estimated organizational capital stock using parameter estimates from Table 1. In each firm-year, we set a variable equal to one if the firm's 10-K mentions "personnel", "key talent" or "talented employee," zero otherwise. The figure reports the t-statistics (each year) for the difference in mean test for the top vs. bottom quintiles sorted by each estimation of organizational capital. The red horizontal line is at $\mathrm{t}=1.96$. "HH" (Hulten and Hao) estimates organizational capital using $\gamma_{S}$ from column (1) of Table 1. "Trading" estimates organizational capital using $\gamma_{S}$ from column (3) of Table 1 and "Exits" estimates organizational capital using $\gamma_{S}$ column (5). All estimates assume $\delta_{S}=0.2$.

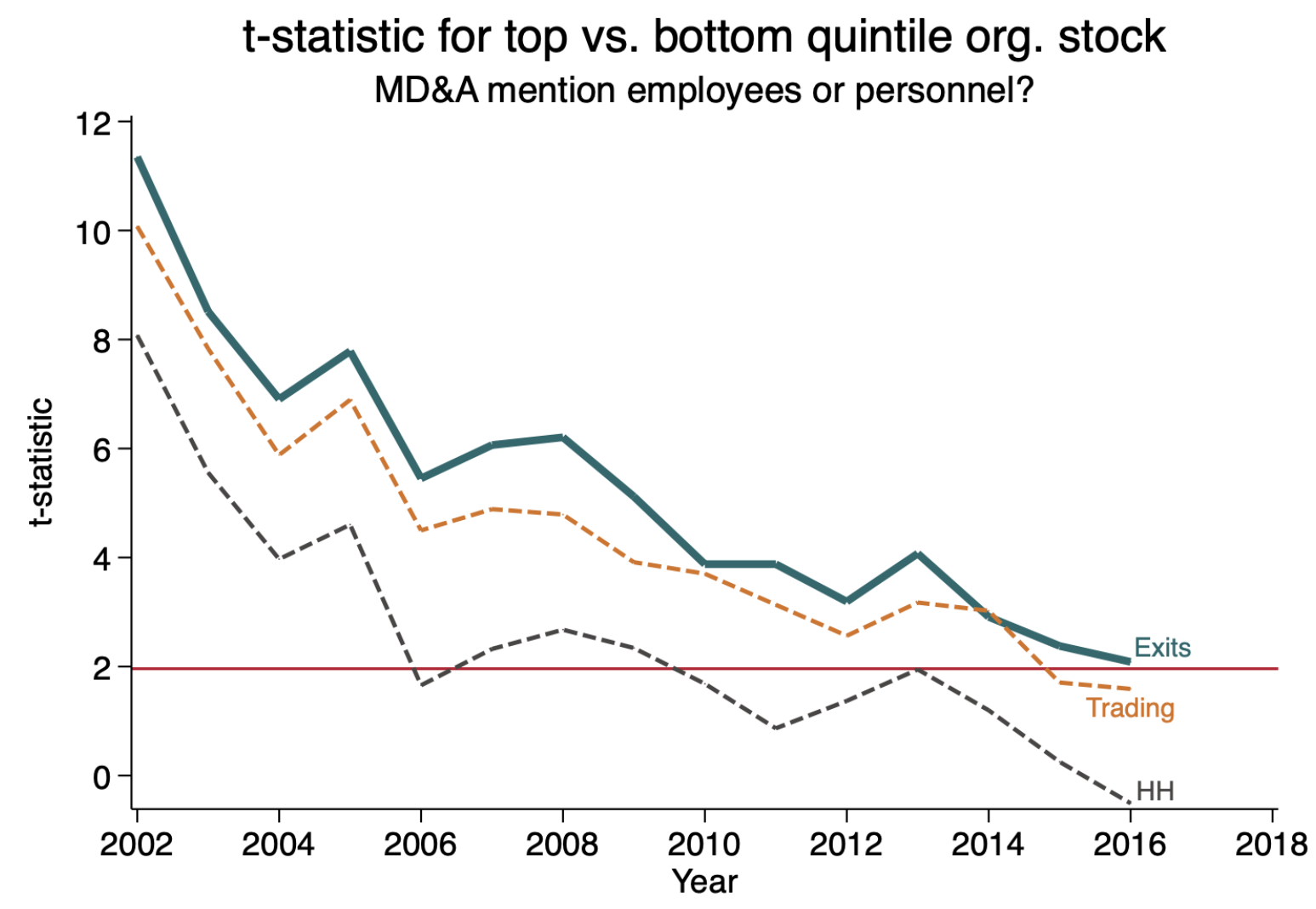


Figure 5: Patent valuations

The figure reports the ratio of $R^{2}$ from the following yearly regressions estimated using the BEA-HH parameters in columns (1) and (2) of Table 1 (denominator) and those from the alternative approaches (numerator):

$$
\log \left(\text { Patent }_{i t}\right)=\beta_{0}+\beta_{1} X_{i t}+\beta_{2} \log \left(\hat{G}_{i t}+\hat{S}_{i t}+I_{i t}\right)+\nu_{i t}
$$

where Patent ${ }_{i t}$ is the patent valuation from Kogan, Papanikolaou, Seru, and Stoffman (2017) (set to zero if there are no patents in the year). The sum $\hat{G}_{i t}+\hat{S}_{i t}+I_{i t}$ is the estimated total intangibles and $X_{i t}$ is the lagged count of the firm's patents. The two market-price based alternatives to BEA-HH are the Trading and Exits samples (see Section 2.3). "Trading" estimates organizational capital using $\gamma_{S}$ from column (3) of Table 1 and "Exits" estimates organizational capital using $\gamma_{S}$ column (5). All estimates assume $\delta_{S}=0.2$.

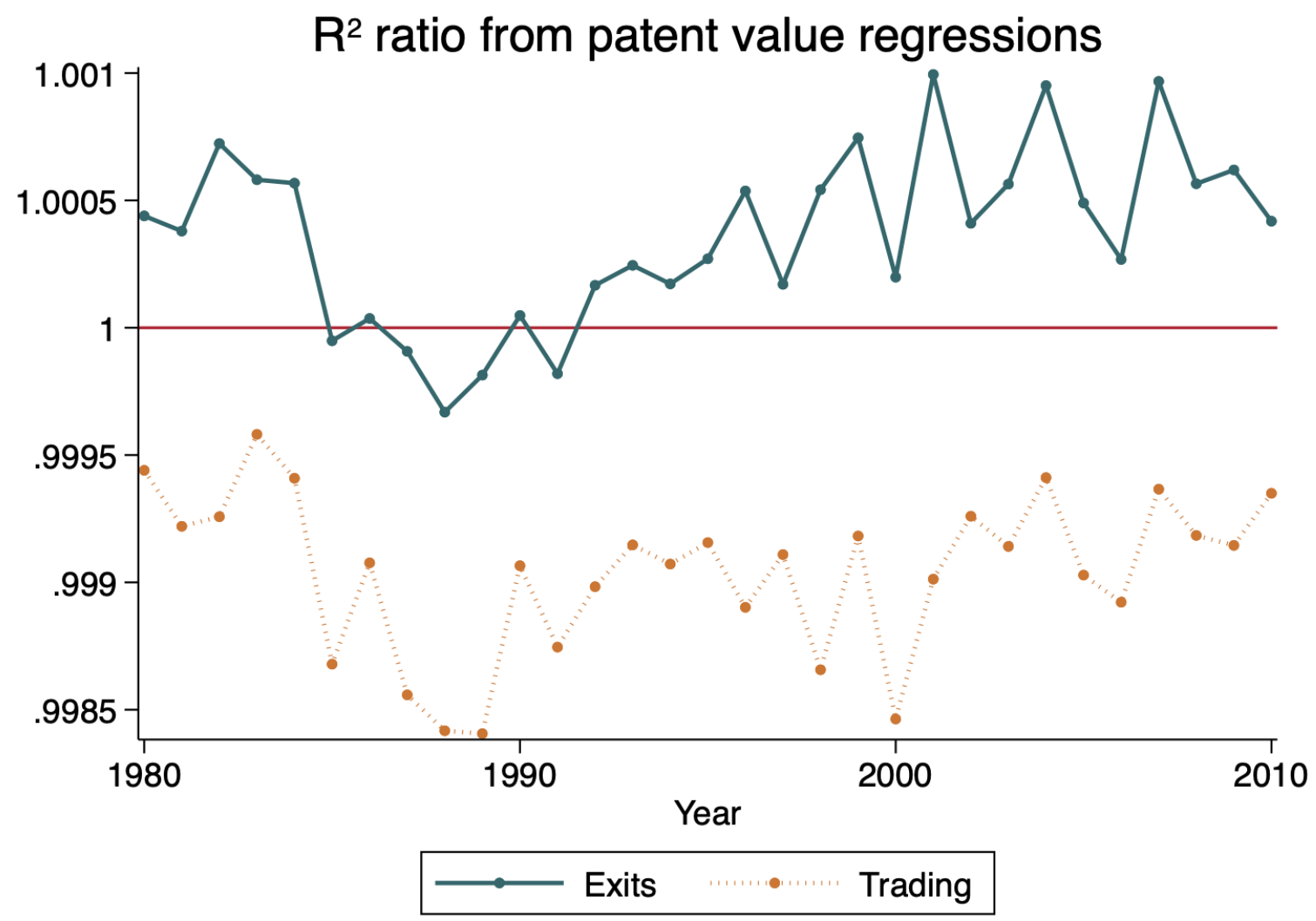


Figure 6: Explaining newly filed trademarks

The figure reports the ratio of $R^{2}$ for Exits-based and Trading-based intangible stocks (see parameter estimates in Table 1) relative to the $R^{2}$ for BEA-HH intangible stocks. We regress the log of total new trademarks plus one (Trademark ${ }_{i t}+1$ ) granted in year $t$ (data from Heath and Mace (2020)) on the alternative total intangible stock estimates and lagged trademark stock $\left(\log \left(T S_{i t-1}+1\right)\right)$ :

$$
\log \left(\operatorname{Trademark}_{i t}+1\right)=\alpha_{0}+\alpha_{1} \log \left(\hat{S}_{i t-1}+\hat{G}_{i t-1}+I_{i t-1}+1\right)+\alpha_{2} \log \left(T S_{i t-1}+1\right)+\nu_{i t}
$$

A ratio greater than one indicates the alternative measure provides relatively more explanatory power than the current method in BEA-HH. "Trading" estimates organizational capital using $\gamma_{S}$ from column (3) of Table 1 and "Exits" estimates organizational capital using $\gamma_{S}$ column (5). All estimates assume $\delta_{S}=0.2$.

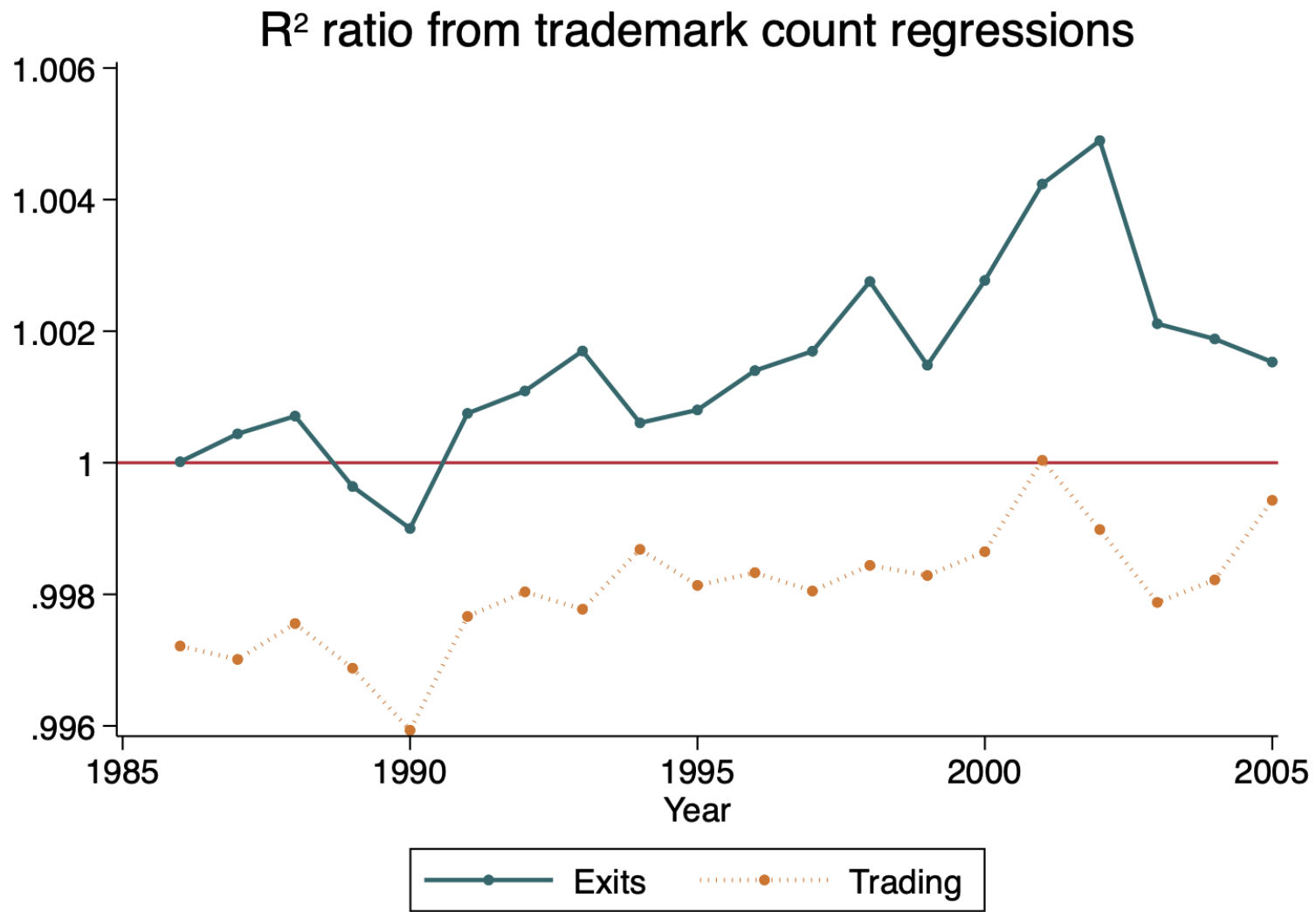


Figure 7: Differences in the size of estimated intangibles vs BEA-HH

The figure reports average percentage difference between the intangible capital stocks constructed using BEA$\mathrm{HH}$ and the Exits (see Section 2.3) parameter estimates across all firms and by industry. A positive percentage difference implies that the alternative measure of intangible stock is larger than BEA-HH. Averages by year and within-industry are reported.

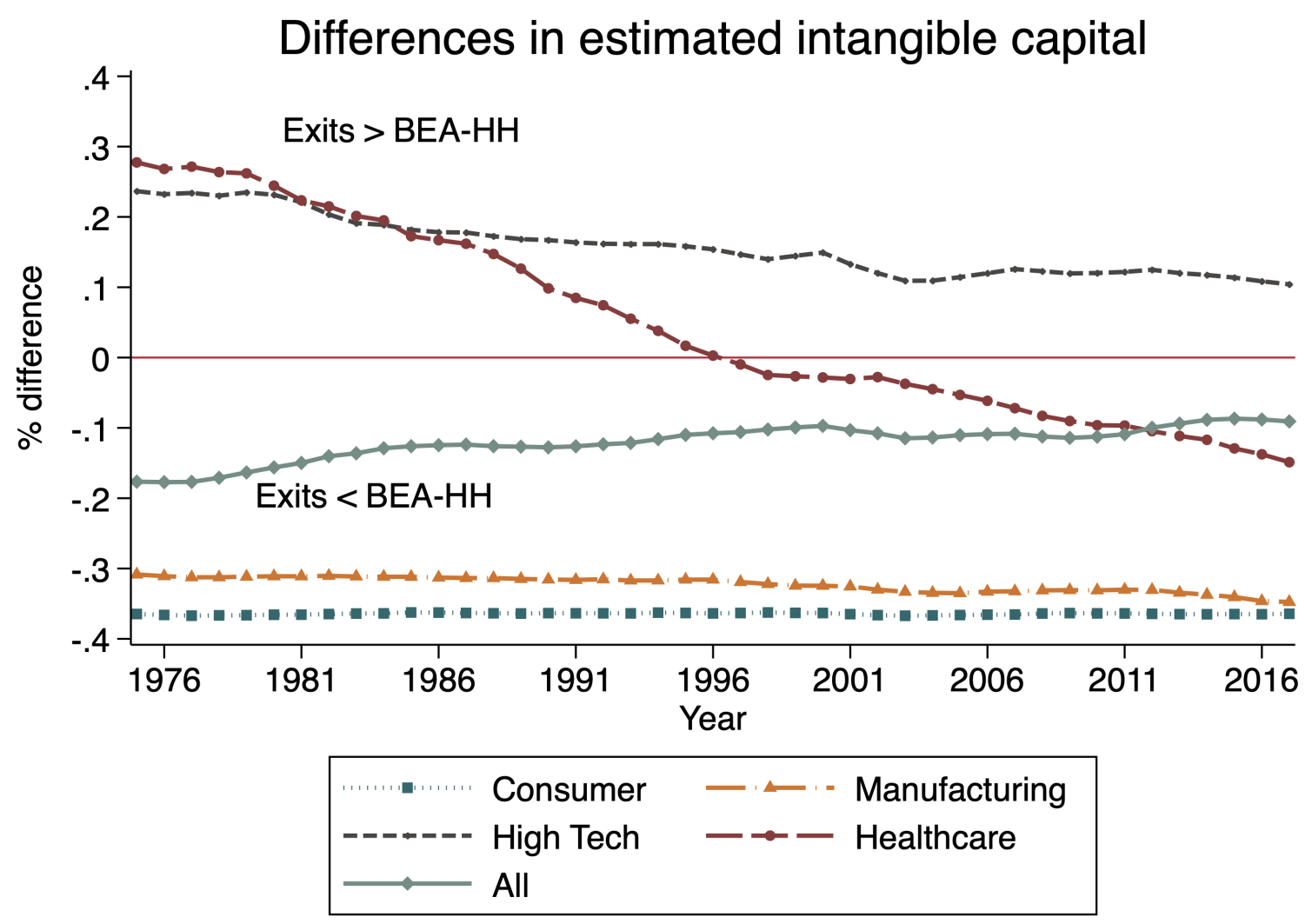




\section{Figure 8: Intangible assets intensities}

(a) Intangible asset intensity

The figure reports the average ratio of total intangibles - capitalized using the Exits-based parameters and those on the balance sheet - scaled by total capital stock (PPE + intangibles): $\frac{K^{i n t}}{K^{i n t}+K^{p h y}}$. across all firms within each industry-year. $K^{i n t}$ is the sum of knowledge and organizational capital using the estimates from Table 1 and a firm's previous 10 years of R\&D and SG\&A expenditures and its externally acquired goodwill and intangibles. $K^{\text {phy }}$ is the firm's PPE (gross). The "All" line reports the mean across all firms. The "Other" industry is not reported separated, but included in the "All" series.

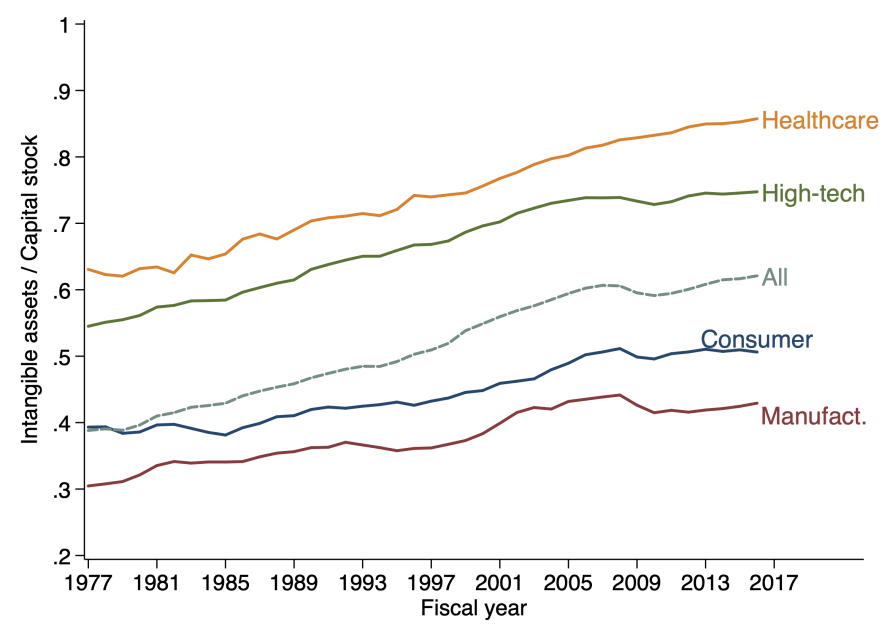

(b) Knowledge capital as a fraction of total intangible capital

The figure reports of the ratio of knowledge capital - the accumulated R\&D using the estimates from the "Exitsbased" columns of Table 1 - to total intangibles (sum of knowledge and organizational capital) averaged across all firms in each industry-year.

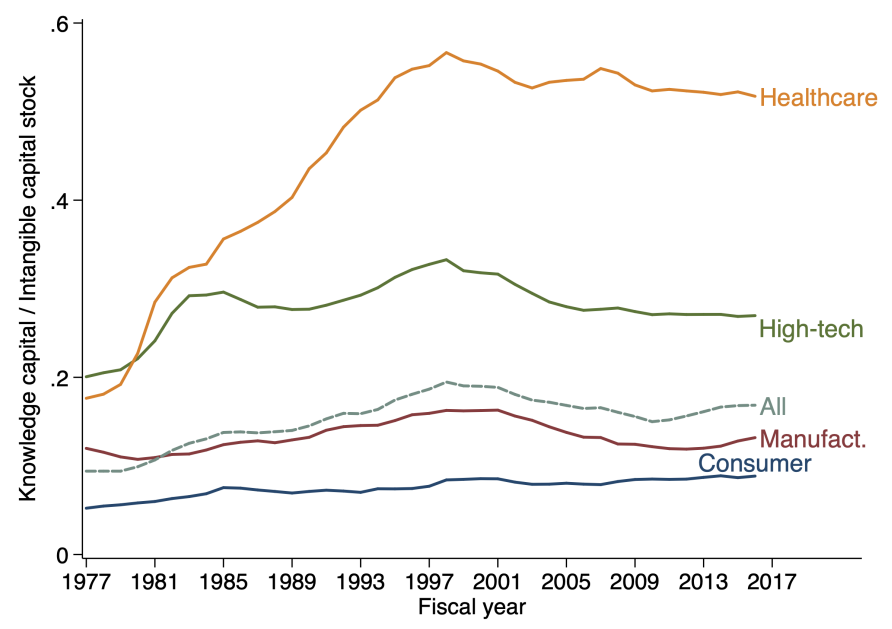


Figure 9: Market-to-book ratios with and without Exits-adjusted intangibles: 1977-2017

The figure reports the average (2.5\% tail winsorized) market-to-book ratios for Compustat firms outside of financials, mining, real estate, utilities and all acquiring firms in our sample. To avoid mechanical outperformance over BEA-HH, this analysis also excludes any firm-years used in the parameter estimation of Equation 12 (i.e. acquisition targets and delisted firms in the Exits sample). The numerator in both series is the sum of market value of equity at the end of the fiscal year, total liabilities and book preferred stock. For the blue circle series, the denominator is total assets (including acquired intangibles). For the green diamond series, the denominator also includes the knowledge and organizational capital stocks estimated using the Exits parameters in Columns (5) and (6) of Table 1. The two dotted red lines present the linear fit of each time series.

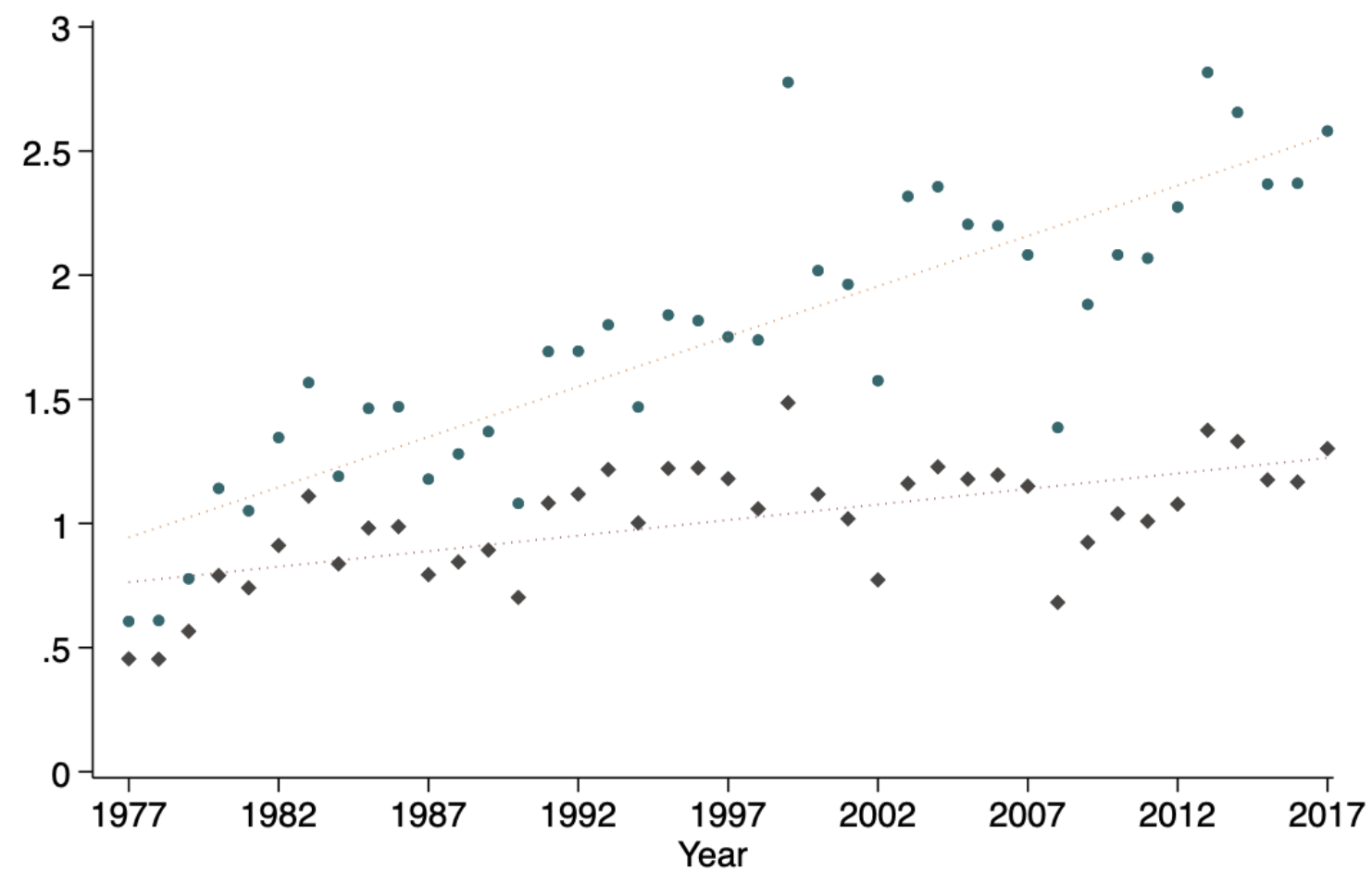

- MV Assets/Assets - MV Assets/(K phys. + Know. + Org.) 
Figure 10: Return on Equity with intangibles adjustment

The figure reports the average return on equity (ROE) using two alternative measures for public firms in the S\&P 500. "Unadjusted" uses the standard ROE definition of net income scaled by lagged book equity. The "Exits" time series adjusts book equity for knowledge and organizational capital using the Exits parameter estimates. The scatter plot reports the average of the difference of the two measures (with the linear fit).

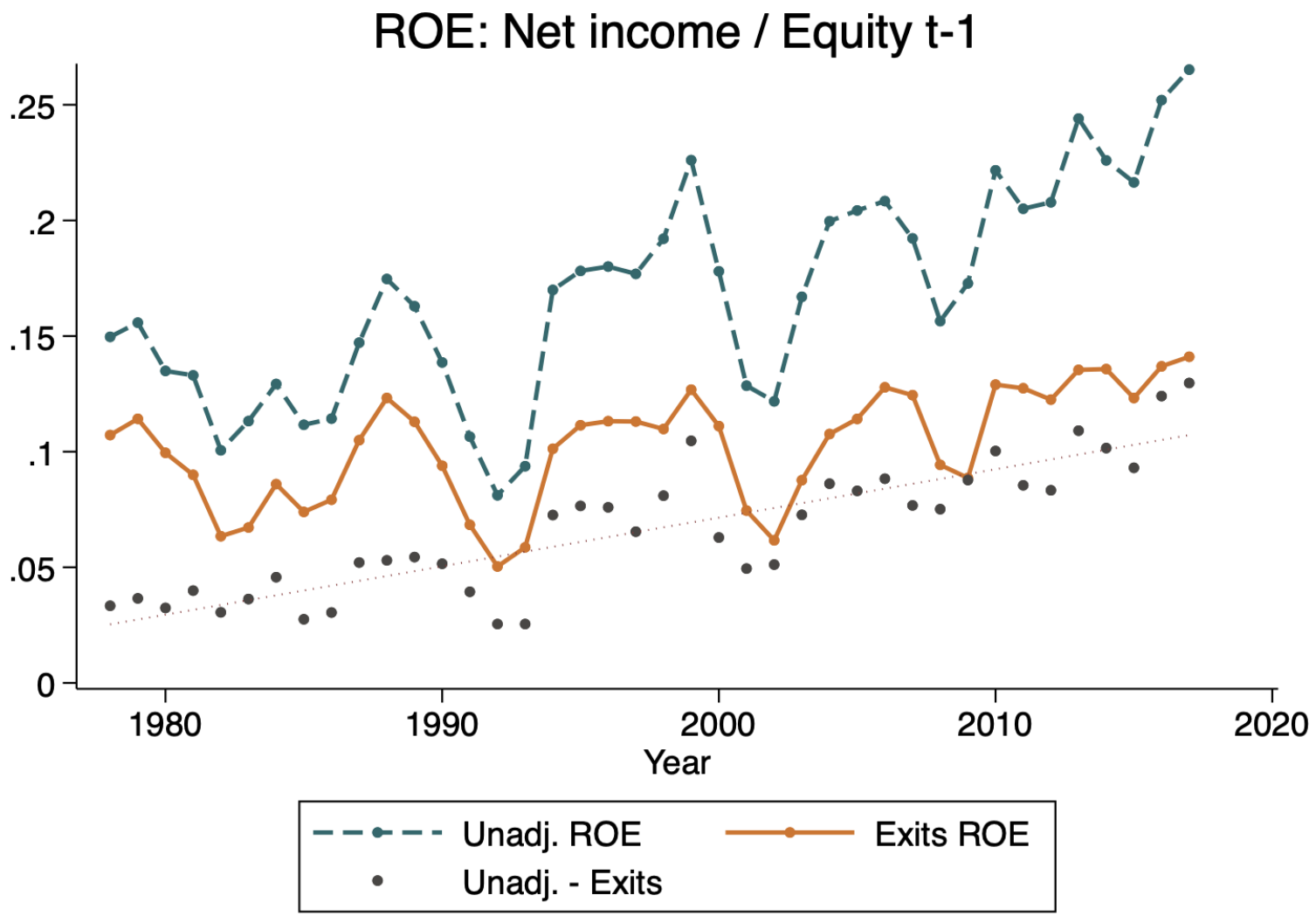


Figure 11: Robustness: organizational stock assumption and time-varying parameters

(a) Estimation sensitivity under different organizational stock depreciation assumptions

The figure reports the results of re-estimating the main model for different values of the organizational stock depreciation parameter $\delta_{S}$. Recall that our main results assume that $\delta_{S}=.2$. Here we vary this parameter and present the estimated $\gamma_{S}$ (fraction of SG\&A that is investment), $\delta_{G}$ (the knowledge capital depreciation rate) and the $R^{2}$ from the estimation. The vertical red line indicates the main model assumption. The left y-axis reports the parameter estimates and the right y-axis reports the $R^{2}$.

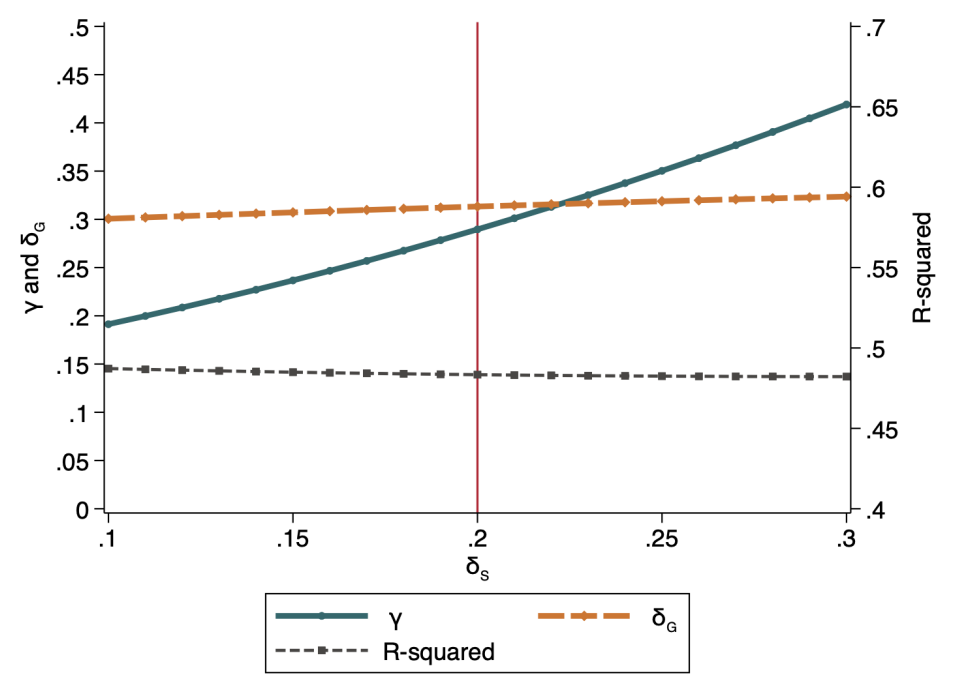

(b) Rolling Estimates of Parameter Values in 10-Year Windows

The figure reports estimates of $\gamma_{S}$ (the fraction of SG\&A which represents investment in long-lived organizational capital; blue, solid line) and $\delta_{G}$ (the depreciation rate of knowledge capital; red, dashed line) from the non-linear least squares estimation of equation (12) run on rolling 10-year windows of events. The horizontal axis reports the first year of the subsample window. The blue and red horizontal lines represent the full-sample point estimates of $\gamma_{S}$ and $\delta_{G}$, respectively, from Table 1 .

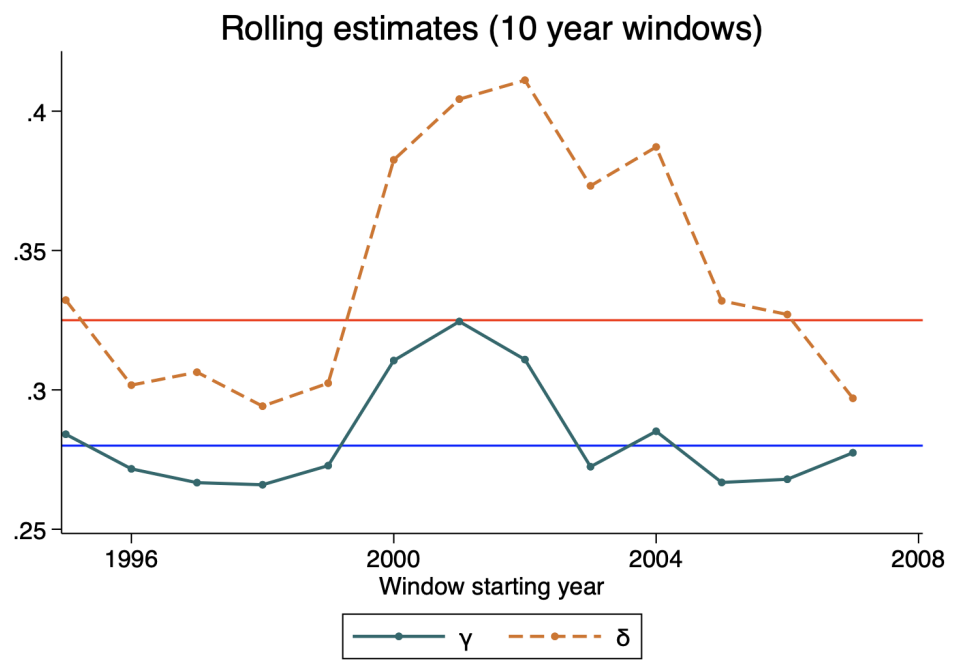


Table 1: Parameter estimates from non-linear least squares estimation

Parameter estimates are based on non-linear least squares regressions of the price of intangible firm assets on accumulated intangible assets:

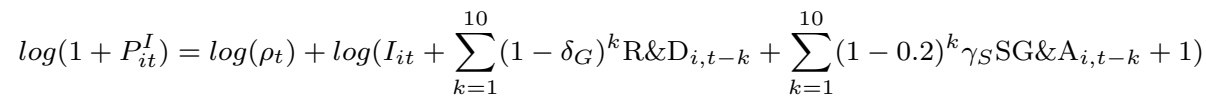

where $P_{i t}^{I}$ is the price of the firm's total intangible capital as discussed in Section 2.3 and $I_{i t}$ is the target's externally-acquired intangibles reported to the balance sheet. The year fixed effects $\left(\rho_{t}\right)$ are constrained to an average of $0(\log$ of 1$)$ across all years. The "All" row reports the pooled sample estimates, while all other rows are separate estimations for the modified Fama-French 5 industry classifications. Firms can have up to ten years of financial data.

Columns (1) and (2) summarize the parameters used in the BEA-HH methodology discussed in Section 1.3. Columns (3) and (4) report parameter estimates from the Compustat sample defined in Section 2.1 where we mark up the book value of Property, Plant and Equipment to the gross book value. Columns (5) and (6) report parameter estimates from the sample of firm exits discussed in Section 2.2. To get total intangibles for failures, we use the average fraction of acquired intangibles to total deal size in the same industry from the acquisition sample.

In each pair of columns, the first reports the estimates of $\gamma_{S}$, the fraction of SG\&A that is investment. The $\delta_{S}$ is assumed to be 0.2 (i.e., not estimated). The $\delta_{G}$ column reports the estimate of R\&D depreciation rate. Pseudo $R^{2}$ estimates are calculated as the percent improvement in the exponentiated root mean squared error relative to a model which includes only a constant. Column (2) reports the average R\&D depreciation rates from $\mathrm{Li}$ and Hall (2016) for SIC codes in each of the major industry groups (one obs. per SIC). Bootstrapped (1000 replications at the firm-level) standard errors reported in parentheses. $N$ reports the number of unique firms in the estimation.

\begin{tabular}{lcc|cc|cc}
\hline & \multicolumn{2}{c}{ BEA-HH } & \multicolumn{2}{c}{ Trading } & \multicolumn{2}{c}{ Exits } \\
& $(1)$ & $(2)$ & $(3)$ & $(4)$ & $(5)$ & $(6)$ \\
& $\gamma_{S}$ & $\delta_{G}$ & $\gamma_{S}$ & $\delta_{G}$ & $\gamma_{S}$ & $\delta_{G}$ \\
\hline All & 0.30 & 0.28 & 0.45 & 0.19 & 0.27 & 0.33 \\
& & & $(0.013)$ & $(0.012)$ & $(0.026)$ & $(0.038)$ \\
Consumer & 0.30 & 0.31 & 0.37 & 0.25 & 0.19 & 0.33 \\
& & & $(0.016)$ & $(0.068)$ & $(0.027)$ & $(0.317)$ \\
Manufacturing & 0.30 & 0.25 & 0.37 & 0.28 & 0.22 & 0.42 \\
& & & $(0.021)$ & $(0.033)$ & $(0.055)$ & $(0.163)$ \\
High Tech & 0.30 & 0.31 & 0.62 & 0.28 & 0.44 & 0.46 \\
& & & $(0.031)$ & $(0.020)$ & $(0.060)$ & $(0.072)$ \\
Health & 0.30 & 0.18 & 0.56 & 0.11 & 0.49 & 0.34 \\
& & & $(0.064)$ & $(0.022)$ & $(0.138)$ & $(0.065)$ \\
Other & 0.30 & \multirow{2}{*}{$\mathrm{N} / \mathrm{A}$} & 0.81 & 0.19 & 0.34 & 0.30 \\
& & & $(0.047)$ & $(0.074)$ & $(0.062)$ & $(0.184)$ \\
\hline Pseudo- $R^{2}$ & & & \multicolumn{2}{c|}{0.376} & \multicolumn{2}{c}{0.515} \\
$\mathrm{~N}$ & & & \multicolumn{2}{c}{10,348} & \multicolumn{2}{c}{2,000}
\end{tabular}


Table 2: Brand ranking

The table reports the OLS estimates from a regression of log brand ranking on measures of intangible capital estimated from BEA-HH, Trading, and Exits. Brand rankings are from the Interbrand listings which are merged to Compustat U.S. public companies. A unit of observation is a firm-year. "Log org. cap. S (BEA-HH)" is the log of organizational capital using the BEA-HH parameters from Table 1. "Log org. cap. S (Exits)" and "Log org cap S (Trading)" show the same estimated stocks using the Exits and Trading parameter estimates. "Trading" estimates organizational capital using $\gamma_{S}$ from column (3) of Table 1 and "Exits" estimates organizational capital using $\gamma_{S}$ column (5). All estimates assume $\delta_{S}=0.2$. "Log total intan. K" is the sum of externally acquired intangibles, estimated knowledge capital and estimated organizational capital. "Year FE" are fixed effects for fiscal year. Robust standard errors reported in parentheses. We use ${ }^{* * *},{ }^{* *}$, and ${ }^{*}$ to denote significance at the $1 \%, 5 \%$, and $10 \%$ level.

\begin{tabular}{|c|c|c|c|c|c|c|}
\hline & \multicolumn{6}{|c|}{ Log of brand ranking } \\
\hline & (1) & $(2)$ & (3) & (4) & $(5)$ & (6) \\
\hline Log org. cap. S (HH) & $\begin{array}{l}-0.044^{* * *} \\
(0.0080)\end{array}$ & & & & & \\
\hline Log org cap. S (Exits) & & $\begin{array}{r}-0.053^{* * *} \\
(0.0083)\end{array}$ & & & & \\
\hline Log org. cap. S (Trading) & & & $\begin{array}{r}-0.046^{* * *} \\
(0.0077)\end{array}$ & & & \\
\hline Log total intan. K (BEA-HH) & & & & $\begin{array}{r}-0.21^{* * *} \\
(0.026)\end{array}$ & & \\
\hline Log total intan. K (Exits) & & & & & $\begin{array}{c}-0.23^{* * *} \\
(0.026)\end{array}$ & \\
\hline Log total intan. K (Trading) & & & & & & $\begin{array}{r}-0.22^{* * *} \\
(0.026)\end{array}$ \\
\hline Observations & 1122 & 1122 & 1122 & 1122 & 1122 & 1122 \\
\hline$R^{2}$ & 0.014 & 0.023 & 0.018 & 0.093 & 0.11 & 0.10 \\
\hline Year FE? & $\mathrm{Y}$ & $\mathrm{Y}$ & $\mathrm{Y}$ & $\mathrm{Y}$ & $\mathrm{Y}$ & $\mathrm{Y}$ \\
\hline
\end{tabular}


Table 3: Best company to work for rankings: rank regression and correlations

The table reports the regression estimates and pairwise correlations between the annual "Best Company to Work For" from Edmans (2011) and Glassdoor listings of the same type for later years. The first panel regresses the log of brand rank (lower ranking is better) on the ranking of firms in the sample by the three organizational capital stocks. "Rank org. cap. S" is the ranking of firms in this sample using the knowledge capital estimate from BEA-HH. "Rank org. cap. S (Exits)" uses the estimate from the Exits-based sample and "Rank org. cap. S (Trading)" uses the ranks by publicly traded stocks. "Trading" estimates organizational capital using $\gamma_{S}$ from column (3) of Table 1 and "Exits" estimates organizational capital using $\gamma_{S}$ column (5). The other rows report ranks by organizational capital ("Org. cap. S") and total intangibles (knowledge plus organizational "Total intan. cap."). Robust standard errors in parentheses. We use ${ }^{* * *},{ }^{* *}$, and ${ }^{*}$ to denote significance at the $1 \%$, $5 \%$, and $10 \%$ level for non-zero correlation.

\section{Panel A}

Log company rank: employee satisfaction (0 highest)

\begin{tabular}{l|ccc}
\hline Log org. capital S rank (HH) & 0.0015 & & \\
& $(0.030)$ & & \\
Log org. capital S rank (Exits) & & $0.051^{*}$ & \\
& & $(0.030)$ & \\
Log org. capital S rank (Trading) & & & 0.037 \\
& & & $(0.030)$ \\
\hline Observations & 910 & 910 & 910 \\
$R^{2}$ & 0.0000023 & 0.0026 & 0.0014 \\
\hline
\end{tabular}

Panel B

Company rank: employee satisfaction (1 highest)

\begin{tabular}{l|c}
\hline Rank org. cap. S (HH) & $0.097^{* * *}$ \\
Rank org. cap. S (Exits) & $0.155^{* * *}$ \\
Rank org. cap. S (Trading) & $0.137^{* * *}$ \\
Rank know. cap. G (BEA) & $0.130^{* * *}$ \\
Rank know. cap. G (Exits) & $0.152^{* * *}$ \\
Rank know. cap. G (Trading) & $0.132^{* * *}$ \\
Rank total intan. cap. (BEA-HH) & $0.107^{* * *}$ \\
Rank total intan. cap. (Exits) & $0.134^{* * *}$ \\
Rank total intan. cap. (Trading) & $0.122^{* * *}$ \\
\hline
\end{tabular}


Table 4: The value premium: including intangibles in book value

The table reports summary statistics for HML portfolio returns from 1976 through 2017. The unadjusted portfolios are constructed as in Fama and French (1992). The adjusted portfolios are constructed similarly, with the measure of book equity augmented by the intangible capital stocks implied by the parameters in Table 1 , columns (5) and (6). Returns are reported in percentage points per month.

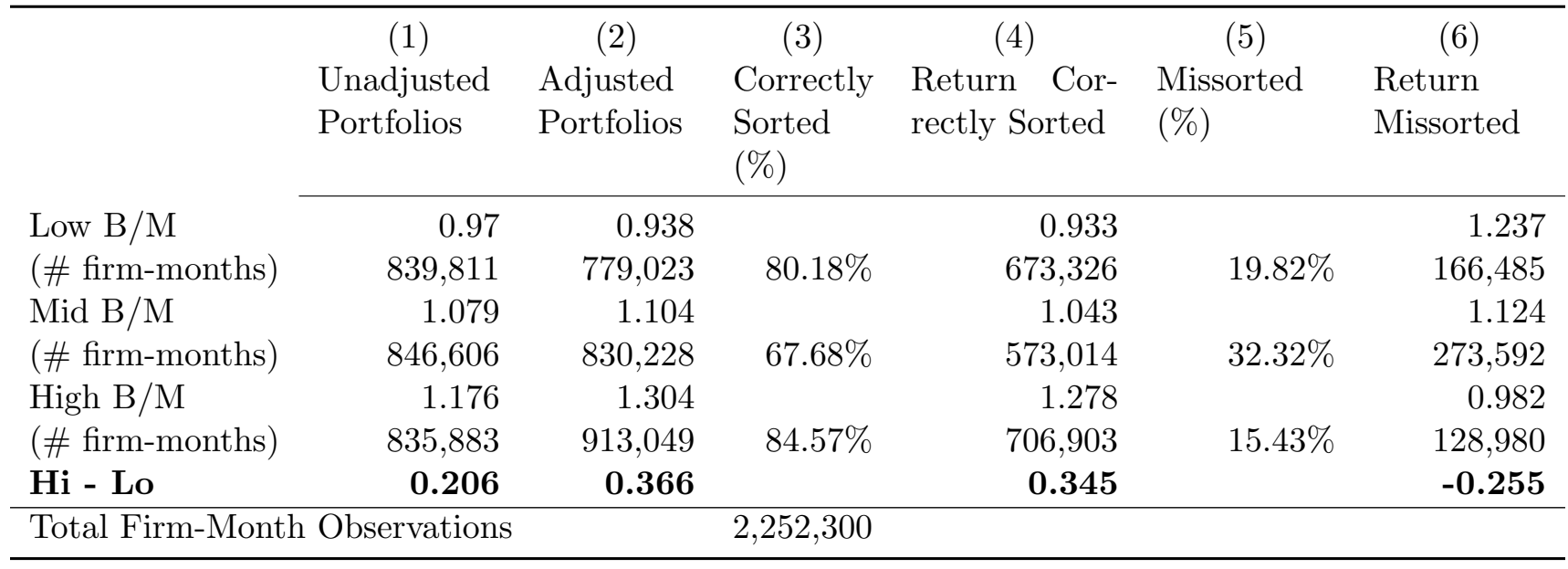


Table 5: Parameter estimates: non-adjusted goodwill and excluding delistings

Parameter estimates are based on non-linear least squares regressions of the price of intangible firm assets on accumulated intangible assets:

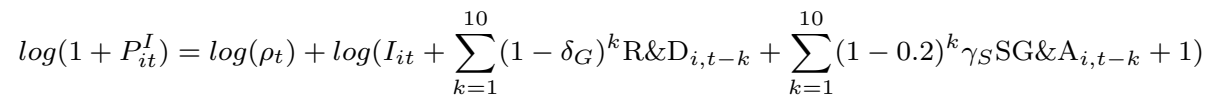

where $P_{i t}^{I}$ is the price of the firm's total intangible capital and $I_{i t}$ is the target's externally-acquired intangibles reported to the balance sheet. The year fixed effects $\left(\rho_{t}\right)$ are constrained to an average of $0(\log$ of 1$)$ across all years. The "All" row reports the pooled sample estimates, while all other rows are separate estimations for the modified Fama-French 5 industry classifications. Firms can have up to ten years of financial data.

The first column reports the estimates of $\gamma_{S}$, the fraction of SG\&A that is investment. $\delta_{S}$ is assumed to be 0.2. The second column reports the estimate of $\mathrm{R} \& \mathrm{D}$ depreciation rate, $\delta_{G}$. The third column reports the number of unique firms in the estimation, $N$. Pseudo $R^{2}$ estimates are calculated as the percent improvement in the exponentiated root mean squared error relative to a model which includes only a constant. Bootstrapped (1000 replications at the firm-level) standard errors reported in parentheses.

(a) Panel A reports the parameter estimates found in Table 1 after excluding the sample of acquisitions in bankruptcy.

\begin{tabular}{lccc}
\hline Panel A: Excl. acquisitions via bankruptcies \\
& $\gamma_{S}$ & $\delta_{G}$ & $\mathrm{~N}$ \\
All & 0.43 & 0.27 & 1521 \\
Consumer & 0.38 & 0.31 & 335 \\
Manufacturing & 0.24 & 0.23 & 186 \\
High Tech & 0.58 & 0.39 & 612 \\
Health & 0.62 & 0.23 & 218 \\
Other & 0.52 & -0.14 & 170 \\
& Pseudo- $R^{2}: .423$ & \\
\hline
\end{tabular}

(b) Panel B of the table reports the parameter estimates as found in Table 1 where we do not adjust the goodwill for synergies and over-payment (see Section A2.2).

\begin{tabular}{lccc}
\hline \multicolumn{4}{c}{ Panel B: Unadjusted goodwill prices } \\
All & $\gamma_{S}$ & $\delta_{G}$ & $\mathrm{~N}$ \\
Consumer & 0.43 & 0.22 & 2000 \\
Manufacturing & 0.27 & 0.05 & 511 \\
High Tech & 0.46 & 0.31 & 233 \\
Health & 0.71 & 0.38 & 715 \\
& 0.71 & 0.21 & 245 \\
& Pseudo- $R^{2}: 0.530$ \\
\hline
\end{tabular}




\section{Appendix}

Table A1: Variables and definitions of terms

The table presents variable and term definitions used throughout the paper.

\begin{tabular}{|c|c|}
\hline Variable/Term & Definition \\
\hline Deal effective year & Year the acquisition was completed. \\
\hline Year announced & The year that the acquisition was announced to the public. \\
\hline Services firm (target) & An indicator equal to one if the acquisition target is in the services sector. \\
\hline Value of transaction (mil) & The total value of the acquisitions (in 2012, USD millions) as reported in SDC. \\
\hline Target Net Sales LTM (mil) & $\begin{array}{l}\text { The last twelve month net sales for the target firm at the time of acquisition } \\
(2012 \text { USD). }\end{array}$ \\
\hline Target EBITDA LTM (mil) & $\begin{array}{l}\text { The last twelve month EBITDA for the target firm at the time of acquisition } \\
\text { (2012 USD). }\end{array}$ \\
\hline Target total assets & Total assets of the acquired firm at the time of acquisition (2012 USD). \\
\hline CA HQ (acq.) & $\begin{array}{l}\text { An indicator variable that is equal to one if the firm is headquartered in } \\
\text { California. }\end{array}$ \\
\hline NY HQ & $\begin{array}{l}\text { An indicator variable that is equal to one if the firm is headquartered in New } \\
\text { York state. }\end{array}$ \\
\hline Intangible assets (IIA) & $\begin{array}{l}\text { The total identified intangible assets from the acquisition revealed through the } \\
\text { purchase price allocation. Reported in millions ( } 2012 \text { USD). }\end{array}$ \\
\hline Goodwill (mil) & The total goodwill allocated in the acquisition (2012 USD). \\
\hline Goodwill (adj., mil) & $\begin{array}{l}\text { The total goodwill net of an estimate of synergy and any over/under-payment } \\
\text { of the target by the acquirer. The former is approximated by the sum of the } \\
\text { product of 2-day window cumulative abnormal (CAR) and pre-deal market } \\
\text { value for both target and acquirer, while the latter is the negative of the } \\
\text { acquirer's CAR times the pre-deal market valuation. }\end{array}$ \\
\hline All stock & An indicator variable equal to one if the acquisition was an all-stock deal. \\
\hline All cash & An indicator variable equal to one if the acquisition was an all-cash deal. \\
\hline Balance sheet intan. & $\begin{array}{l}\text { The total intangible assets already on the balance sheet of the firm, typically } \\
\text { from past acquisitions of intangibles and goodwill. }\end{array}$ \\
\hline Organizational capital & $\begin{array}{l}\text { The capitalization of some fraction } \gamma \text { of SG\&A expenditures by a firm. It is } \\
\text { meant to capture the knowledge used to combine human skills and tangible } \\
\text { capital into systems for producing and delivering want-satisfying products. }\end{array}$ \\
\hline Knowledge capital & $\begin{array}{l}\text { The consensus proxy for the flows of a firm's knowledge capital in the intan- } \\
\text { gibles literature is its periodic disclosure of research and development expen- } \\
\text { ditures. }\end{array}$ \\
\hline BEA-HH & $\begin{array}{l}\text { The acronym for the depreciation parameter assumptions from Li and Hall } \\
\text { (2016) for knowledge capital and the fraction of SG\&A that is investment } \\
\text { from Hulten and Hao (2008). }\end{array}$ \\
\hline
\end{tabular}




\section{A1 Acquisition accounting}

The U.S. General Accepted Accounting Principles (GAAP) treatment for business acquisition has evolved significantly over time. This section constitutes a brief overview of the guidelines and principles provided by the FASB, and discusses their differential impact to the financial statements of the acquiring firm.

From 1970 until 2001, Accounting Principles Board (APB) Opinion No. 16 stated that "the purchase method and the pooling of interests method are both acceptable in accounting for business combinations, although not as alternatives for the same business combination." If the acquiring firm was in accordance with a list of specified conditions, it would account for the transaction as a pooling acquisition, otherwise it would use the purchase method.

In the purchase method, the acquirer restates all of the target's net assets to their fair value and records the difference between the fair value of the acquirer's consideration and the fair value of the target's net assets as goodwill. The acquirer's goodwill asset would then be subjected to annual impairment tests if the carrying value of goodwill related to the reporting unit is suspected to be less than its fair value. ${ }^{47}$ In the pooling method, the acquirer must finance the purchase entirely with stock. The assets and liabilities of the target firm are combined with the acquirer at book value, essentially implying that fair market values of the acquirer's consideration and the target's net assets are ignored for accounting purposes. The target firm's retained earnings are aggregated together with the acquirer's retained earnings. Equity shares issued by the acquirer for the purchase are recorded based upon book value of the target's net assets. Because of this, no excess of acquisition cost over the target's book value of net assets exists, and thus no new goodwill is recorded to the acquirer. Studies that have examined the firm's use of purchase versus pooling methods have generally found that the larger the difference between the book value of the target's asset and the price paid by the acquirer, the more likely that the acquirer will opt for the pooling method (Robinson and Shane (1990); Ayers, Lefanowicz, and Robinson (2000)). This is because the purchase method would result in the target's net assets being marked to market and any goodwill added to the acquirer's balance sheet being depreciated and amortized over time, resulting in an additional expense against the firm's reported profits in the subsequent years. As discussed below, any acquisitions using the pooling method cannot be used in our analysis.

On December 15, 2001 FASB enacted FAS 141 ${ }^{48}$, which eliminated the use of pooling-of-interest accounting in acquisitions. ${ }^{49}$ At the same time, FAS 141 eliminated the amortization of purchased

\footnotetext{
${ }^{47}$ Prior to 2001, goodwill was amortized using a straight-line depreciation method over a period not to exceed forty years.

${ }^{48}$ https : //www.fasb.org/summary/stsum141.shtml

${ }^{49}$ The FASB justified the elimination of the pooling method because "the purchase method, as modified by the board during deliberations, reflects the underlying economics of business combinations by requiring that the
} 
goodwill. Instead, goodwill would be considered an indefinite life asset, and amounts on the acquirer's books would be subject to "impairment" tests, which would be conducted when expectations for the reporting unit have been significantly reduced. At this time, the goodwill would be revalued and compared with its carrying book value, with any differences being expensed as a write-off for the acquiring firm. ${ }^{50}$

On December 15, 2007, FASB superseded FAS 141 with FAS 141R (now referred to as ASC 805 as of September 15, 2009). ${ }^{51}$ ASC 805 stands as the current method of accounting for acquisitions. This method, known as the "acquisition method" is similar to the purchase method for acquisitions, with a few notable adjustments. (1) In FAS 141, there was no forced recognition of contingent assets or liabilities being acquired. Under FAS 141R, guidance for the recognition of contingent assets and liabilities depends on whether the contingencies are contractual, such as a warranty agreement, or non-contractual, such as the outcome of a lawsuit. Contractual contingencies are accounted for at fair value, while non-contractual contingencies are accounted for if the probability of realization of the contingent asset is greater than fifty percent. (2) In FAS 141, transaction costs such as legal fees, banking fees or other direct acquisition costs were included in the purchase price allocation, where as in FAS 141R they are recorded as expenses. (3) In FAS 141, in-process research and development (IPR\&D) could be expensed immediately upon completion of the acquisition if the acquired IPR\&D has no alternate use. In FAS 141R, IPR\&D exists as an indefinite-lived intangible asset until the completion or abandonment of the associated R\&D project.

current values of the assets and liabilities exchanged be reported to investors. Without the information that the purchase method provides, investors are left in the dark as to the real cost of one company buying another and, as a result, are unable to track future returns on the investment." See http://ww2.cfo.com/2001/ 01/fasb-reaffirms-plan-to-eliminate-pooling-updated-2/

${ }^{50}$ For example, on April 25, 2014 Microsoft acquired the mobile hardware division of Nokia for $\$ 7.9$ billion. In 2015 , they announced a goodwill write-off of $\$ 7.5$ billion related to the Nokia acquisition. In note 10 of the $10-\mathrm{K}$, they cite the following reason for the impairment: "Upon completion of the annual testing as of May 1, 2015, Phone Hardware goodwill was determined to be impaired. In the second half of fiscal year 2015, Phone Hardware did not meet its sales volume and revenue goals, and the mix of units sold had lower margins than planned. These results, along with changes in the competitive marketplace and an evaluation of business priorities, led to a shift in strategic direction and reduced future revenue and profitability expectations for the business. As a result of these changes in strategy and expectations, we have forecasted reductions in unit volume growth rates and lower future cash flows used to estimate the fair value of the Phone Hardware reporting unit, which resulted in the determination that an impairment adjustment was required." https://www.sec.gov/Archives/edgar/data/789019/000119312515272806/ d918813d10k.htm

${ }^{51}$ https://www.fasb.org/pdf/fas141r.pdf 


\section{A2 Details on Acquisition Sample Construction}

\section{A2.1 Sample Construction}

We require data availability of the acquirer's purchase price allocation of the target's assets in order to collect the prices paid for goodwill and identifiable intangible assets (IIA). When available, these purchase price allocations were found in the acquirer's subsequent 10-K, 10-Q, 8-K or S-4 filing. We found information on the purchase price allocation for $81 \%(1,719)$ of all candidate acquisitions. ${ }^{52}$ In the final step, we merge the target and acquirer firms to Compustat and CRSP. For each target firm merged to Compustat, we gather up to 10 years of the firm's past R\&D and SG\&A expenditures along with any pre-acquisition acquired intangibles on its balance sheet. ${ }^{53,54}$ The final sample includes 1,521 events (70\%). Below we describe how these deals differ from those lost in the data collection process.

Any remaining selection issues after incorporating bankruptcies take one of two forms. If most acquisition targets are low productivity innovators (e.g., Bena and $\mathrm{Li}$ (2014)), then we may estimate too high a depreciation rate and too low a value of $\gamma$. Alternatively, acquired firms may on average represent firms with successful innovation projects or that are purchased at the peak of their innovative productivity. In this case, we would estimate too low a depreciation rate and/or too high a fraction of organizational capital investment $(\gamma)$. It is not clear which source of selection issues dominate, so we use the well-identified parameter estimates from Li and Hall (2016) to help judge our estimates. Since their estimation of depreciation parameters for R\&D is derived from a representative set of firms (from a small set of industries), a lack of systematic differences with our estimates would indicate that our sample selection is not severe. ${ }^{55}$

\section{A2.2 Synergy and overpayment: adjusting goodwill}

Acquisitions may be motivated by pair-specific synergy values, and prior research has documented that managers may overpay for a target due to agency frictions or hubris (e.g., Roll (1986)). These issues could potentially affect the representativeness of our imputed parameter estimates when applied to the full population of firms. Extending our parameter estimates to all publicly

\footnotetext{
${ }^{52}$ Some filings lacked the footnote for the acquisition (e.g., the acquisition was immaterial) or we could not identify any filing for the acquiring firm (e.g., the firm has a unique registration type with the SEC).

${ }^{53}$ If Compustat has less than 10 years of data and the firm is older than 10 years old, then we impute any missing R\&D and SG\&A using observed growth rates for the same age firms with non-missing data. All results are robust to excluding these imputed data.

${ }^{54}$ We also lose acquisitions because we either failed to find a Compustat identifier or the firm did not have stock price data in CRSP (e.g., it was traded on the OTC markets).

${ }^{55}$ For robustness, we later run all analyses with and without the bankrupt firms and show that the estimates change as predicted.
} 
listed firms requires that the prices paid for intangible capital in our sample represent a public or market value. Fortunately, the purchase price allocation process directly separates intangible assets that can be identified via either a separability criterion or previously established contractual legal criterion. Thus, pair-wise values arising from the acquisition - synergies - will be recorded as goodwill. Because we are interested in the stand-alone value of assets, our analyses adjust goodwill accordingly.

To make these adjustments, we apply the market's assessment of synergy value and under/overpayment of the target firm by using changes in the target and acquirer's market valuation around the acquisition event date. We follow the Bhagat, Dong, Hirshleifer, and Noah (2005) framework for estimation merger value creation as an adjustment to goodwill. Specifically, using this probability scaling method for announcement day returns, we estimate the synergy and over-payment component of the acquisition value and then remove this estimate from goodwill valuations from the purchase price allocation. ${ }^{56}$ This estimate is removed from goodwill valuations from the purchase price allocation. ${ }^{57}$

For each acquisition event, we first calculate the $[-5,5]$ day change cumulative abnormal return for both the target and acquirer. ${ }^{58}$ Multiplying by the pre-deal $(t=-6)$ market value of each gives the abnormal change in market valuation at deal announcement. Next, as the market's response incorporates expectations about merger failures, we weight them by the inverse of the probability of acquisition success implied by the end-of-period market price of the target compared to the offer price in the deal. ${ }^{59}$ The sum of the target and acquirer's changes - the expected synergy - is subtracted from goodwill. ${ }^{60}$ We remove the acquirer's change in valuation as it incorporates under/overpayment. Here, a decline in the acquirer's market value would signal overpayment for the target, leading to goodwill that is abnormally large when compared to payment at fair market value; as such, this overpayment must be removed from goodwill. We find that the goodwill adjustments to be substantial, with the average (median) deal adjustment resulting in a $34 \%$ (21\%) decline in goodwill. ${ }^{61}$

\footnotetext{
${ }^{56}$ We cannot easily implement the second "intervention method" with our relatively small sample size.

${ }^{57}$ In cases where the adjustment exceeds goodwill (less than $15 \%$ of deals), the remainder is removed from the IIA valuation.

${ }^{58}$ The estimates below are robust to 2,4 and 30 day event windows.

${ }^{59}$ That is, the probability of a successful merger is $\frac{P_{1}-P_{0}}{P_{\text {offer }}-P_{0}}$, where $P_{1}$ is the end-of-day target share price, $P_{0}$ is the pre-announcement share price and $P_{\text {offer }}$ is the original offer price. For example, if the pre-announcement price is 100 and the tender offer is 200, an end-of-day share price of 170 implies a $70 \%$ probability of deal completion. When this is unavailable or outside the unit interval, we use the observed success rate in SDC over our sample period (78\%).

${ }^{60}$ If the result is negative, then the remainder is subtracted from the identifiable intangible assets.

${ }^{61}$ Internet Appendix Figure IA3 reports the percentage of acquisition deal size allocated to goodwill and IIA after these adjustments. The prevalence of goodwill in deal size falls in all years (see the green arrows), which has an impact on the total intangible value in acquisitions.
} 


\section{A2.3 Main variables}

Figure A1 (a) shows the prevalence of goodwill and IIA for our acquisition sample. It reports the percentage of all deals that have some amount of either asset in the purchase price allocation. We observe an upward trend in these components since the mid-1990s, with over $85 \%$ of deals containing goodwill or IIA since 2004. To ensure that our observations are not driven by smaller acquisitions, Figure A1 (b) repeats the analysis but replaces the y-axis with a dollar-weighted measure, which is the sum of all IIA and goodwill in the sample, scaled by the sum of all acquisition deal sizes in the sample. The patterns remain. Figure A2 asks how much of the total enterprise value is comprised of goodwill and IIA. The latter represents $25 \%$ of total transaction value over the sample period, while the former accounts for approximately $35 \%$ of the typical deal size over the full sample period. This suggests that intangibles play a major role in the U.S. acquisition market.

\section{A2.4 Summary statistics}

Panel A of Table A2 presents summary statistics on deals and the parties. All dollar values are in 2012 dollars. The average deal year is 2005 with an average (median) deal size of $\$ 2.3 \mathrm{~b}(\$ 426 \mathrm{~m})$. Deal size as measured by enterprise value (thus including assumed liabilities) averages $\$ 2.5 \mathrm{~b}$. We assign firm industries using the Fama-French 5 industry classification. Consumer firms represent $18 \%$ of targets, while the average target has an EBITDA of $\$ 142 \mathrm{~m}$. Over one-quarter of the acquirers are headquartered in California, which is slightly above the rate for all public firms. This is likely a consequence of both our focus on acquisitions and our requirements for observability of the purchase price allocation for intangibles. We also see that goodwill is on average $\$ 1.1 \mathrm{~b}$ with a much lower median of $\$ 159 \mathrm{~m} .{ }^{62}$ IIA comprises $38 \%$ of total intangible capital (goodwill plus IIA) on average. Finally, total intangibles represent $75 \%$ of enterprise deal size on average. In 281 acquisitions, the total intangible capital exceeds the enterprise value of the firm. We randomly checked 20 acquisitions in this sub-sample and verified that this is a result of the target's net tangible assets being less than zero. Correspondingly, we found that these targets tended to be high-tech or healthcare targets with very high R\&D and SG\&A expenditures and very low levels of PP\&E on their balance sheets.

\footnotetext{
${ }^{62}$ In a few of our observations, total intangibles (identifiable intangible assets and goodwill) is negative. These instances, while rare, occur because goodwill can take on negative values and in these cases, the negative value is larger than the value of identifiable intangible assets. Since goodwill is the plug variable that equates the balance sheet, negative goodwill occurs when the acquirer is able to purchase the target at a price that is below the fair value of net tangible assets that is measured during the due diligence appraisal. This negative goodwill is immediately recorded to the income statement as an extraordinary gain. See Figure IA2 in the Internet Appendix for an example. We allow goodwill to be negative, but because the estimation is done in logs we bottom code total intangibles to zero.
} 
Panel B of Table A2 summarizes the acquisitions in the bankrupt firm sample. The average failure date in our sample is earlier than the acquisition date (2002 vs. 2004). In fact, over a quarter of the delistings in our sample occur in years 2000 and 2001, the burst of the e-commerce dot-com bubble. In contrast to acquired firms, These firms are more to be in the consumer industry (34\% vs. $18 \%)$. Not surprisingly, the average failed firm tends to be small and unprofitable with an average asset size of $\$ 252 \mathrm{~m}$ and net loss of $\$ 80 \mathrm{~m}$. Total intangibles - which are estimated as a function of the "deal size" defined in the previous section - are small with an average of $\$ 35 \mathrm{~m}$, keeping in mind that we make no assumption about the breakdown of goodwill or identifiable intangibles, only the total.

\section{A2.5 Selection of acquisitions}

Our final acquisition sample (excluding delistings from bankruptcies) excludes 588 deals in which an extensive search failed to find the purchase price allocation. Thus, inferences derived using this final acquisition sample should address these potential sample selection issues. Fortunately, Table A3 shows that our sample of acquisitions is reasonably similar to those excluded. The rightmost columns present the excluded acquisitions. These acquisitions occurred earlier in the sample, are less likely to be in manufacturing, and have a smaller median deal size ( $\$ 177$ vs. $\$ 385 \mathrm{~m}$ ). The smaller size implies these acquisitions are more likely to be immaterial to the acquirer and, consequently, to not have a purchase price allocation in their filings. Reassuringly, the targets are not significantly smaller in the excluded group when measured by pre-acquisition assets or net sales. Overall, Table A3 shows that our acquisition sample likely tilts toward larger deals and more recent events. The inclusion of delisted firms - with low assumed "acquisition" values and no time period constraints - helps to balance many of these differences out. 
A8 Appendix Figures and Tables 
Figure A1: Percentage of acquisition deals with non-zero intangible assets or goodwill

The figure in Panel A reports the percentage of all acquisitions in the sample (see Section 2.3) that have non-zero intangible assets or goodwill acquired. The deals included are those where we could find a purchase price allocation in the target's $10-\mathrm{K}, 10-\mathrm{Q}, \mathrm{S}-4$ or $8-\mathrm{K}$. Panel B reports the percentage of all deal dollars in our sample of acquisitions (see Section 2.3) associated with deals that have non-zero goodwill or intangible assets acquired. So the "Goodwill" figure is the annual sum of transactions with some positive goodwill divided by the total amount of transaction dollars in that year.

(a) Prevalence of IIA and goodwill

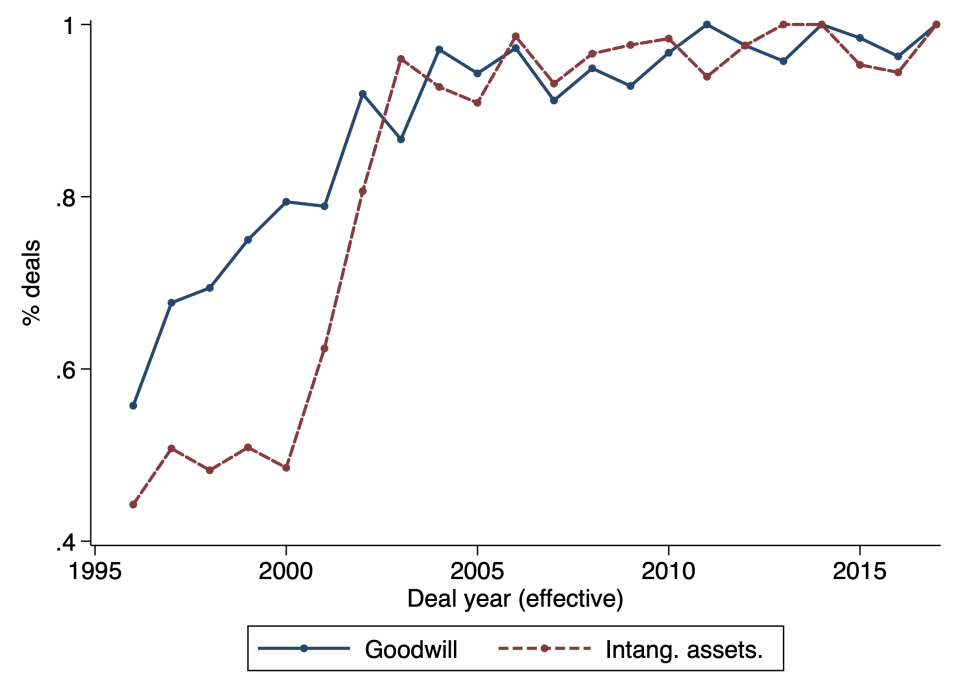

(b) Deal-weighted

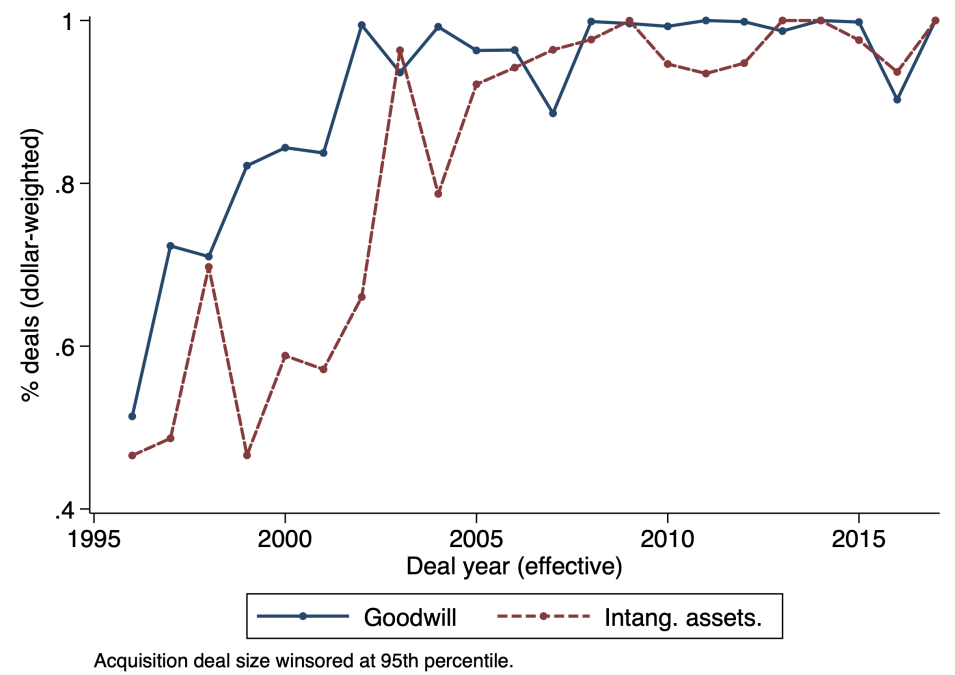


Figure A2: Percentage of acquisition deal size for intangible assets

The figure reports the average percentage of an acquisition deal size (i.e., enterprise value of the deal) attributed to goodwill, intangible assets (IIA) and their sum. The sample is the subset of acquisitions (see Section 2.3) associated with deals that have non-zero goodwill or intangible assets acquired.

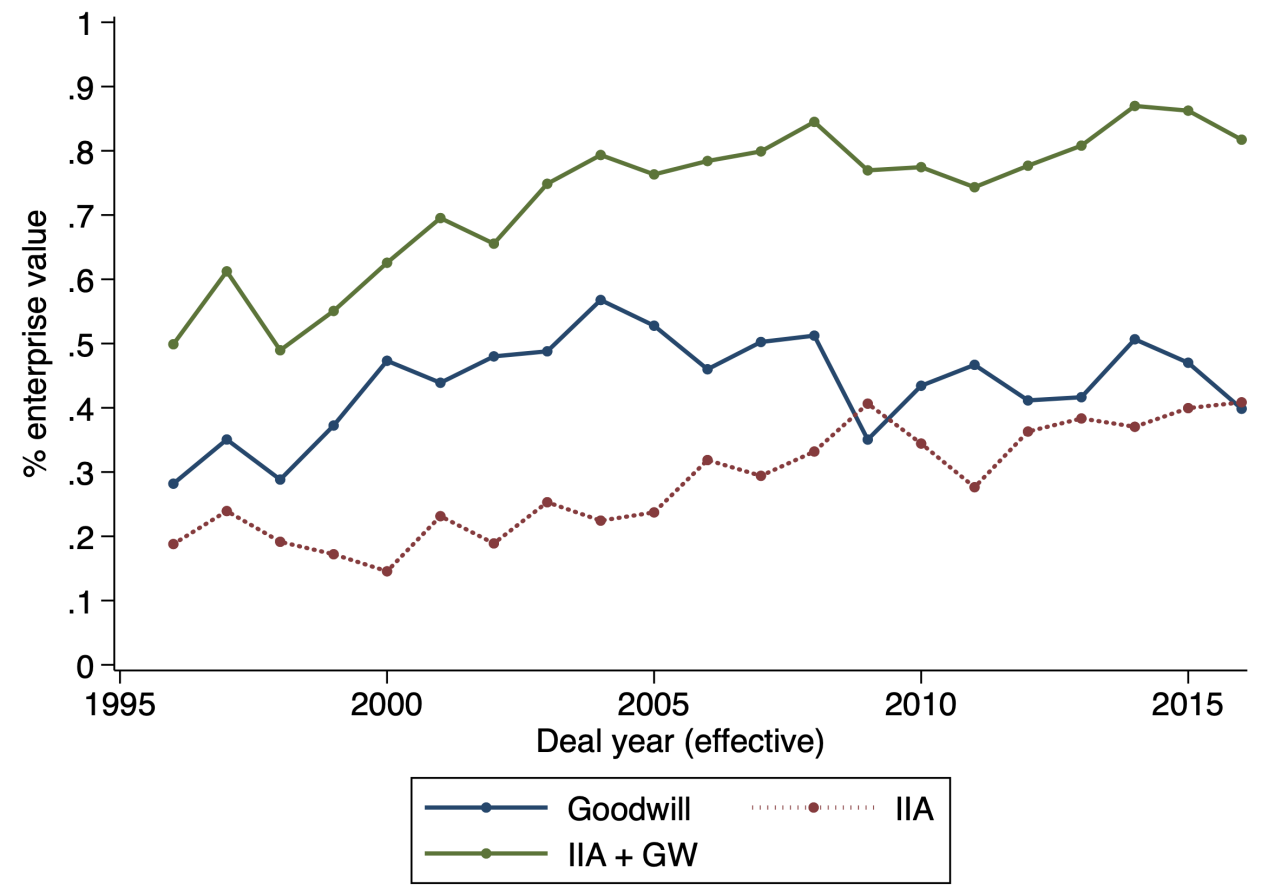




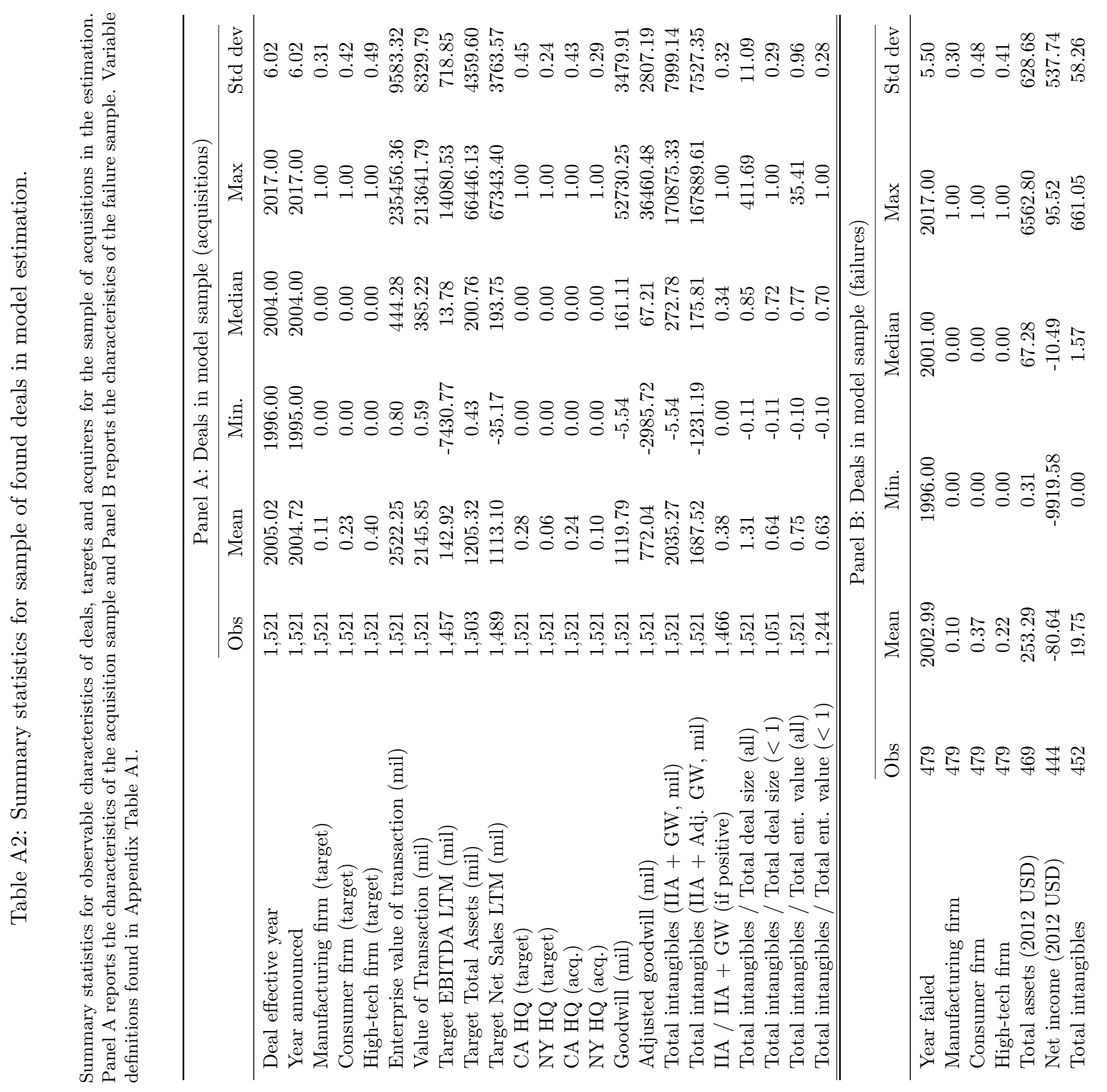




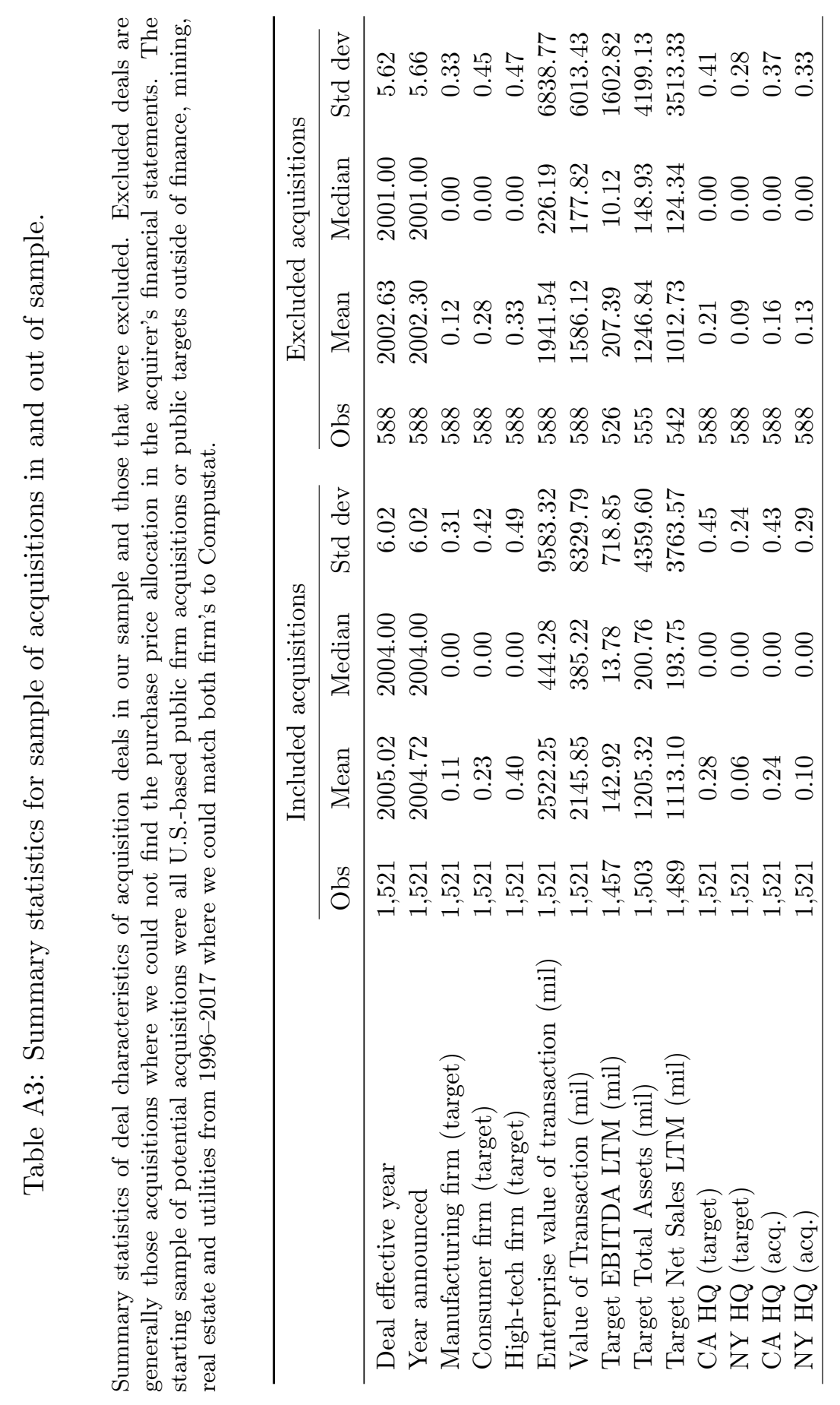




\section{Internet Appendix for "Measuring Intangible Capital with Market Prices" (Ewens, Peters and Wang (2020))}

\section{IA1 Figures and tables}

Figure IA1: Example of Purchase Accounting

Acquiring firm (A) acquires target firm (T) in an acquisition which closes on March 31, 2018. Book value of T's net assets ex-acquisition is 55. In the due diligence process, T's net assets are marked to market to a value of 95 following ASC 805. Identifiable intangible assets of 35 are revealed on A's balance sheet post-acquisition date. A agrees to purchase $\mathrm{T}$ by issuing stock with a fair market value of 150. Goodwill of 55 is recorded to A's balance sheet to represent the additional value paid by the acquirer over and above the fair value of all of T's identifiable net assets.

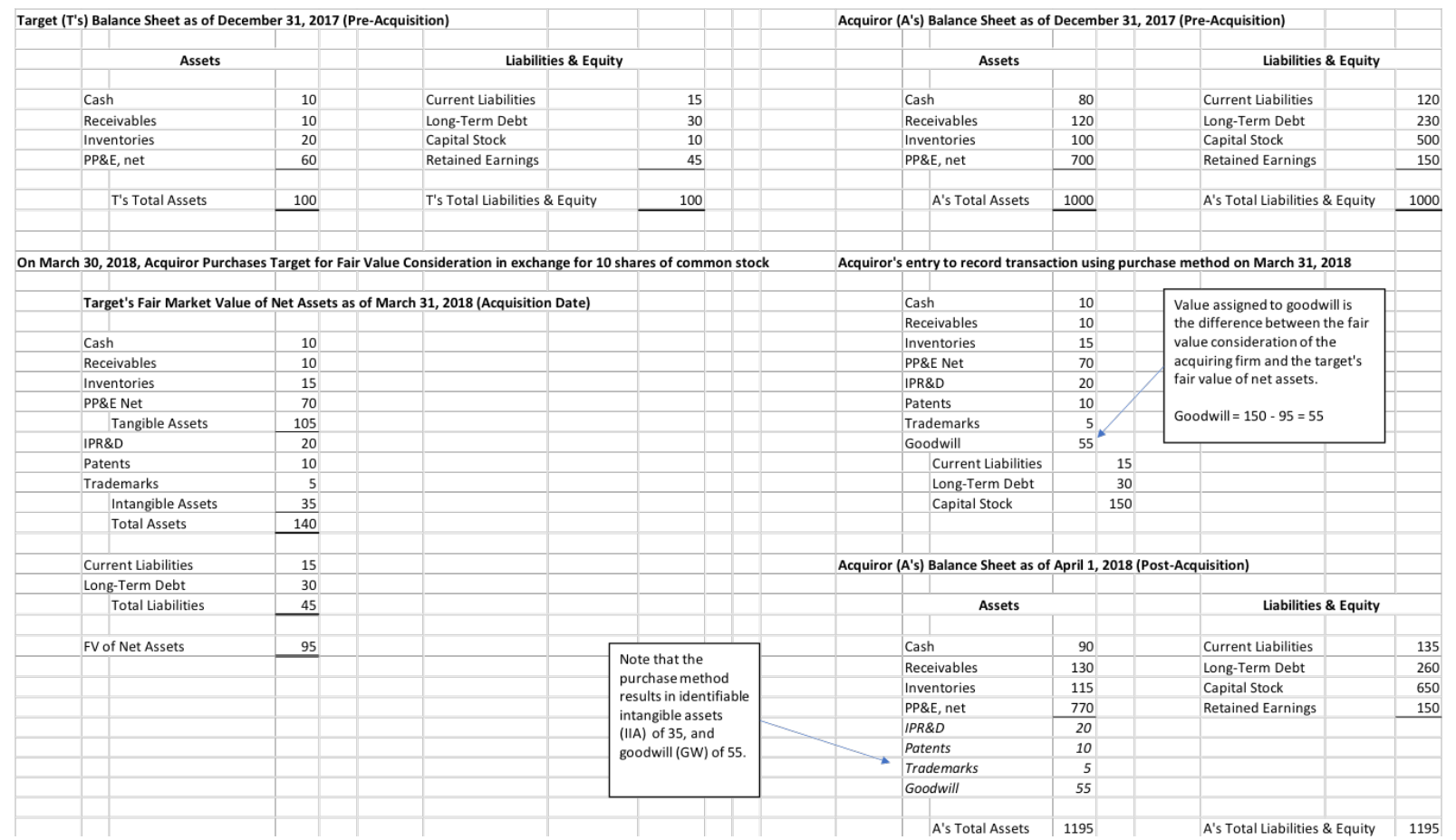


Figure IA2: Example of goodwill accounting and negative goodwill

A credits-and-debits analysis of goodwill and negative goodwill.

Standard Case: Goodwill contains synergies, mark-to-market of assets is too conservative, or overpayment.

Fair Value of Assets of Acquirer (+A)

Fair Value of Liabilities of Acquirer (-L)

Cash (-A)

${ }^{*}$ Goodwill (+A)

80
100

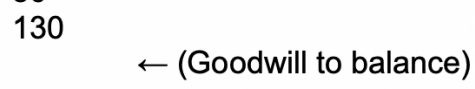

*Goodwill asset impaired over subsequent years, until is depleted.
Amortization of Goodwill (-E)
Goodwill (-A)
$X X$
$X X$

Rare Case: Negative goodwill. May arise due to bargain purchase of target (e.g., distressed fire-sale), too conservative in mark-to-market of liabilities (or off-balance sheet liabilities exist),

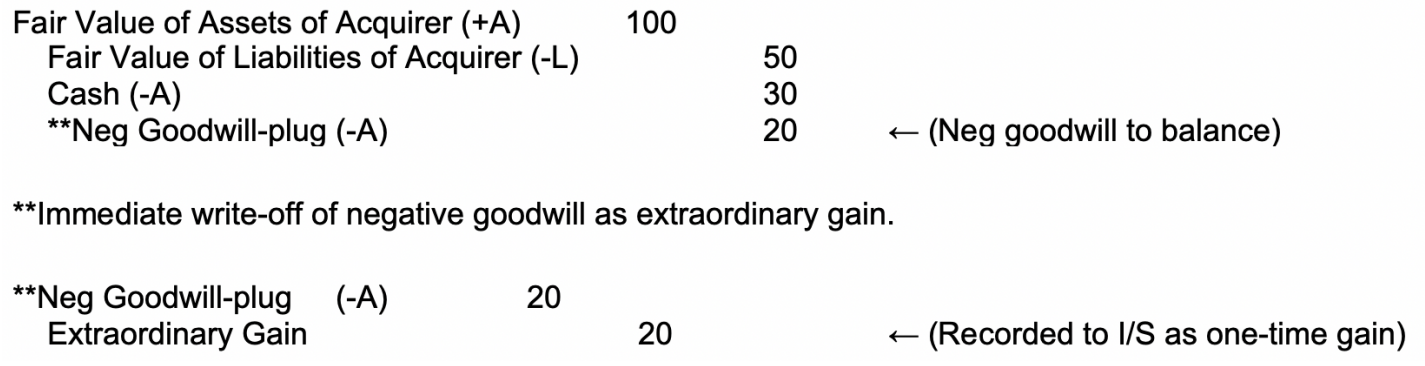

${ }^{* *}$ Immediate write-off of negative goodwill as extraordinary gain.

**Neg Goodwill-plug $\quad(-A)$ Extraordinary Gain

20 
Figure IA3: Percentage of acquisition deal size for intangible assets: post-goodwill adjustment

The figure reports the average percentage of an acquisition deal size (i.e., enterprise value of the deal) attributed to goodwill after synergy or over-payment adjustment and its sum with IIA. The adjustment detailed in Section A2.2 uses the market reaction to the acquisition announcement for both the target and acquirer. The sample is the subset of acquisitions (see Section 2.3) associated with deals that have non-zero goodwill or intangible assets acquired.

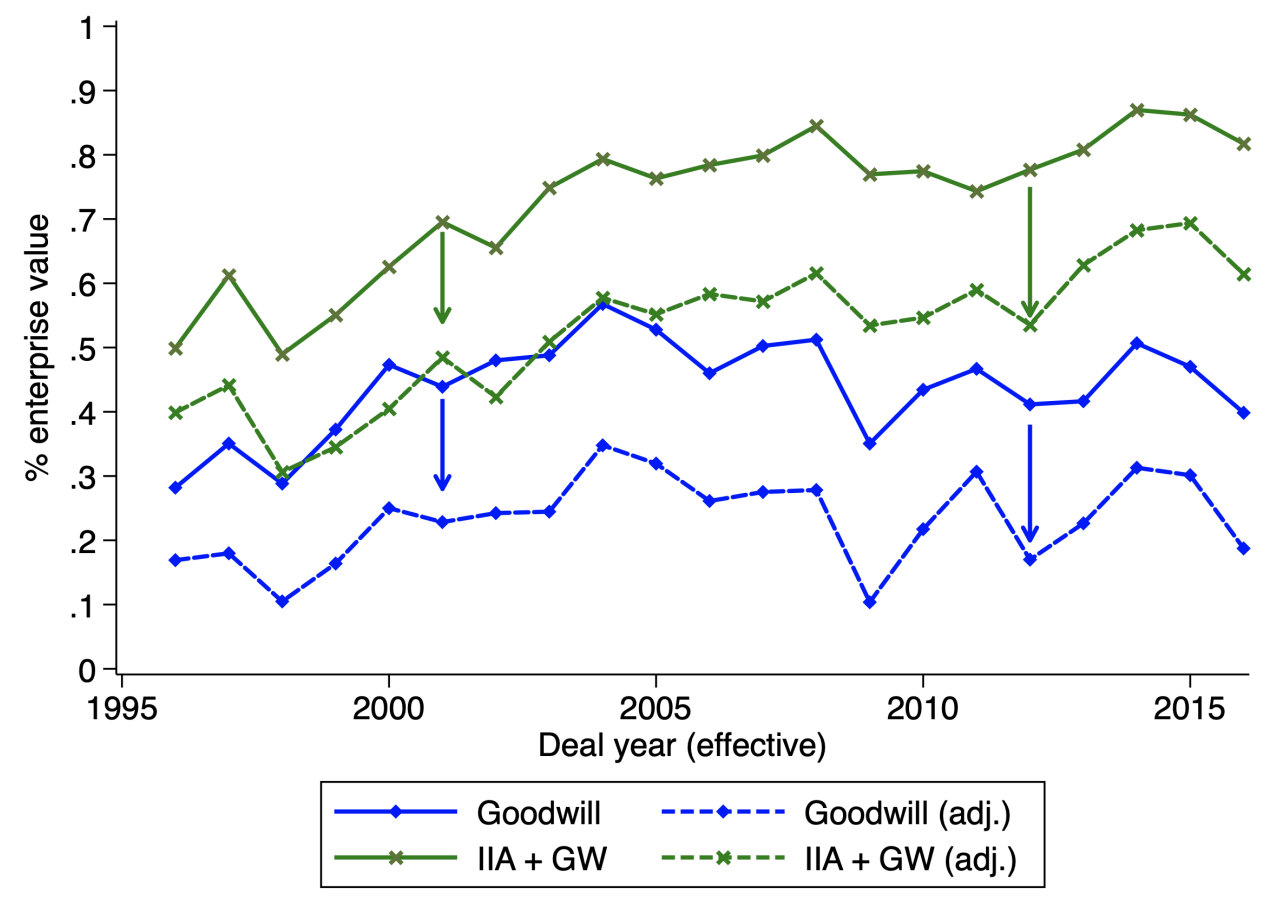


Figure IA4: Estimated year fixed effects and S\&P 500 index

The figure reports the exponentiated year fixed effects $\rho_{t}$ from the non-linear least squares estimation of equation (12):

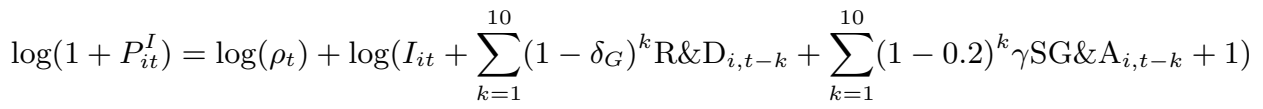

using the Exits prices along with de-meaned, de-trended levels of the S\&P 500 index at the end of the 2nd quarter of each year (dashed line). The year fixed effects are estimated in logs and constrained such that they average zero over all years.

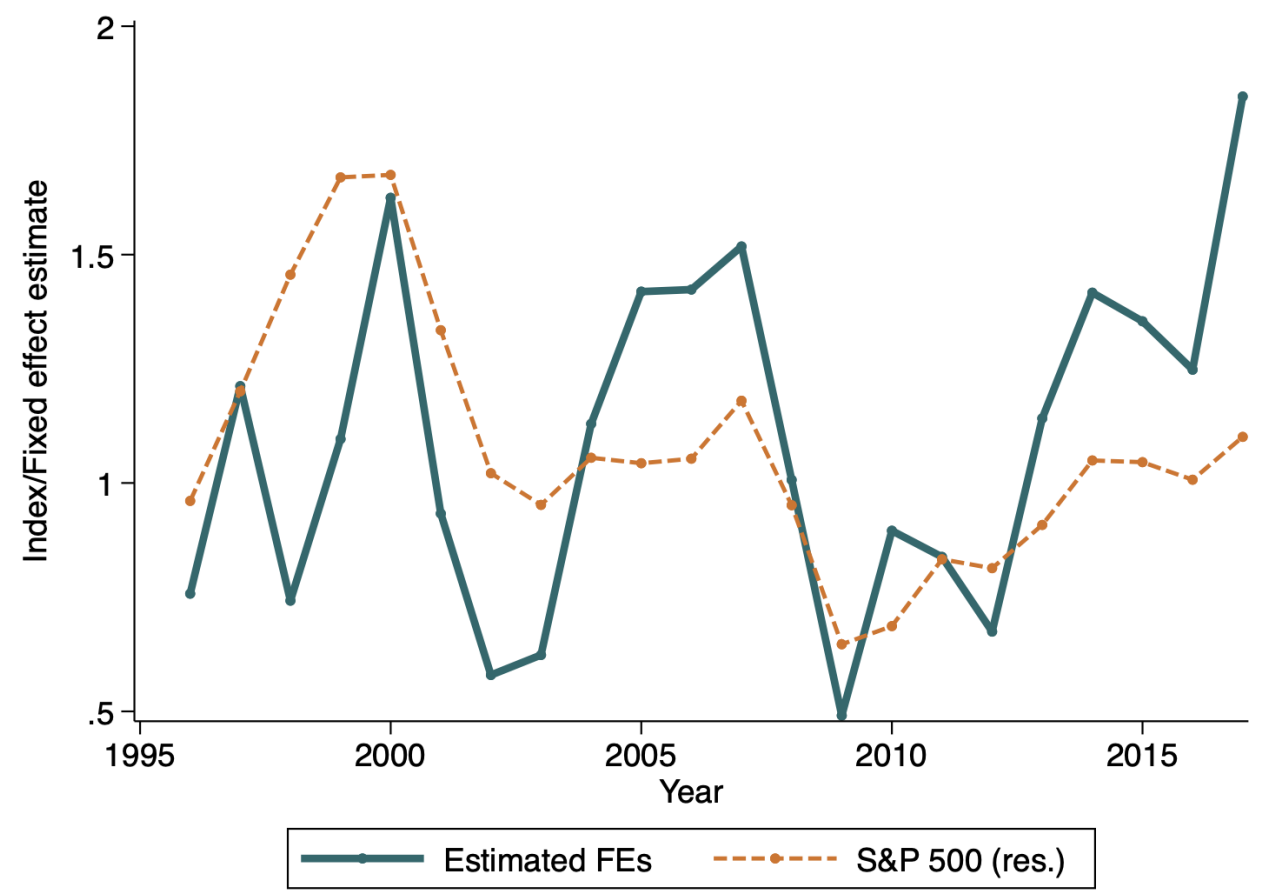


Table IA1: Eisfeldt and Papanikolau (2013), Table IA.I: Using the Ewens, Peters and Wang (2020) organizational stocks

The table repeats the analysis of Table IA.I in Eisfeldt and Papanikolaou (2013)'s Internet Appendix. The table reports the statistics of various firm observables in an unconditional annual sort using our new measure of organizational stocks.

Ewens, Peters and Wang

\begin{tabular}{|c|c|c|c|c|c|}
\hline & Lo & 2 & 3 & 4 & $\mathrm{Hi}$ \\
\hline & mean & mean & mean & mean & mean \\
\hline Organization capital to book assets & 0.04 & 0.09 & 0.18 & 0.31 & 0.81 \\
\hline Market capitalization $(\log )$ & 6.48 & 6.60 & 6.36 & 5.85 & 5.10 \\
\hline Tobin's Q & 1.13 & 1.32 & 1.36 & 1.34 & 1.66 \\
\hline Tobin's Q (scaled by PPE) & 4.72 & 8.10 & 8.83 & 7.67 & 7.62 \\
\hline Total Q (Ewens, Peters and Wang (2018) & 3.05 & 2.39 & 2.27 & 1.67 & 1.08 \\
\hline Total Q (Peters and Taylor (2017) & 2.96 & 2.30 & 2.14 & 1.62 & 1.11 \\
\hline Sales to book assets $(\%)$ & 68.56 & 84.76 & 104.96 & 122.20 & 144.70 \\
\hline Earnings to book assets (\%) & 7.22 & 7.80 & 7.94 & 6.35 & -0.49 \\
\hline Advertising expenditures to book assets & 1.09 & 1.60 & 2.52 & 3.68 & 6.37 \\
\hline Investment to capital (organization, \%) & 192.75 & 149.35 & 132.14 & 114.02 & 85.50 \\
\hline Investment to capital (physical, \%) & 17.83 & 15.79 & 15.32 & 14.66 & 14.46 \\
\hline Physical capital to book assets & 64.80 & 61.33 & 50.47 & 41.14 & 42.62 \\
\hline Debt to book assets & 33.38 & 29.18 & 25.21 & 20.83 & 16.54 \\
\hline Capital to labor (log) & 4.83 & 4.58 & 4.21 & 3.96 & 3.74 \\
\hline \multirow[t]{3}{*}{ Firm Solow Residual } & -37.31 & -9.16 & 8.78 & 19.60 & 14.09 \\
\hline & Lo & 2 & 3 & 4 & $\mathrm{Hi}$ \\
\hline & mean & mean & mean & mean & mean \\
\hline Executive compensation to book assets (\%) & 0.17 & 0.28 & 0.37 & 0.47 & 0.65 \\
\hline CEO turnover & 0.18 & 0.16 & 0.18 & 0.18 & 0.20 \\
\hline
\end{tabular}


Table IA2: OLS Results from an Investment- $q$ Relation: By industry

Results are from OLS panel regressions of investment on lagged Tobin's $q$ and firm and year fixed effects. A unit of observation is a firm-year for public firms from 1996-2016. We follow the Peters and Taylor (2017) method to construct both a new total capital that incorporates intangibles and a modified investment rate for $S G \& A$. Each column uses a different investment measure noted in the top rows

$$
I_{i t}=\beta Q_{i t}+\mu_{i}+\eta_{t}+\varepsilon_{i t}
$$

"Total Q (PT)" is the $Q_{i t}$ from Peters and Taylor (2017) that uses the BEA-HH depreciation rates. The row "Total Q (EPW)" presents an alternative total Q that uses the depreciation and investment fractions from Table 1 to calculate total intangible stock. Because our main parameters in Table 1 are estimated by industry, each panel here is an industry sub-sample. The "Within-R2" are the within-firm and -year $R^{2}$. Standard errors clustered at the firm-year reported in parentheses. Significance: ${ }^{*} p<0.10,{ }^{* *} p<0.05,{ }^{* * *} p<0.01$.

\begin{tabular}{|c|c|c|c|c|c|c|c|c|}
\hline & (1) & $(2)$ & $(3)$ & (4) & (5) & (6) & $(7)$ & (8) \\
\hline & \multicolumn{2}{|c|}{$\mathrm{R} \& \mathrm{D}$} & \multicolumn{2}{|c|}{ SG\&A } & \multicolumn{2}{|c|}{ CAPX } & \multicolumn{2}{|c|}{$\mathrm{CAPX}+\mathrm{R} \& \mathrm{D}+\mathrm{SG} \& \mathrm{~A}$} \\
\hline & \multicolumn{8}{|c|}{ Consumer } \\
\hline Total Q (PT) & $\begin{array}{l}0.0016^{* * *} \\
(0.00034)\end{array}$ & & $\begin{array}{l}0.0075^{* * *} \\
(0.00078)\end{array}$ & & $\begin{array}{l}0.0079^{* * *} \\
(0.00093)\end{array}$ & & $\begin{array}{l}0.017^{* * *} \\
(0.0014)\end{array}$ & \\
\hline Total Q (EPW) & & $\begin{array}{l}0.0018^{* * *} \\
(0.00035)\end{array}$ & & $\begin{array}{l}0.0071^{* * *} \\
(0.00071)\end{array}$ & & $\begin{array}{l}0.0083^{* * *} \\
(0.00088)\end{array}$ & & $\begin{array}{l}0.017^{* * *} \\
(0.0012)\end{array}$ \\
\hline Observations & 29435 & 29435 & 29442 & 29442 & 29462 & 29462 & 29435 & 29435 \\
\hline$R^{2}$ & 0.57 & 0.58 & 0.64 & 0.63 & 0.38 & 0.37 & 0.50 & 0.49 \\
\hline \multirow[t]{2}{*}{ Within- $R^{2}$} & 0.047 & 0.048 & 0.13 & 0.16 & 0.077 & 0.084 & 0.16 & 0.18 \\
\hline & \multicolumn{8}{|c|}{ Manufacturing } \\
\hline Total Q (PT) & $\begin{array}{l}0.0026^{* * *} \\
(0.00055)\end{array}$ & & $\begin{array}{l}0.0057^{* * *} \\
(0.00077)\end{array}$ & & $\begin{array}{c}0.0059^{* * *} \\
(0.0011)\end{array}$ & & $\begin{array}{l}0.014^{* * *} \\
(0.0018)\end{array}$ & \\
\hline Total Q (EPW) & & $\begin{array}{l}0.0029^{* * *} \\
(0.00057)\end{array}$ & & $\begin{array}{l}0.0052^{* * *} \\
(0.00070)\end{array}$ & & $\begin{array}{c}0.0059^{* * *} \\
(0.0010)\end{array}$ & & $\begin{array}{l}0.014^{* * *} \\
(0.0016)\end{array}$ \\
\hline Observations & 18467 & 18467 & 18469 & 18469 & 18476 & 18476 & 18467 & 18467 \\
\hline$R^{2}$ & 0.56 & 0.62 & 0.59 & 0.57 & 0.30 & 0.29 & 0.43 & 0.44 \\
\hline \multirow{2}{*}{ Within- $R^{2}$} & 0.057 & 0.058 & 0.11 & 0.11 & 0.050 & 0.053 & 0.13 & 0.13 \\
\hline & \multicolumn{8}{|c|}{ High Tech } \\
\hline Total Q (PT) & $\begin{array}{l}0.0046^{* * *} \\
(0.00035)\end{array}$ & & $\begin{array}{l}0.0060^{* * *} \\
(0.00037)\end{array}$ & & $\begin{array}{l}0.0071^{* * *} \\
(0.00052)\end{array}$ & & $\begin{array}{l}0.018^{* * *} \\
(0.0010)\end{array}$ & \\
\hline Total Q (EPW) & & $\begin{array}{l}0.0050^{* * *} \\
(0.00039)\end{array}$ & & $\begin{array}{l}0.0069^{* * *} \\
(0.00044)\end{array}$ & & $\begin{array}{l}0.0071^{* * *} \\
(0.00051)\end{array}$ & & $\begin{array}{l}0.019^{* * *} \\
(0.0011)\end{array}$ \\
\hline Observations & 28783 & 28783 & 28784 & 28784 & 28795 & 28795 & 28783 & 28783 \\
\hline$R^{2}$ & 0.61 & 0.62 & 0.53 & 0.51 & 0.42 & 0.42 & 0.56 & 0.55 \\
\hline \multirow[t]{2}{*}{ Within- $R^{2}$} & 0.12 & 0.13 & 0.17 & 0.15 & 0.17 & 0.16 & 0.29 & 0.27 \\
\hline & \multicolumn{8}{|c|}{ Healthcare } \\
\hline Total Q (PT) & $\begin{array}{l}0.0060^{* * *} \\
(0.00070)\end{array}$ & & $\begin{array}{l}0.0060^{* * *} \\
(0.00049)\end{array}$ & & $\begin{array}{l}0.0048^{* * *} \\
(0.00070)\end{array}$ & & $\begin{array}{l}0.017^{* * *} \\
(0.0014)\end{array}$ & \\
\hline Total Q (EPW) & & $\begin{array}{l}0.0072^{* * *} \\
(0.00074)\end{array}$ & & $\begin{array}{l}0.0057^{* * *} \\
(0.00069)\end{array}$ & & $\begin{array}{l}0.0042^{* * *} \\
(0.00066)\end{array}$ & & $\begin{array}{l}0.017^{* * *} \\
(0.0015)\end{array}$ \\
\hline Observations & 13519 & 13519 & 13519 & 13519 & 13524 & 13524 & 13519 & 13519 \\
\hline$R^{2}$ & 0.54 & 0.61 & 0.56 & 0.48 & 0.28 & 0.26 & 0.47 & 0.44 \\
\hline Within- $R^{2}$ & 0.066 & 0.077 & 0.14 & 0.078 & 0.077 & 0.068 & 0.18 & 0.16 \\
\hline Year / Firm FE & $\mathrm{Y}$ & $\mathrm{Y}$ & $\mathrm{Y}$ & $\mathrm{Y}$ & $\mathrm{Y}$ & $\mathrm{Y}$ & $\mathrm{Y}$ & $\mathrm{Y}$ \\
\hline
\end{tabular}




\title{
IA2 Real-world purchase price allocation examples
}

\author{
Matrix Pharmaceutical, February 20, 2002
}

\section{Note 4 - Acquisition of Matrix Pharmaceutical, Inc.}

On February 20, 2002, Chiron acquired Matrix Pharmaceutical, Inc. a company that was developing tezacitabine, a drug to treat cancer. As of March 31, 2002, Chiron acquired substantially all of the outstanding shares of common stock of Matrix Pharmaceutical at $\$ 2.21$ per share, which, including estimated acquisition costs, resulted in a total preliminary purchase price of approximately $\$ 67.1$ million. Matrix Pharmaceutical is part of Chiron's biopharmaceuticals segment. Tezacitabine expanded Chiron's portfolio of cancer therapeutics.

Chiron accounted for the acquisition as an asset purchase and included Matrix Pharmaceutical's operating results, including the seven business days in February 2002, in its consolidated operating results beginning on March 1, 2002. The components and allocation of the preliminary purchase price, based on their fair values, consisted of the following (in thousands):

\begin{tabular}{|c|c|c|}
\hline \multicolumn{3}{|l|}{ Consideration and acquisition costs: } \\
\hline Cash paid for common stock & $\$$ & 49,986 \\
\hline Cash paid for options on common stock & & 1,971 \\
\hline Common stock tendered, not yet paid & & 8,751 \\
\hline Options on common stock, not yet paid & & 260 \\
\hline Acquisition costs paid as of March 31, 2002 & & 3,323 \\
\hline Acquisition costs not yet paid as of March 31, 2002 & & 2,796 \\
\hline Total purchase price & $\$$ & 67,087 \\
\hline \multicolumn{3}{|l|}{ Allocation of preliminary purchase price: } \\
\hline Cash and cash equivalents & $\$$ & 17,337 \\
\hline Assets held for sale & & 2,300 \\
\hline Deferred tax asset & & 10,000 \\
\hline Other assets & & 1,469 \\
\hline Write-off of purchased in-process technologies & & 54,781 \\
\hline Accounts payable & & $(2,898)$ \\
\hline Accrued liabilities & & $(15,902)$ \\
\hline Total purchase price & $\$$ & 67,087 \\
\hline
\end{tabular}

\section{Electronic Data Services, August 26, 2008}

On August 26, 2008, HP completed its acquisition of EDS, a leading global technology services company, delivering a broad portfolio of information technology, applications and business process outsourcing services to clients in the manufacturing, financial services, healthcare, communications, energy, transportation, and consumer and retail industries and to governments around the world. The acquisition of EDS will strengthen HP's service offerings for information technology outsourcing, including data center services, workplace services, networking services and managed security; business process outsourcing, including health claims, financial processing, CRM and HR outsourcing; and applications, including development, modernization and management. 
The total preliminary estimated purchase price for EDS was approximately $\$ 13.0$ billion and was comprised of:

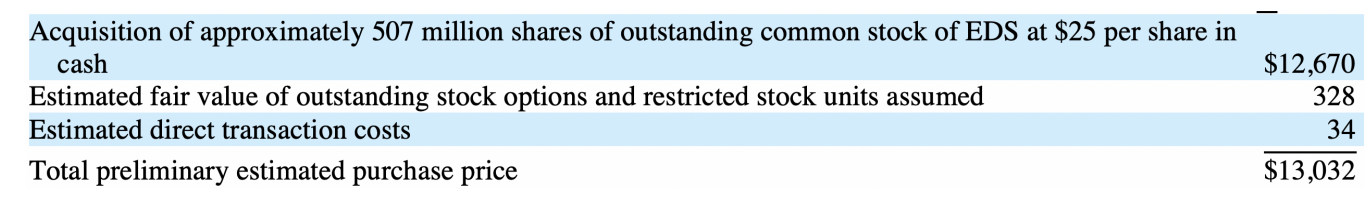

In connection with the acquisition, HP assumed options to purchase approximately 8 million shares of HP's common stock at a weighted-average exercise price of approximately $\$ 50$ per share. HP also assumed approximately 11 million restricted stock units with a weighted-average grant date fair value of $\$ 45$. [...]

Direct transaction costs include investment banking, legal and accounting fees and other external costs directly related to the acquisition.

The purchase price allocations as of the date of the acquisition in the table below reflect various preliminary estimates and analyses, including preliminary work performed by third-party valuation specialists, and are subject to change during the purchase price allocation period (generally one year from the acquisition date) as valuations are finalized.

In millions

\begin{tabular}{lr}
\hline Cash and short-term investments & $\$ 3,034$ \\
Accounts receivable & 2,549 \\
Property, plant and equipment & 3,203 \\
Other tangible assets & 3,126 \\
Notes payable and debt & $(3,298)$ \\
Pension liability (Note 15) & $(2,243)$ \\
Restructuring liability (Note 8$)$ & $(1,515)$ \\
Net deferred tax liabilities & $(1,427)$ \\
Other liabilities assumed & $(5,370)$ \\
Total net tangible liabilities & $\$(1,941)$ \\
Amortizable intangible assets: & \\
Customer contracts and related relationships & 3,199 \\
Developed technology and trade name & 1,349 \\
Goodwill & 10,395 \\
IPR\&D & 30 \\
Total preliminary estimated purchase price & $\$ 13,032$
\end{tabular}

J. Jill, May 3, 2006

4. ACQUISITION OF J. JILL 
On May 3, 2006, the Company acquired J. Jill, a multi-channel specialty retailer of women's apparel. J. Jill markets its products through retail stores, catalogs, and online. As of May 3, 2006, J. Jill operated 205 stores in the United States. J. Jill circulated approximately 56 million catalogs during 2005. The Company believes that the acquisition of J. Jill will provide the Company with a long-term growth vehicle and an opportunity to maximize the cost synergies of J. Jill and Talbots similar business models, particularly in back office functions. Both J. Jill and Talbots serve the 35 plus customer population; J. Jill focusing on apparel for a sophisticated casual lifestyle, with artistically inspired styles, providing a counterpoint to Talbots offering of updated modern classics.

Talbots acquired all of the outstanding shares of J. Jill for $\$ 24.05$ per share for total consideration of $\$ 518,320$ in cash. The Company used the proceeds from its $\$ 400,000$ loan facility (see Note 9 ), as well as cash on hand to fund the acquisition. The Company also incurred acquisition-related fees and expenses of $\$ 5,967$. The acquisition has been accounted for as a purchase in accordance with Statement of Financial Accounting Standards ("SFAS") No. 141, Business Combinations ("SFAS No. 141"), and accordingly, the results of operations of J. Jill have been included in the accompanying condensed consolidated statements of operations for the thirteen and twentysix weeks ended July 29, 2006 from the date of the acquisition. In accordance with SFAS No. 141, the total purchase price has been preliminarily allocated to the tangible and intangible assets and liabilities acquired based on management's estimates of current fair values and may change as appraisals are finalized and as additional information becomes available. The resulting goodwill and other intangible assets will be accounted for under SFAS No. 142, Goodwill and Other Intangible Assets ("SFAS No. 142"). The following table summarizes the preliminary estimated fair values of the assets acquired and liabilities assumed, at the date of the acquisition, for an aggregate purchase price of $\$ 524,287$, including acquisition costs.

\begin{tabular}{ll} 
& $\begin{array}{l}\text { As of } \\
\text { May 3, 2006 }\end{array}$ \\
\cline { 2 - 2 } Cash & $\$ 30,445$ \\
Other current assets & 109,842 \\
Property and equipment & 154,553 \\
Goodwill & 221,171 \\
Trademarks & 80,000 \\
Other intangible assets & 93,152 \\
Current liabilities & $(55,266)$ \\
Deferred income taxes & $(98,224)$ \\
Other long-term liabilities & $(11,386)$ \\
\hline & \\
Total & $\$ 524,287$ \\
\hline
\end{tabular}

As part of the purchase price allocation, all intangible assets were preliminarily identified and 
valued. Of the total purchase price, $\$ 80,000$ was assigned to trademarks, and $\$ 93,152$ was assigned to other intangible assets, which consist of customer relationships of $\$ 77,700$, non-compete agreements of $\$ 4,500$, and favorable leasehold interests of $\$ 10,952$. Management is in the process of finalizing the valuation of the acquired J. Jill intangibles. The amortization of the intangible assets that are subject to amortization is expected to be recognized over a weighted average life of approximately 11 years.

The acquired trademarks have been assigned an indefinite life and will not be amortized. Trademarks will be reviewed for impairment or for indicators of a limited useful life on an annual basis or when events indicate that the asset may be impaired.

The amount assigned to customer relationships, $\$ 77,700$, is being amortized using a method that reflects the pattern in which the economic benefits of the intangible asset are expected to be consumed over a weighted average life of approximately twelve years. The amount assigned to non-compete agreements, $\$ 4,500$, is being amortized on a straight-line basis over the period that the agreements are enforceable, approximately twenty months. The amount assigned to favorable leasehold interests, $\$ 10,952$, is being amortized on a straight-line basis over the remaining lease period, or a weighted average of approximately eight years.

The excess of the purchase price over the fair value of tangible and identifiable intangible net assets was allocated to goodwill, which is non-deductible for tax purposes and preliminarily is estimated to be $\$ 221,171$. In accordance with SFAS No. 142 , this amount will not be amortized. Goodwill will be reviewed for impairment on an annual basis or when events indicate that the asset may be impaired.

\section{R.R. Donnelley \& Sons acquires Edgar Online, May 3, 2006 ${ }^{63}$}

On August 14, 2012, the Company acquired EDGAR Online, a leading provider of disclosure management services, financial data and enterprise risk analytics software and solutions. The acquisition of EDGAR Online will expand and enhance the range of services that the Company offers to its customers. The purchase price for EDGAR Online was $\$ 71.5$ million, including debt assumed of $\$ 1.4$ million and net of cash acquired of $\$ 2.1$ million. Immediately following the acquisition, the Company repaid the $\$ 1.4$ million of debt assumed. EDGAR Online's operations are included in the U.S. Print and Related Services segment.

$[\ldots]$

The XPO and EDGAR Online acquisitions were recorded by allocating the cost of the acquisitions to the assets acquired, including intangible assets, based on their estimated fair values at the acquisition date. The excess of the cost of the acquisitions and the fair value of the contingent consideration over the net amounts assigned to the fair value of the assets acquired was recorded as goodwill. The preliminary tax deductible goodwill related to these acquisitions was $\$ 12.3$ million. [...] Based on the current valuations, the purchase price allocations for these acquisitions were as follows:

\footnotetext{
${ }^{63}$ https://www.sec.gov/Archives/edgar/data/29669/000119312512446613/d416826d10q.htm
} 


\begin{tabular}{lr} 
Accounts receivable & $\$ 15.4$ \\
Prepaid expenses and other current assets & 0.8 \\
Property, plant and equipment & 2.2 \\
Amortizable other intangible assets & 24.2 \\
Other noncurrent assets & 14.0 \\
Goodwill & 4.4 \\
Accounts payable and accrued liabilities & $(16.3)$ \\
Other noncurrent liabilities & $(0.1)$ \\
Deferred taxes-net & 10.4 \\
Total purchase price-net of cash acquired & 95.0 \\
Less: debt assumed & 1.4 \\
Less: fair value of contingent consideration & 3.5 \\
Net cash paid & $\underline{\$ 90.1}$ \\
\hline
\end{tabular}

The fair values of technology, amortizable intangible assets, contingent consideration and goodwill associated with the acquisitions of XPO and EDGAR Online were determined to be Level 3 under the fair value hierarchy. The following table presents the fair value, valuation techniques and related unobservable inputs for these Level 3 measurements:

\begin{tabular}{|c|c|c|c|c|c|}
\hline \multirow{2}{*}{ Customer relationships } & \multicolumn{2}{|c|}{$\begin{array}{c}\begin{array}{c}\text { Fair } \\
\text { Value }\end{array}\end{array}$} & Valuation Technique & Unobservable Input & \multirow{2}{*}{$\begin{array}{c}\text { Range } \\
16.0 \%-17.5 \% \\
7.0 \%-20.0 \%\end{array}$} \\
\hline & $\bar{s}$ & 20.2 & $\begin{array}{l}\text { Excess earnings, with } \\
\text { and without method }\end{array}$ & $\begin{array}{l}\text { Discount rate } \\
\text { Attrition rate }\end{array}$ & \\
\hline Technology & & 13.4 & $\begin{array}{l}\text { Excess earnings, relief- } \\
\text { from-royalty method, } \\
\text { cost approach }\end{array}$ & $\begin{array}{c}\text { Discount rate } \\
\text { Obsolescence factor } \\
\text { Royalty rate (after-tax) }\end{array}$ & $\begin{array}{c}16.0 \%-17.0 \% \\
10.0 \%-20.0 \% \\
\quad 4.5 \%\end{array}$ \\
\hline Trade names & & 3.1 & $\begin{array}{l}\text { Relief-from-royalty } \\
\text { method }\end{array}$ & $\begin{array}{c}\text { Discount rate } \\
\text { Royalty rate (after-tax) }\end{array}$ & $\begin{array}{c}15.5 \%-17.5 \% \\
0.5 \%-1.2 \%\end{array}$ \\
\hline Non-compete agreements & & 0.9 & $\begin{array}{l}\text { With and without } \\
\text { method }\end{array}$ & Discount rate & $17.5 \%$ \\
\hline Contingent consideration & & 3.5 & $\begin{array}{l}\text { Probability weighted } \\
\text { discounted future cash flows }\end{array}$ & Discount rate & $4.5 \%$ \\
\hline
\end{tabular}

